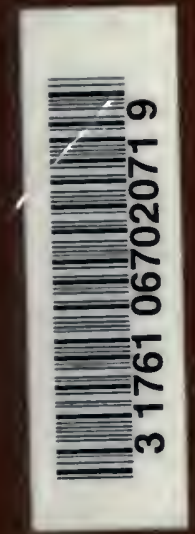





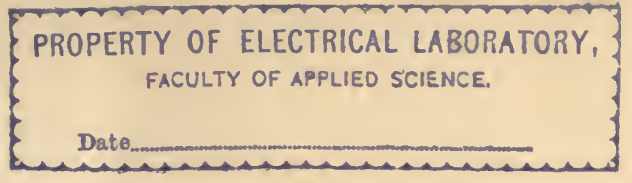



PROPERTY OF ELECTRICAL LABORATORY,

FACULTY OF APPLIED SCIENCE.

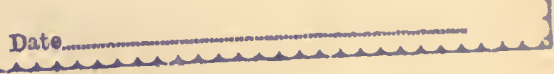





\title{
THE INDUCTION MOTOR
}

\section{A Short Treatise on its Theory and Design, with Numerous Experimental Data and Diagrams}

\section{B. A. BEHREND}

Member Inst. C: E., Member Inst. E. E., Germany; Member Iust. E. E., Switzerland; Associate Member American Inst. E.

E.; Formerly Assistant Chief Electrician of the Oerlikon Engineering Works,

\author{
Switzerlind
}

"The absence of atmatyticul difficulties allozus attention to be more easily concentrated on the physicat aspects of the question, and thus gites the student at more sivid idea and "more manageable grasp of the subject than he would be likely to attain if he merely regarded electrical phenomena through a clout of "analytical symbols."

J. J. Tuomsox.

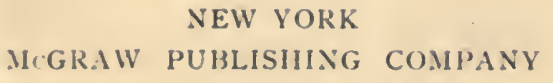

I 14 LIBERTY STREET 
COPYRIGHTED, 1901, BY

ELECTRICAL WORLD AND ENGINEER

(INCORPORATED)

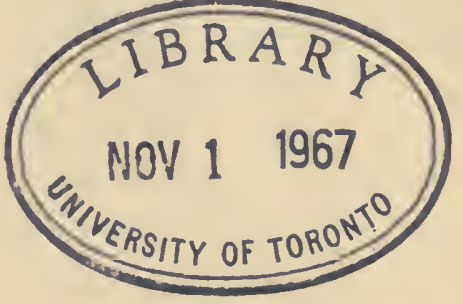


TO

MY FRIEND AND TEACHER

MR. GISBERT KAPP

I INSCRIBE THIS WORK. 


\section{Digitized by the Internet Archive in 2007 with funding from Microsoft Corporation}




\section{PREFACE.}

The literature of electrical engineering has become so vast and extensive that it is impossible for any man to kecp pace with all that is written on electrical subjects. He who produces a new book that adds to the swelling tide of new publications, may justly be asked for his credentials. My justification for writing this tract will be found in the fact that, though almost all branches of applied electricity have enlisted the industry of authors, the induction motor has received comparatively little attention from competent engineers. The few whose experience and knowledge would entitle them to speak with authority on this subject are deterred from publishing by commercial reasons.

I have made the induction motor the subject of early and special studies, and a comparison of my treatment of its theory with the purely analytical theories will show how far I have succeeded in simplifying and elucidating so complex a subject. The graphical treatment of abstruse natural phenomena is constantly gaining ground, and I quote with satisfaction the words of so great a mathematician as Prof. George Howard Darwin, Fellow of Trinity College, Cambridge, who says on p. 509 of the second volume of Lord Kelvin and Prof. Tait's Treatise on Natural Philosophy that "the simplicity with which complicated mechanical interactions may be thus traced out geometrically to their results appears truly remarkable."

All through this little book I have endeavored to let inductive method check at every step the mathematical or graphical deduction of the results. A wide experience with mono- and polyphase alternating current induction motors, gained at the Oerlikon Engineering Works, Switzerland, has enabled me to do so. Thus the careful reader who is willing to profit by the experience of others, will find many valuable hints and results which he can turn to account in his 
practice. Many induction motors have been designed on the principles laid down in this little treatise, and in no case has the theory failed to answer the questions suggested by observation.

The writing of this book has been mainly a labor of love. Those who know of the troubles, cares and labor involved in writing a book and bringing it through the press, not to mention the sacrifice of personal experience by publication, will doubtless be able to appreciate this thoroughly.

I wish to thank the editors of the ELECTRICAL WorLd AND ENGINeER for the pains they have taken with the publication of this book, and I must specially thank Mr. W. D. Weaver for the encouragement he has always given to me. To Mr. T. R. Taltavall, Associate Editor of Electrical World ANd ENGINEER, who has taken endless pains with the proofs of this book, I feel very much indebted.

The substance of this volume was delivered in January, 1900 in the form of lectures at the University of Wisconsin, Madison, Wis., and I wish to thank Prof. John Butler Johnson, Dean of the College of Mechanics and Engineering, for the invitation as non-resident lecturer which he extended to me. To him and to Prof. D. C. Jackson I am greatly indebted for the hospitality conferred upon the stranger within their gates. 


\section{CONTENTS.}

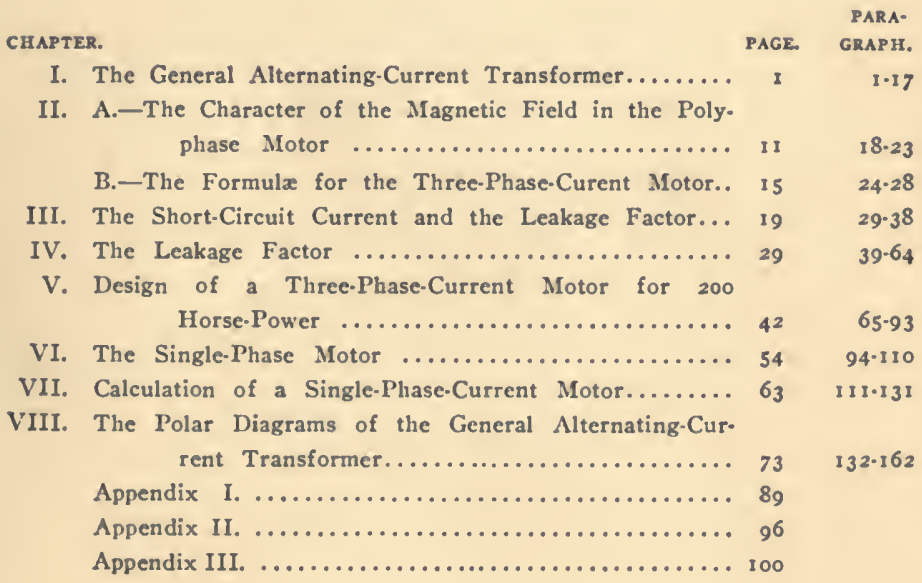





\section{THE INDUCTION MOTOR}

\section{CHAPTER I.}

\section{The General Alternating Current Transformer.}

I. The problem of problems, in the solution of which the electrical engineer is deeply interested, and which underlies all others, is set before us in the form of the alternating current transformer possessing considerable leakage and a relatively large magnetizing current.

2. A transformer with an open secondary takes from the primary mains just so much current as is necessary to produce a magnetic field which can balance the primary voltage. This current-neglecting for the moment hysteresis and eddy currents-lags behind the primary voltage by a quarter of a phase; hence the work done by this current is zero, and the magnetizing current is therefore a "wattless" current. This consideration is true only for a transformer without leakage. The magnetizing current need not be a wattless current in the sense in which this term is generally used. We shall learn more about this in Chapter VIII.

3. If you throw a non-inductive load upon the secondary, that is to say, if the secondary of the transformer be closed through a resistance, then the impedance represented by the action and reaction of the primary and the secondary system of the transformer, is diminished, permitting a larger current to flow. If, for didactic purposes, we make the assumption that the whole magnetic flux of the primary is transmitted without loss into the secondary, and vice versa, then the vector of the primary current must be composed of two vectors, the one representing the magnetizing or wattless current, lagging behind the terminal volts by a quarter of a phase, and the other representing the watt irrent and being in phase with the ter- 


\section{THE INDUCTION MOTOR.}

minal volts. Thus the vector of the primary current for any external resistance is determined by the locus of the point $A$, Fig. $\mathrm{I}$, which is the straight line $\overline{A D}$ parallel with the vector of the impressed e. m. f. The energy consumed by the transformer is given by the equation

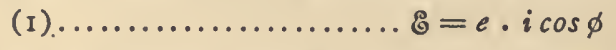

4. The introduction of leakage into the transformer changes the dia. gram as follows: The total number of lines of induction passing through the primary coil must remain constant as long as the terminal voltage remains constant, neglecting for the moment the ohmic resistance of the coil. The magnetomotive force of the main current produces a stray-field proportional to the driving current; this field

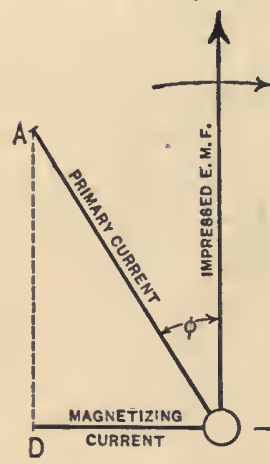

FIG. $I$.

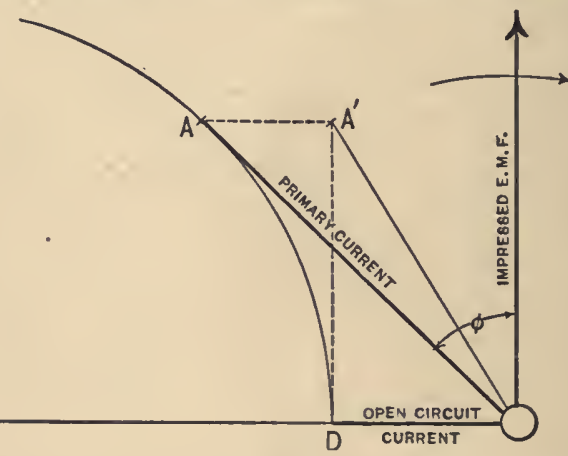

FIG. 2.

added vectorially to the main magnetic field, generates the constant magnetic field included by the primary coil. The result of these actions and reactions is that $A$ does no longer move in a straight line, but in a semi-circle described upon the prolongation of $\overline{O D}\left({ }^{1}\right)$.

${ }^{1}$ A historical remark may not be out of place here. The present writer worked out the theory here given in the summer of 1895 , and sent the paper to the Elektrotechnische Zeitschrift, Berlin, where it was published in February, 1896. Meanwhile Mr. A. Heyland, in some letters to the above-named paper, used the same diagram without, however, giving any proof. When Mr. Heyland's letters were published I inserted a note in my MS. referring to them. I have since, whenever I had an opportunity, given Mr. Heyland ample credit for his priority. and $I$ have done it with satisfaction, as I really admired some of his later papers very much. Mr. Steinmetz informed me some time ago that he had found this relation as early as 1893 , but that commercial reasons prevented him from publishing. 
It is of extreme importance for us to clearly understand these relations as they form the basis for all further reasoning.

5. In Fig. $3 \overline{O A}$ is the vector of the magnetomotive force of the primary, or, in other words, the total number of lines of force (not induction) produced by the primary current, and corresponding to the number of ampere-turns. Not all the lines of induction which the primary current generates can reach the secondary of the transformer.

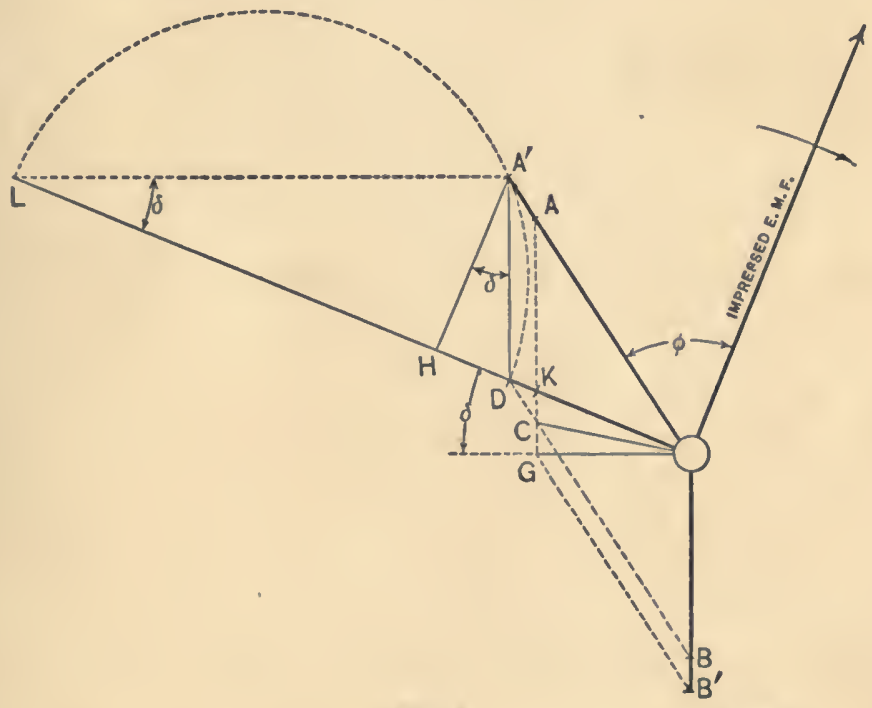

FIG. 3 .

Let us assume that the amount $\overline{A A}^{2}$ is lost, $\overline{O A}$ being equal to $v_{1} . \overline{O A}, v_{1}$ being a factor smaller than one and measuring the loss of lines from the primary to the secondary. Let $\overline{O B^{1}}$ represent the vector of the total number of lines of induction of the secondary, and $\overline{O B}=$ $v_{2} . \overline{O B}^{1}$ the number of lines that extend into the primary, $v_{2}$ being again a coefficient smaller than one, then we see at once that the vector sum of $\overline{O A}$ and $\overline{O B}$ must be equal to the vector of the magneto- 


\section{THE INDUCTION MOTOR.}

motive force which sets up the magnetizing current. The vector of this magnetomotive force is represented by the line $\overline{O C}$.

6. The lines of force which are common to both primary and secondary, are the effect of the two magnetizing forces $\overline{O A}$ and $\overline{O B}$; while the lines of induction which pass through the secondary only, can be found as the resultant of $\overline{O A}$ and $\overline{O B}^{1}$. This resultant, $\overline{O G}$, must be perpendicular to $\overline{O B}$, as $\overline{O B}$ is produced through the oscillations of $\overline{O G}$.

7. The following list will help to make the diagram more clearly understood:

$\overline{O A}^{\prime}=X_{1}$ is the magnetizing force of the primary.

$\overline{O B}=X_{2}$ is the magnetizing force of the secondary.

$\overline{O A}^{1}=\frac{X_{1}}{v_{1}}$

$\overline{O B}^{1}=\frac{X_{2}}{v_{2}}$

$\overline{O A^{1}}-\overline{O A}=X_{1}\left(\frac{\mathrm{I}}{v_{1}}-\mathrm{I}\right)$

$\overline{O B^{2}}-\overline{O B}=X_{2}\left(\frac{1}{v_{2}}-\mathrm{I}\right)$

$\overline{O D}$ is the field balancing the terminal voltage

8. It will readily be seen that, if the drop caused by the ohmic resistance of the primary may be neglected without too much inaccuracy, $\overline{O D}$ is constant if the terminal voltage is so. We have, Fig. 3 ,

$$
\begin{aligned}
\angle H A^{\prime} D & =\angle H O G=\angle \delta \\
\sin \delta & =\frac{\overline{G K}}{\overline{O K}}=\frac{\overline{C K}+\overline{C G}}{\overline{O K}}, \\
\overline{C K} & =X_{2}\left(\mathrm{I}-v_{1}\right) \\
\overline{C G} & =X_{2}\left(\frac{\mathrm{I}}{v_{2}}-\mathrm{I}\right) \\
\overline{O K} & =\overline{O D} \cdot v_{1}
\end{aligned}
$$


GENERAL ALTERNATING CURRENT TRANSFORMER.

Hence,

$$
\begin{aligned}
\sin \delta & =\frac{X_{2}}{\overline{O D}} \frac{\left(1-v_{1}+\frac{1}{v_{3}}-1\right)}{v_{1}} \\
& =\frac{X_{2}}{\overline{O D}}\left(\frac{1}{v_{1} v_{2}}-1\right)
\end{aligned}
$$

In words, this means that $X_{2}$ may be represented as a chord in a semi-circle described upon $\overline{L D}$ as basis, and having a diameter

$$
\overline{L D}=\overline{O D} \cdot\left(\frac{1}{v_{1} v_{2}}-i\right)
$$

If we want to take from the diagram $X_{1}$ directly without having to

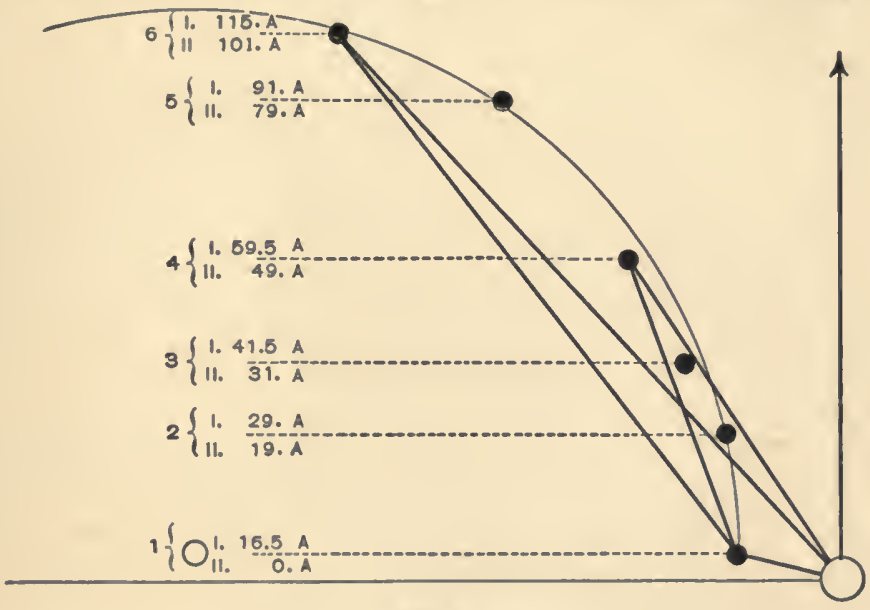

FIG. 4 .

multiply by $v_{1}$, we have to join $A$ and $K$ by a circle. For a more detailed treatment of all these points I refer the reader to Chapter VIII. 9. We call the quotient $\frac{\overline{O D}}{\overline{L D}}$ the leakage factor $\sigma$ of the transformer, and have therefore

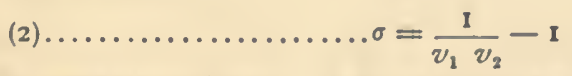

The leakage coefficient $\sigma$ is the most important factor in the theory 


\section{THE INDUCTION MOTOR.}

of the alternating current transformer, and a successful design must endeavor to keep $\sigma$ as small as possible. The determination of $\sigma$ will be treated of in a chapter devoted entirely to the leakage factor.

10. The following table contains the results of a series of measurements as a corroboration of the theory. The data were taken from a three-phase current motor, the armature of which was standing still; the whole apparatus was thus acting as a transformer with considerable leakage. The field contained 36 closed slots, 7 conductors in each slot; resistance of each phase $0.045 \mathrm{ohms}$. The armature contained 90 round holes, 3 conductors in each hole; resistance at each phase 0.172 ohms. Number of poles, 6 . Frequency, $48 \sim .-$

\begin{tabular}{|c|c|c|c|c|c|}
\hline \multicolumn{3}{|c|}{ PRIMARY CIRCUIT. } & \multicolumn{3}{|c|}{ SECONDARY CIRCUIT. } \\
\hline $\begin{array}{c}\text { Volts } \\
\text { (each phase.) }\end{array}$ & Amperes. & Watts. & $\begin{array}{c}\text { Volts } \\
\text { (each phase.) }\end{array}$ & Amperes. & $\begin{array}{l}\text { Watts } \\
\text { (calculated.) }\end{array}$ \\
\hline $\begin{array}{l}97.5 \\
110 \\
110 \\
110 \\
110 \\
110\end{array}$ & $\begin{array}{l}14.3 \\
29 \\
41.5 \\
59.5 \\
91 \\
115\end{array}$ & $\begin{array}{r}1010 \\
7400 \\
11000 \\
16400 \\
24400 \\
28000\end{array}$ & $\begin{array}{r}94 \\
102 \\
100 \\
95 \\
79 \\
70\end{array}$ & $\begin{array}{l}0 \\
16.6 \\
31 \\
46 \\
80 \\
97\end{array}$ & $\begin{array}{r}0 \\
5080 \\
9030 \\
13110 \\
18960 \\
20370\end{array}$ \\
\hline
\end{tabular}

II. A graphic representation of the experimental data of the table is given in Fig 4.

It will be noticed that the observed points lie very closely on a circle, the diameter of which corresponds to 168 amperes primary current. Below each point the primary and secondary currents are written, the latter being taken from the diagram. The agreement between them and the observed values in the table may be called satisfactory, especially since we have had to guess as to the real value of $v_{2}$.

12. From our table we can compute the value of $v_{1}$. A voltage of 97.5 at the primary would, if there were leakage loss, produce at the secondary a voltage of $(93 \times 3 \div 97 \times 7) 97.5=104.5$. We observed, however, only 94 , hence we have

$$
v_{1}=\frac{94}{104.5}=0.90
$$




\section{GENERAL ALTERNATING CURRENT TRANSFORMER.}

13. We should make a great mistake were we to assume that this value would give us a leakage factor $\sigma$ true to reality, since in our case, where the slots in armature and field are closed, $v$ depends greatly upon the saturation of the thin iron bridges closing the slots. The saturation of these bridges is dependent upon the intensity of the

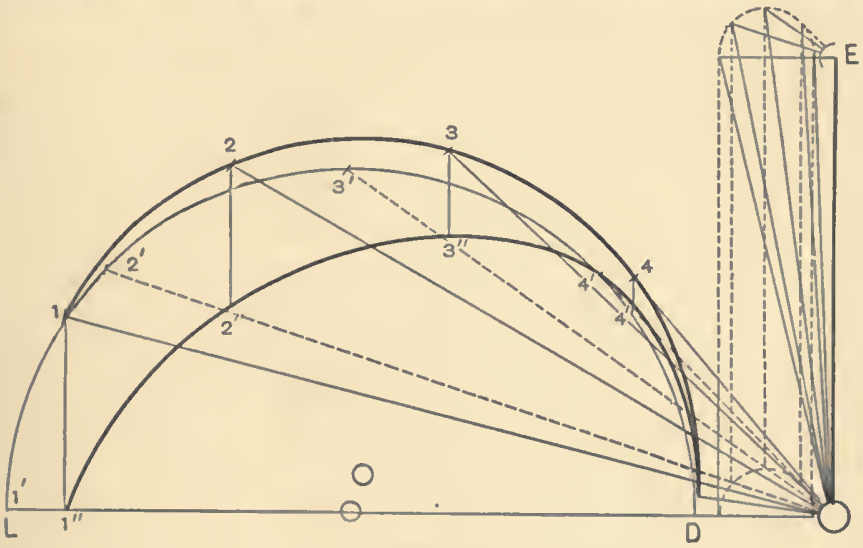

FIG. 5 .

current; beyond a certain intensity $v$, and therefore $\sigma$ is practically constant. Assuming $v_{1}$ to be equal to $v_{2}$, we should get for

$$
\sigma=\frac{I}{0.90 \cdot 0.90}-1=0.235 \text {, instead of } \frac{16.5}{168}=0.098 \text {, }
$$

as follows from the diagram.

14. It may be advisable to emplasize that in the derivation of the diagram the olımic resistance of the primary has not been taken into account. As this point is of extreme theoretical and practical importance, we have to dwell on it at some length.

TIE INFLUENCE OF TIIE RESISTANCE OF THE PRIMARY UPON THE DIAGRAM.

15. The semi-circle $L I^{\prime} z^{\prime} 3^{\prime} 4^{\prime} D$, Fig. 5, represents the locus of the current for a constant terminal voltage $O E$, upon the assumption that the primary resistance be negligible. 'The arc 1234 is the locus of 


\section{THE INDUCTION MOTOR.}

the current if we assume that the drop through ohmic resistance in the primary amounts for point $4^{\prime}$ to $10 \%$ of $O E$. Finally the ordinates of the curve 1 " 2 " 3 " 4" represent the amount of watt-component of the current that is available in the secondary circuit. It would be superfluous here to say anything about the manner in which these curves have been plotted, as everyone familiar with polar diagrams will readily understand it from the lines in the figure.

It is of importance to note that, though the primary resistance was assumed to have a value which exceeds about five times the real value in practice, yet the curves $L I^{\prime} 2^{\prime} 3^{\prime} 4^{\prime} D$ and I $2^{\prime} 34$ deviate comparatively little from each other. If $\overline{O D}$ were zero, then they would not deviate at all. In reality, $\overline{O D} \div \overline{L D}$ is almost always considerably smaller than it is in our figure. If, however, $\overline{O D}$ is large in comparison with $\overline{L D}$, and if the primary resistance is considerable, we have to draw a diagram like Fig. 5. This will be the exception and not the rule.

16. Thus we have learned that the influence of the ohmic resistance upon the locus of the current is, in most practical cases, negligible; but the energy dissipated in the resistance, is in all cases to be taken into account; this can be done by deducting the watt-component corresponding to the ohmic loss from the ordinates of the semi-circle $\overline{L D}$. We thus arrive at a curve similar to I" $2^{\prime \prime} 3^{\prime \prime} 4$ ".

\section{GENERAL CONCLUSIONS AND SUMAARY.}

17. We are now enabled, with the help of the diagram, to solve any question pertaining to the alternating current transformer. We shall, in a later chapter, discuss in detail for a concrete case the many problems of interest which this diagram permits us to solve; here we shall merely summarize the main conclusions at which we have arrived.

In Fig. $6 \overrightarrow{O A}$ represents the primary current $i_{1}, \overline{O D}$ the magnetizing current $i_{0}$, and $\overline{A D}$ is equal to $v_{1} i_{2} \frac{n_{2}}{n_{1}}$, in which $n_{1}$ and $n_{3}$ are the number of turns in the primary and the secondary, respectively. 


\section{GENERAL ALTERNATING CURRENT TRANSFORMER.}

The smallest lag $\phi_{0}$ is determined by the intersection of the semicircle $\overline{L D}$ with the semi-circle $H A O$, as can be seen at a glance. The cosine of this angle can be expressed as follows. It is

$$
\begin{aligned}
& \overline{H A}=\overline{H D}=\frac{i_{0}}{2 \sigma} . \\
& \cos \phi_{0}=\frac{\overline{H A}}{\overline{H O}}=\frac{i_{0}}{2 \sigma\left(i_{0}+\frac{i_{0}^{\circ}}{2 \sigma}\right)} \\
& \cos \phi_{0}=\frac{I}{2 \sigma\left(I+\frac{1}{2 \sigma}\right)} \\
& \frac{\angle D}{O D}=\sigma \\
& \frac{D D}{\angle D} \cdot \frac{D}{\angle D} \\
& \text { (3) } \ldots \ldots \ldots \ldots \ldots \ldots \ldots \cos \phi_{0}=\frac{1}{2 \sigma+1}
\end{aligned}
$$

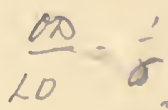

This equation enables us to predict the maximum power factor if the leakage coefficient $\sigma$ is known. I will here premise that the starting current furnishes a value for the determination of the diameter of

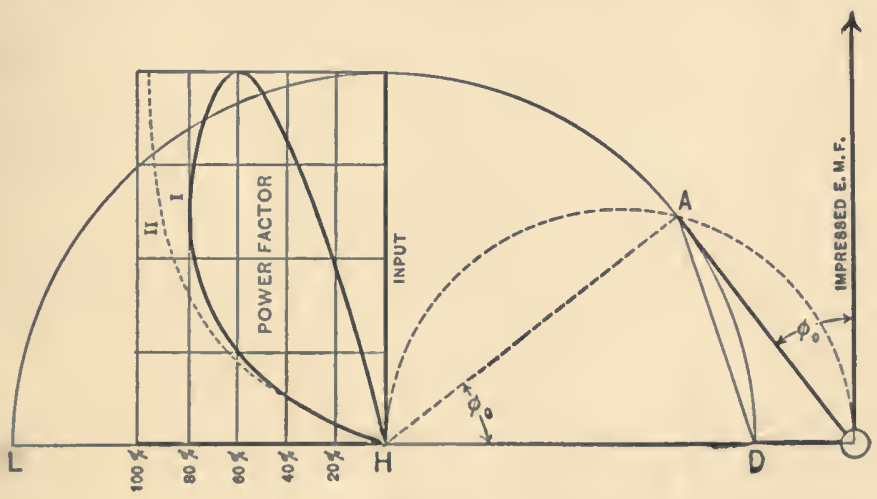

FIG. 6.

the semi-circle, while the magnetizing current can always easily be measured. This method of determining the maximum power factor 


\section{THE INDUCTION MOTOR.}

attainable, thus recommends itself not only to the designer, but, on account of its simplicity and accuracy, also to the customer.

The full curve $I$ of higher order in Fig. 6 , which can easily be constructed, represents the power factor as a function of the power input; the dotted line $I I$ shows the power factor for a transformer without any leakage. 


\section{CHAPTER II.}

\section{A.-The Character of the Magnetic Field in the Polyphase Motor.}

18. The magnetic field in a three-phase current motor is produced by three windings, I, II, and III, Fig. 7. If the current in

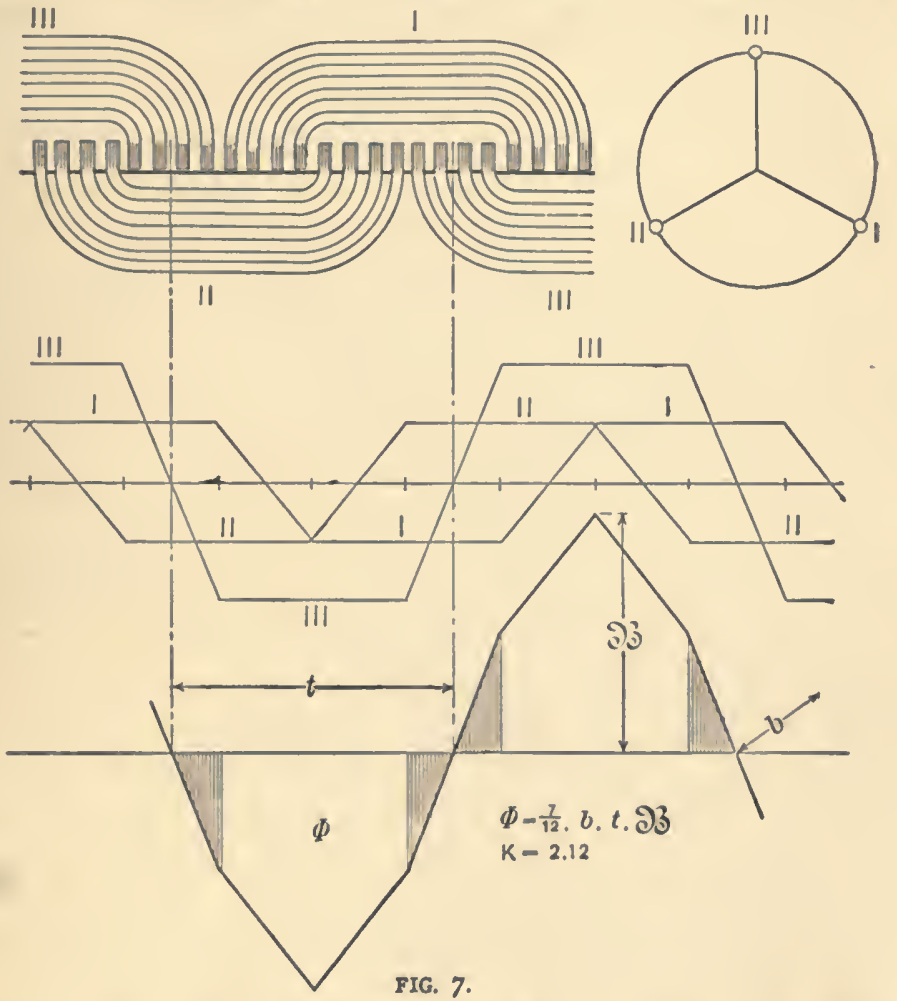

III is a maximum, and if the currents vary acording to a simple sine curve, then the currents in I and II are each equal to half the cur- 


\section{THE INDUCTION MOTOR.}

rent in III. The magnetomotive forces of each phase are represented by the ordinates of the curves I, II, and III respectively. Each ordinate measures the magnetomotive force produced in that place of the circumference in which it is drawn. The adding up of the three curves yields the thick line curve drawn below.

If the magnetic reluctance is the same at every point of the circumference, in other words, if the reluctance of the iron is negligible, then the flux, produced by the magnetomotive force represented by the thick line curve, is proportional to that magnetomotive force. Hence the thick line curve may be taken as a representation of the flux. We call the total number of lines of induction $\Phi$, and we as-

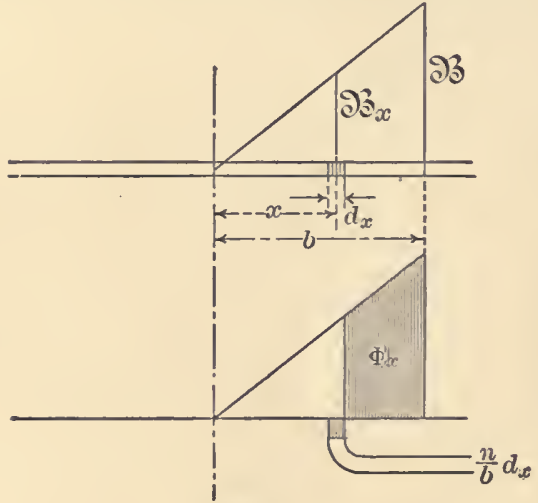

FIG. 8.

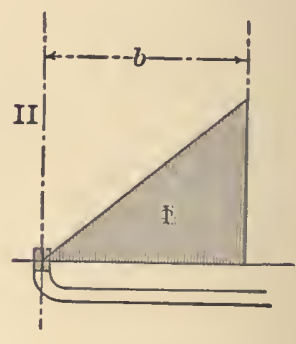

FIG. 9.

sume that this flux varies according to a simple sine law. We shall now proceed to calculate the e.m.f. induced by this field upon each phase.

We have tacitly assumed that the coils I, II, and III are distributed in a practically infinite number of slots. Though this cannot be the case, yet this assumption may safely be made for our present purpose.

19. It is obvious that, if the convolutions of each phase were all concentrated in one slot, the effect of the oscillation or the traveling of 


\section{THE MAGNETIC FIELD IN THE POLYPHASE MOTOR.}

the field would be to set up an e. m. f. equal to $2.22 \sim z \cdot \phi \cdot 10^{-8}$ volts; however, through the distribution of the winding, only the parts of the flux not covered with hetchings can produce an $\mathrm{c}$. $\mathrm{m}$. f. expressed by this formula, while the hatched parts of the field will have a considerably snaller effect. The induced c. $m$. f. can be calculated as follows: The width of the coil is $2 b$; there are $n$ conductors in the coil spread over $2 b$. Per unit length there are, therefore, $-\frac{n}{2 b}$ conductors, hence the element $d x$ contains $d x \cdot \frac{n}{2 b}$ conductors. The number of lines of induction threading the conductors in the element $d x$ is equal to $\Phi_{x}$ represented by the hatched area. We have, therefore,

$$
\begin{aligned}
& d e=2.22 \cdot \sim \cdot \frac{n}{2 b} \cdot d x \cdot \Phi_{x} \cdot 10^{-8} \text { volts. } \\
& \Phi_{x}=B \cdot \frac{b}{2}-Q x \cdot \frac{x}{2}=B \frac{b}{2}-B \cdot \frac{x^{3}}{2 b}
\end{aligned}
$$

Hence

$$
\begin{aligned}
d e & =2.22 \cdot \sim \cdot \frac{n}{2 b}\left[\frac{B \cdot b \cdot d x}{2}-\frac{B \cdot x^{2} \cdot d x}{26}\right] \cdot 10^{-8} \\
e & =2.22 \cdot \sim \cdot \frac{n}{2 b}\left[\int_{0}^{b} \frac{B \cdot b \cdot d x}{2}-\int_{0}^{b} \frac{B \cdot x^{2} \cdot d x}{2 b}\right] \cdot 10^{-8} \\
e & =2.22 \cdot \sim \cdot \frac{n}{2} \cdot B\left[\frac{b}{2}-\frac{b}{6}\right] \cdot 10^{-8} \\
e & =2.22 \sim-\frac{n}{2} \cdot B \cdot \frac{b}{3} \cdot 10^{-8}
\end{aligned}
$$

We have $\Phi=\frac{B \cdot b}{2}$, therefore

$$
\text { (4) } \ldots . e=2.22 \cdot \sim \cdot \frac{n}{2} \cdot\left(\frac{2}{3} \Phi\right) 10^{8}
$$

This is in words, The e. $m$. $f$. induced by the field $\Phi$ upon a coil of the width $b$ is two-thirds as large as the e. $\mathrm{m}$. $\mathrm{f}$. which would be in- 


\section{THE INDUCTION MOTOR.}

duced by the same field upon a coil which is not distributed, but lodged in only one groove. The latter. case is represented in Fig. 9. It may not be amiss to call attention to the fact that a coil like that in Fig. 9 would produce a rectangular magnetic field twice as large as that shown in the figure. Hence the inductance of the flat coil is one-third as large as the inductance of the coil lodged in one slot.

20. The e. m. f. generated by the field in Fig. 7 can now easily be calculated.

The number of lines of induction represented by the white area in Fig. 7 is equal to

$$
\left(\frac{2}{3} \cdot t \cdot b \cdot B\right)-\frac{3}{4} .
$$

The e. $m$. f. produced by this flux is

$$
e_{1}=2.22 \cdot \sim \cdot z \cdot\left(\frac{3}{4} \cdot \frac{2}{3} \cdot t \cdot b \cdot B\right)_{10: 8}
$$

The hatched areas represent a flux equal to

$$
\frac{I}{6} \cdot t \cdot b \cdot \frac{B}{2}
$$

The e. $m$. f. produced by this flux is

Hence

$$
e_{11}=2.22 \cdot \sim \cdot z \cdot \frac{2}{3}\left(\frac{1}{12} \cdot t \cdot b \cdot B\right) 10^{-8}
$$

$$
e=e_{1}+e_{11}=2.22 \cdot \sim \cdot z \cdot\left(\frac{20}{36} \cdot t \cdot b \cdot B\right) \cdot 10^{-8}
$$

The total flux amounts to

$$
\begin{aligned}
\phi & =\frac{7}{12} \cdot b \cdot t \cdot B \text {, hence } \\
e & =2.22 \cdot \sim \cdot z \cdot \frac{20}{2 \mathrm{I}} \cdot \Phi \cdot 10^{-8} \\
(5) \ldots . c & =2.12 \cdot \sim \cdot z \cdot \Phi \cdot 10^{-8} \text { volts. }
\end{aligned}
$$

21. The ampere-turns in each phase which are needed to produce the induction $B$ in the air-gap are determined by the consideration, which follows immediately from Fig. 7, that

$$
2\left(0 \cdot 4 \pi \cdot n \cdot i_{0} \cdot \sqrt{2}\right)=B \cdot 2 \triangle
$$


THE MAGNETIC FIELD IN THE POLYPHASE MOTOR.

In this equation $i_{0}$ is the magnetizing current, $n$ the number of conductors per pole and phase, and $\Delta$ the air-gap in $\mathrm{cm}$. The reluctance of the iron is supposed to be negligible.

From this equation follows

(6)...............

22. If the reluctance of the iron is not negligible, the magnetic induction $\mathbb{B}$ has to be determined point for point, which can easily be done with the help of a magnetizing curve. It is of importance to not: that the maximum induction does not extend over a very large part of the pole-pitch, hence it is not objectionable to have an induction of 15,000 or 16,000 in the teeth, as this high induction hardly increases the magnetizing current on account of its being limited to $a$ very small part of the surface of the pole.

23. I have not entered upon a detailed consideration of the elementary phenomena in the polyphase motor, as they have been treated by Gisbert Kapp and André Blondel ${ }^{3}$ with a lucidity and clearness which it would be impossible for me to surpass.

\section{B.-The Formulæ for the Three-Phase Current Motor.}

24. It remains to prove that the theory of the general alternating current transformer is directly applicable to the polyphase motor. That this is true, as long as the armature of the motor is standing still, is evident. If the armature runs at synchronism, the number of its revolutions corresponds to the frequency of the feeding current $\sim_{1}$. If the armature runs slower than the field, the difference being $\sim_{1}-\sim_{2}$, then an e. $m$. $f$. is induced in the armature proportional to the slip $\sim_{1}-\sim_{2}$. If the armature resistance per phase is $r_{2}$, then a current will flow proportional to $\frac{\sim_{1}-\sim_{2}}{r_{2}}$. The same current can be attained in the transformer with the secondary at rest, if the resistance be thus chosen that the relation exists

\footnotetext{
${ }^{2}$ Electric Transmission of Energy, p. 304 and following, reprinted in Appendix I.

'L'Eclairage Electrigue, 1895.
} 


\section{THE INDUCTION MOTOR.}

$$
\text { (7)............ }
$$

$r$, signifying the internal and external resistance of the secondary of the transformer. Under this condition the same diagram represents the currents in size and phase in the transformer as well as in the motor. That this must be so becomes clear as soon as we remember that the impedance of the motor is equal to $\sqrt{r_{2}{ }^{2}+A\left(\sim_{1}-\sim_{2}\right)^{2}}, A$ being a constant. The impedance of the transformer is equal to

hence

$$
\sqrt{r^{2}+A \cdot \sim_{1}^{2}}
$$

$$
\begin{aligned}
\frac{\sim_{1}}{\sqrt{r^{2}+A \sim_{1}^{2}}} & =\frac{\sim_{1}-\sim_{2}}{\sqrt{r_{2}{ }^{2}+A\left(\sim_{1}-\sim_{2}\right)^{2}}} \\
\frac{\sim_{1}{ }^{2}}{r^{2}+A \sim_{1}^{2}} & =\frac{\left(\sim_{1}-\frac{\left.\sim_{2}\right)^{2}}{\left(\sim_{2}^{2}+A\left(\sim_{1}-\sim_{2}\right)^{2}\right.}\right.}{\sim_{1} \cdot r_{2}}=\left(\sim_{1}-\sim_{2}\right) r,
\end{aligned}
$$

which equation is identical with (7). Credit is due to Dr. BehnEschenburg, Oerlikon, for having first prominently put forth this relation.

25. The Torque.-Imagine the armature to be turned against the magnetic field, which is supposed to stand still, with an angular velocity equal to $\omega_{1}-\omega_{2}$. If $D$ is the torque in $m k g$, then we have

$$
\text { 9.8I . D. }\left(\omega_{1}-\omega_{2}\right)=3 i_{2}^{2} r_{2} \text {, }
$$

$i_{2}$ being the current in, and $r_{2}$ the resistance of, each phase.

We have

$$
\omega_{1}=2 \pi \cdot \frac{\sim_{1}}{p},
$$

if $p$ is the number of north or south poles. And also

$$
9.8 \mathrm{I} \cdot D \cdot \omega_{2}=P \text { watts. }
$$

From these equations follows

$$
\begin{aligned}
& 9.8 \mathrm{I} \cdot D \mathrm{mkg} \cdot\left(2 \pi \cdot \frac{\sim_{1}}{p}-\omega_{2}\right)=3 i_{2}{ }^{2} \cdot r_{2} \\
& 9.8 \mathrm{I} \cdot 2 \pi \cdot D m k g \cdot \frac{\sim_{1}}{p}-P=3 i_{2}{ }^{2} \cdot r_{2}
\end{aligned}
$$


THE MAGNETIC FIELD IN THE POLYPHASE MOTOR.

(8).........6.6.6. $D$ mkg $=\frac{p}{\sim_{1}}\left(3 i_{2}{ }^{2} r_{2}+P_{\text {watts }}\right)$.

If we want to have the torque in foot-pounds, the formula is

$$
\text { 8.5. } D_{f t . l b s .}=-\frac{p}{\sim_{1}}\left(3 i_{2}{ }^{2} r_{2}+P_{\text {watts }}\right) .
$$

The torque is, therefore, proportional to the algebraic sum of the output of the motor plus the energy dissipated in the armature.

26. Starting Torquc.-At starting $P$ is zero. All the energy that goes into the motor, is dissipated into heat; therefore, $3\left(i_{1}^{2} r_{1}+i_{2}{ }^{2} r_{2}\right) \div 3 e$ must be equal to the ordinate of our circle. If $r_{1}$ and $r_{2}$ are known, the point on the circle corresponding to this case can easily be found by trying.

A glance at our diagram shows us that we can attain at starting any running torque; but the starting current will always te equal to, and never smaller than, the running current," unless the motor is started under conditions, as higher or lower voltage, etc., different from those under load.

27. Efficiency.-The energy which flows into the motor neglecting hysteresis can be taken from the diagram. If $e_{3}$ is the impressed e. $m . f ., i_{1}$ the current in each phase, then we have

$$
\text { (9) } \ldots \ldots \ldots \ldots \ldots \ldots \text {. } 8=3 e_{1} i_{1} \cos \phi
$$

To obtain the output we have to deduct the ohmic losses, the load losses, and the friction. Hysteresis and eddy currents may be taken into account, since they are practically constant at all loads, as though they were olımic losses in a coil so placed upon the primary as to have no leakage at all, the energy wasted in this coil being equal to the loss through hysteresis and eddy currents. We have, then,

$$
\text { (ro) } \ldots \ldots \ldots \ldots \ldots P=3 e_{1} i_{1} \cos \phi-3 i_{1}{ }^{2} r_{1}-3 i_{2}{ }^{2} r_{2}-F-Q
$$

"Prof. Silvanus P. Thompson, "Polyphase Electric Currents," first edition, p. 213 , says of a polyphase motor: "This motor starts under full load, taking less than full-load current." This is an impossible figment. In the second, very inuch enlarged, edition of l'rof. Thompson's interesting book, this statement is changed, and we read on page 255: "This motor starts under full load, taking less than twice the full-load current." The motor should theoretically not take more than full-load current, but just as much, and in nractice this is also generally obtained, as, in this case, the rotor is equipped with slide rings. 


\section{THE INDUCTION MOTOR.}

$F$ being the friction loss in watts, $Q$ the loss through hysteresis and eddy currents.

The efficiency $\eta$ is,

$$
\text { (II) } \ldots \ldots \ldots \ldots \ldots \eta=\frac{P}{3 e_{1} i_{1} \cos \phi}
$$

23. The most important formulæ for the design of the polyphase motor have thus been determined, and it will be useful to give them in the form of a table.

Maximum Power Factor-

(3) $\ldots \ldots \ldots \cos \phi_{0}=\frac{I}{2 \sigma+1}$

Magnetic Field-

(5) $\ldots \ldots \cdots \cdots+\cdots,=2 \cdot 12 \cdot \sim \cdot z_{1} \cdot \Phi \cdot 10^{-8}$ volts.

\section{Magnetizing Current-}

(6).............. i $i_{0}=\frac{B \cdot r \cdot 6 \triangle}{2 n \cdot \sqrt{2}}$

Slip-

$$
\begin{aligned}
(7) \ldots \ldots \ldots \cdot \frac{\sim_{1}}{r} & =\frac{\sim_{1}-\sim_{2}}{r_{2}} \\
\frac{\sim_{1}-\sim_{2}}{\sim_{1}} & =\frac{r_{2}}{r}=\frac{3 i_{2}{ }^{2} r_{2}}{P+3 i_{2}{ }^{2} r_{2}}
\end{aligned}
$$

Torque-

$$
\text { (8) } \ldots .61 .6 \cdot D_{m k g}=\frac{p}{\sim_{1}}\left(3 i_{2}^{2} r_{2}+P_{\text {watts }}\right)
$$

Impressed Energy-

(9) $\ldots \ldots \ldots \ldots \ldots g=3 e_{1} i_{1} \cos \phi$

\section{Output-}

$$
\text { (10)......... P watts }=3 e_{1} i_{1} \cos \phi-3 i_{1}^{2} r_{1}-3 i_{2}{ }^{2} r_{2}-F-Q^{\prime}
$$

\section{Efficiency-}

(II) $\ldots \ldots \ldots \ldots \ldots \eta=\frac{P}{3 e_{1} i_{1} \cos \phi}$ 


\section{CHAPTER III.}

\section{The Short-Circuit Current and the Leakage Factor}

29. An invaluable aid in the design of polyphase motors is afforded by the short-circuit current characteristic. In a motor having a squirrel-cage armature, the starting current under different voltages is identical with the short-circuit characteristic. If the resistances of the armature and of the field were known, the power factor of the feeding current could be calculated; thus it would not even be necessary to use a wattmeter unless very accurate measurements were required. Theoretically, then, the short-circuit characteristic is sufficient for the determination of the leakage factor; in practice, however, it will, in the majority of cases, be unadvisable to depend upon the short-circuit curve, on account of the corrections which become necessary. If the total resistance of the motor is small, the lag of the current amounts to nearly a quarter of a period; the inductance of a motor at standstill (short-circuit) should always be as small as possible; therefore, a very large current will go through the motor at full voltage. Now, the leakage factor is always more or less dependent upon the strength of the currents which cause the leakage, hence the leakage factor at starting with only a small resistance in the armature may be very different from-as a rule, smaller than-the leakage factor upon which the diagram is constructed. In fact, we do not work the motor in that quadrant of the semi-circle, which corresponds to the short-circuit characteristic. If, therefore, I shall not make much use of the short-circuit curve for the determination of the absolute value of the leakage factor, I shall all the more avail myself of it for comparative purposes where it does not so much matter whether the absolute value is correct or not, but where the relative value is of importance. Such questions as the influence of a closed or open slot, of the number of slots, of the air. 


\section{THE INDUCTION MOTOR.}

gap, and of the pole-pitch upon the leakage factor, can all be answered by consulting the short-circuit characteristic. I shall proceed to discuss, point for point, the influence of these factors on the leakage coefficient.

\section{THE SLOTS.}

30. The curves $A$ and $B$, in Fig. Io, represent the short-circuit characteristics for a closed slot of the shape marked $A$, and of the open slots of the shape marked $B$. The slots of the armature were closer
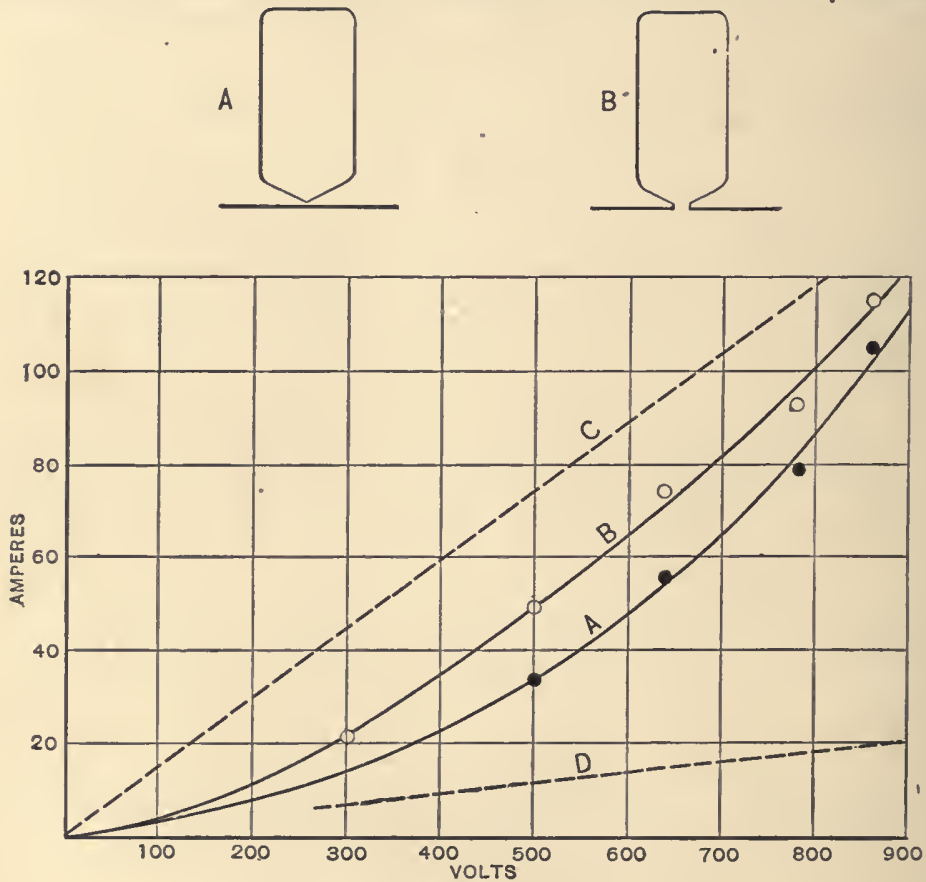

FIG. IO.

in each case. Curve $C$ shows the ideal short-circuit curve obtainable only if the leakage paths contain no iron at all. Curve $D$ is the magnetizing current reduced from the measured value of $42.2 \mathrm{am}-$ 


\section{SHORT-CIRCUIT CURRENT AND LEAKAGE FACTOR.}

peres at 1900 volts to the various voltages in the diagram. The increase of the magnetic reluctance of the main field through the opening of the slots proved too small to influence the magnetizing current in any perceptible manner.

We see that for voltages above 600 the curves $A, B$, and $C$ converge : in other words, the short-circuit current at the full voltage of 1900 will be almost the same whether the slots are open or closed. Hence the maximum flow of energy which can be impressed upon the motor is by no means so much dependent upon the form of the slot as would appear at first sight. The tendency of the closed slot is to change the fundamental diagram in the way shown by the full line curve in

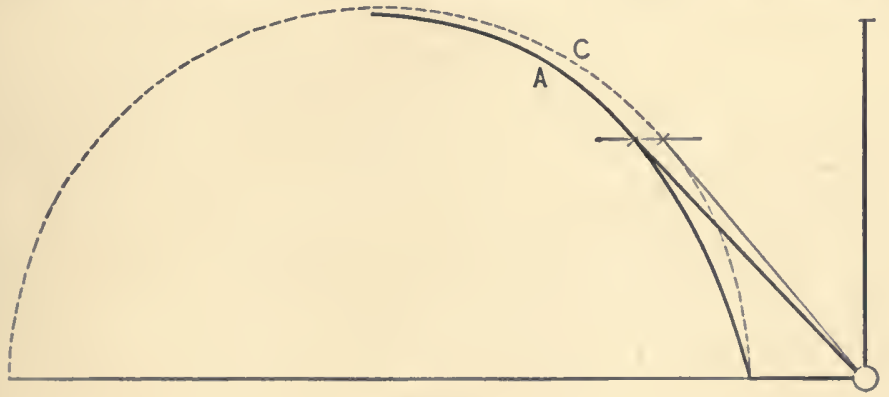

FIG. II.

Fig. II. From this curve follows that, though the maximum power factor is 0.715 instead of 0.755 , and the current for the same output 58 instead of 55 , yet the maximum output of the motor is hardly reduced as the maximum ordinate of the semi-circle, represented by the broken line, is only inconsiclerably larger than the maximum ordinate of the full line curve. If the iron bridges are kept very thin, excellent motors can be built with closed slots, in no way inferior to motors with open slots. The objection to closed slots, then, resolves itself-neglecting at present the load losses which may probably be caused by the bridges-into a commercial one, viz., the question, Which slot is cheaper? Labor being expensive in America, it is 


\section{THE INDUCTION MOTOR.}

cheaper to wind the coils on forms and to use open slots. The cost of labor being considerably smaller in Europe, some of the leading builders of polyphase motors have preferred to use closed slots and to wind by hand. Coils wound outside of the machine require more insulating material, and as the room is always somewhat scant in polyphase motors, the European method offers some advantages. On the other hand, we have to bear in mind that the greater ease with which machine-wound coils can be exchanged, should not be underrated, and might even be bought with the loss of another advantage. A design is more or less of a compromise, and the best design is that which combines the greatest number of advantages with the least number of drawbacks.

NUMBER OF SLOTS PER POLE.

31. A little consideration teaches us that we obtain the least amount of fluctuation in the field the more slots we have per pole. Theoretically, then, it would be advisable to have as many slots as possible. From a commercial standpoint, however, it is advisable to have as few as possible. Either extreme is impracticable; we must try to strike the golden mean.

32. The influence of the number of slots upon the leakage can also readily be seen. The more conductors we have in a slot the larger will be the leakage field surrounding the slot. The active field iswith enough accuracy for our present consideration-the same whether we distribute the same number of conductors in a few slots or in many. The e. m. f. induced by this field upon these conductors may, therefore, be set constant independently of the number of slots. Let us take a concrete case. If we have, for instance, Ioo conductors arranged in 5 slots, there are in each slot 20 conductors. The leakage field per slot is produced by these 20 conductors, hence proportional to their number. The e. m. f. induced by the leakage field per slot in the 20 conductors in each slot, is proportional to 20 times 20 . Hence 


\section{SHORT-CIRCUIT CURRENT AND LEAKAGE FACTOR.}

the total e. $\mathrm{m}$. $\mathrm{f}$., induced in the 100 conductors by the 5 leakage fields, is proportional to $20 \times 20 \times 5=2000$.

33. Now, let us arrange the roo conductors in ro slots. Each slot, then, contain s ro conductors, the leakage field per slot being proportional to ro. The e. m. f. induced by the leakage field in the ro conductors in each slot is proportional to ro times 10. Hence the total e. $\mathrm{m}$. f. induced in all the conductors in the ro slots is proportional to 10 $\times 10 \times 10=1000$. In other words, the counter c. m. f. of leakage is twice as large in the case of 5 slots as in the case of Io slots.

The above calculation rests upon the assumption that the reluctance of the leakage path of each slot is the same in the two cases under consideration. Though this is true only with some qualifications, yet the argument clearly shows the superiority of many over few slots, as far as leakage is concerned.

34. A general rule for the most favorable number of slots can hard!y be given. To take more than 5 slots per pole and phase in the field is

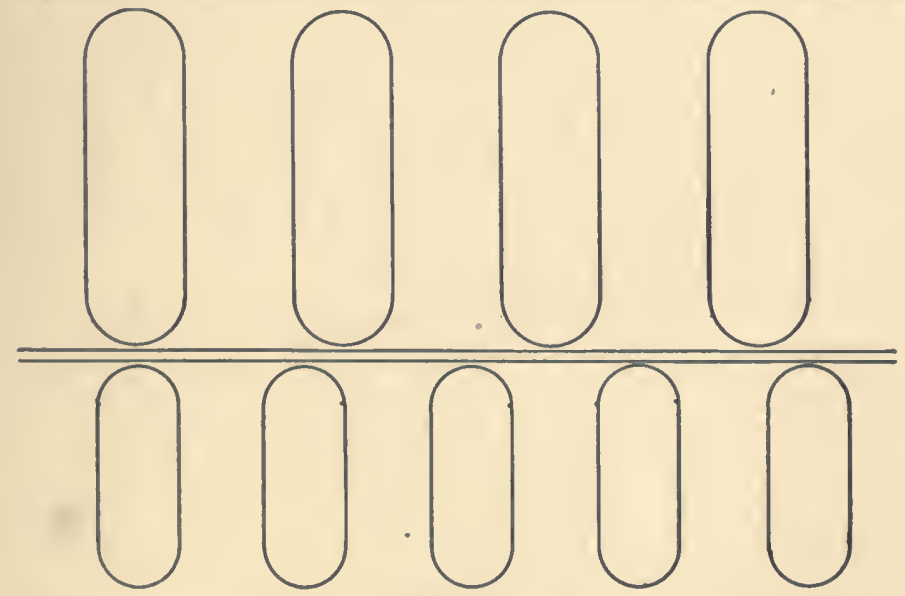

FIG. 12 .

hardly advisable unless the pole-pitch be very large, as in motors for low frequencies. As the maximum of ampere-conductors per slot 600 


\section{THE INDUCTION MOTOR.}

might be put down; but this should be no rigid rule. Never take fewer than 3 slots per pole and phase, if possible. If you put too few conductors in a slot, the leakage field is not saturated, and thus the

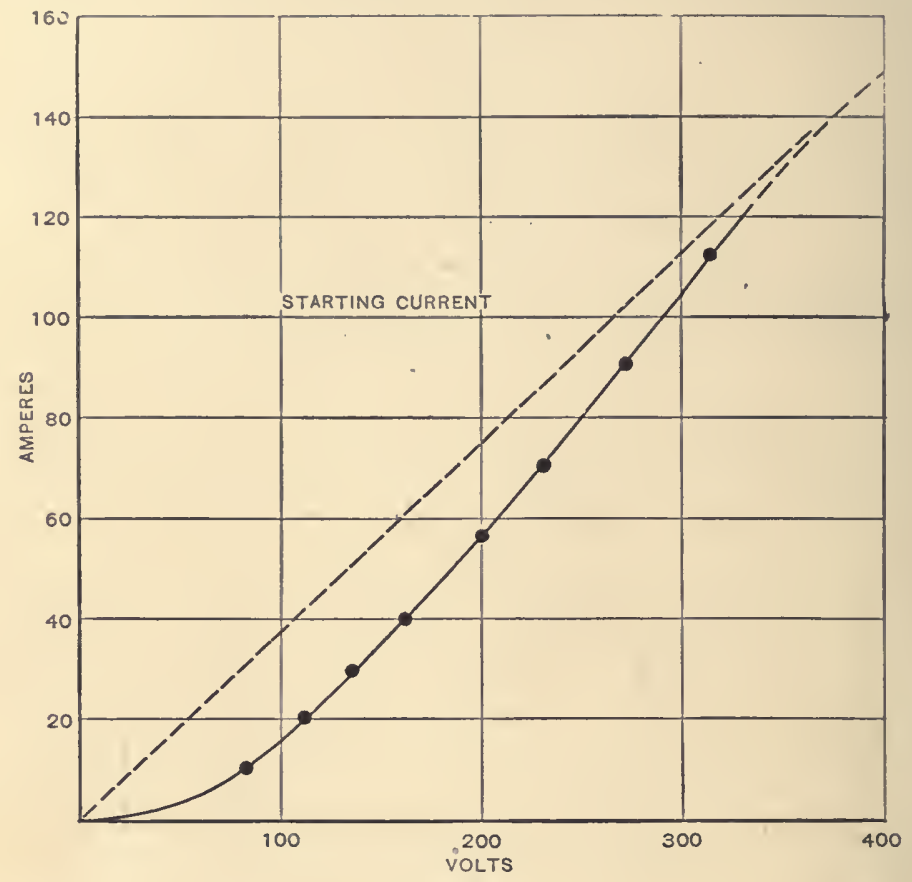

FIG. I3.

advantage of a great number of slots may be balanced by this greater leakage.

Thus we see that in spite of many rules, still a great deal is left to the individual judgment of the designer.

35. To enable the reader to form for himself an opinion of the accuracy of the theory, I give the complete experimental data of a smal! three-phase current motor with short-circuited armature. 


\section{SHORT-CIRCUIT CURRENT AND LEAKAGE FACTOR.}

The motor shall develop 20 horse-power, at a voltage of 380 between the lines, and a frequency of $47 \mathrm{p} . \mathrm{p}$. s. The slots in armature and field were closed, but the bridges were thin. The shape of the slots in armature and field are represented in Fig. 12. The motor had six poles, therefore its synchronous speed was 940 r. p. m.

The following table shows the starting or short-circuit current as. a function of the terminal volts measured between the lines:

\begin{tabular}{|ccc|ccc|}
\hline Volts & Amperes. & Frequency. & Volts. & Amperes. & Frequency. \\
82 & 11 & 46.7 & 200 & 56 & 46.7 \\
108 & 20 & - & 233 & 70 & - \\
135 & 30 & - & 273 & 90 & - \\
162 & 40 & & 314 & 112 & - \\
\hline
\end{tabular}

36. These values are graphically represented in Fig. I3. From this curve we interpolate for 380 volts a current of 140 amperes. The energy dissipated into heat in the windings and in the iron amounted to 30 kilowatts. This point lies upon the broken line curve in Fig. 15. deviating, therefore, not inconsiderably from the full line curve, representing the semi-circle of our diagram. The data determining this circle are given in the following table:

\begin{tabular}{|c|c|c|c|c|c|c|c|c|}
\hline $\begin{array}{l}\dot{5} \\
\dot{0} \\
\dot{0} \\
\dot{a}\end{array}$ & 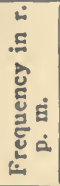 & $\frac{5}{0}$ & 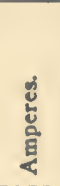 & 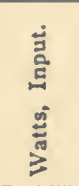 & 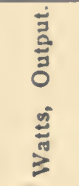 & $\begin{array}{c}\text { Efficiency. } \\
\eta \\
\%\end{array}$ & $\begin{array}{c}\text { Power } \\
\text { Factor. } \\
\cos \phi \\
\%\end{array}$ & $\begin{array}{c}\text { Apparent } \\
\text { Efticiency. } \\
\eta \cos \phi \\
\%\end{array}$ \\
\hline $\begin{array}{l}930 \\
931 \\
926 \\
910 \\
912 \\
894 \\
892 \\
880 \\
846 \\
860 \\
\end{array}$ & $\begin{array}{l}932 \\
940 \\
930 \\
918 \\
925 \\
912 \\
922 \\
922 \\
896 \\
940 \\
\end{array}$ & $\begin{array}{l}380 \\
382 \\
380 \\
380 \\
380 \\
380 \\
380 \\
380 \\
382 \\
391 \\
\end{array}$ & $\begin{array}{l}5.5 \\
9 \\
14.5 \\
20.5 \\
26 \\
31 \\
42 \\
57 \\
64.5 \\
74.5 \\
\end{array}$ & $\begin{array}{r}2,100 \\
5,400 \\
9,000 \\
12,900 \\
15,600 \\
18,600 \\
25,100 \\
32,400 \\
35,400 \\
40,100 \\
\end{array}$ & $\begin{array}{r}1,300 \\
4,050 \\
7,300 \\
10,800 \\
13,200 \\
15,600 \\
20,600 \\
24,300 \\
25,500 \\
26,100 \\
\end{array}$ & $\begin{array}{l}62 \\
75 \\
82 \\
84 \\
84.5 \\
84 \\
82 \\
75 \\
72 \\
65 \\
\end{array}$ & $\begin{array}{l}58 \\
90.7 \\
94.4 \\
95.5 \\
91.5 \\
91 \\
91 \\
86.5 \\
83 \\
79.5 \\
\end{array}$ & $\begin{array}{l}36 \\
68 \\
76.5 \\
80.2 \\
77.3 \\
76.5 \\
74.5 \\
65 \\
59.7 \\
58.7\end{array}$ \\
\hline
\end{tabular}

The curves corresponding to these data, are graphically represented. in Fig. 14. The maximum output of the motor is 35 horse-power. 


\section{THE INDUCTION MOTOR.}

This point lies very near the maximum ordinate of the semi-circle in Fig. 15. The diameter of this circle is 122.5 amperes, the magnetizing current 4.5 amperes, hence

$$
\sigma=\frac{4.5}{122.5}=0.0367 \text {. }
$$

The maximum power factor attainable is, equation (3),

$$
\cos \phi_{0}=\frac{\mathrm{I}}{2 \sigma+\mathrm{I}}=0.93
$$

Fig. 15 and the data given above clearly show the inaccuracy which

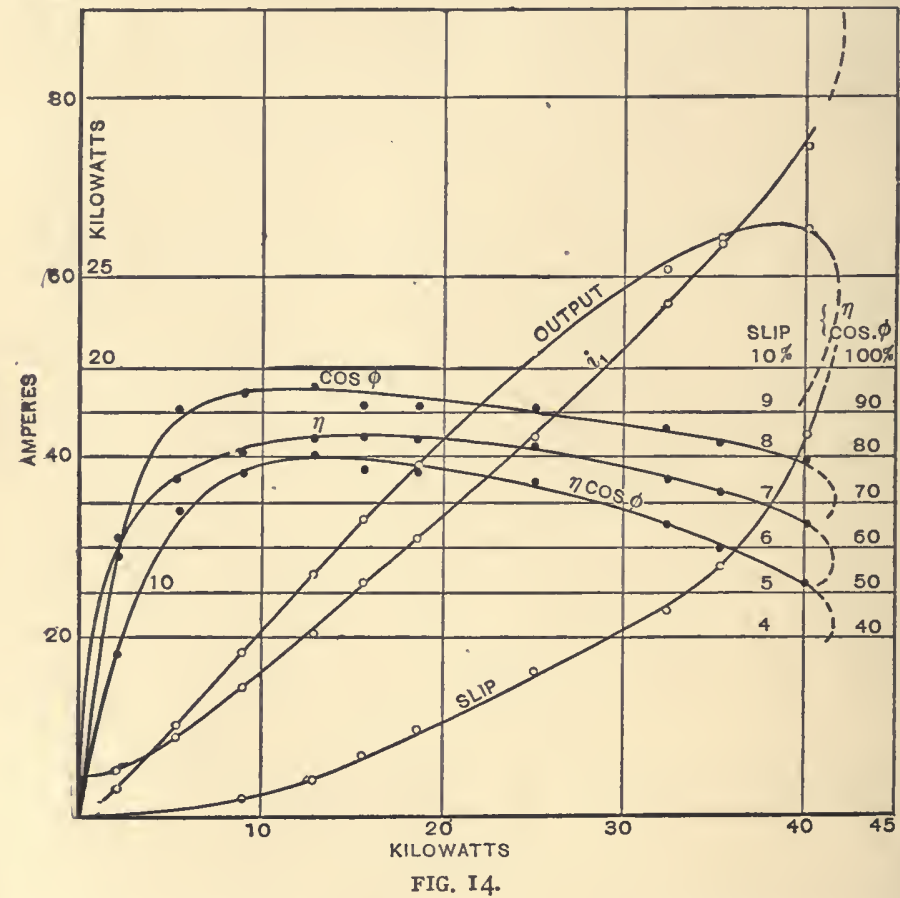

would arise if we were to use the short-circuit current as a means of determining the absolute value of the leakage factor. 


\section{SHORT-CIRCUIT CURRENT AND LEAKAGE FACTOR.}

37. I want to call attention to the load losses, which are always present in polyphase motors, the causes of which are, however, still very obscure.

The maximum efficiency of this motor is 84.5 per cent. The losses are:

Hysteresis, eddy currents and friction........ 800 watts.

Ohmic loss in primary.................. 600 "

Ohmic loss in secondary................. 200 "

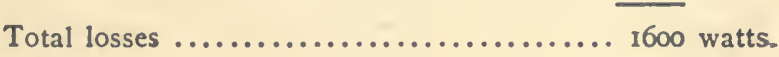

Output ..13200

Input . I 4800 watts.

The energy which the motor actually consumed amounted to 15600 watts, corresponding to an additional loss-the load loss-of 6 per

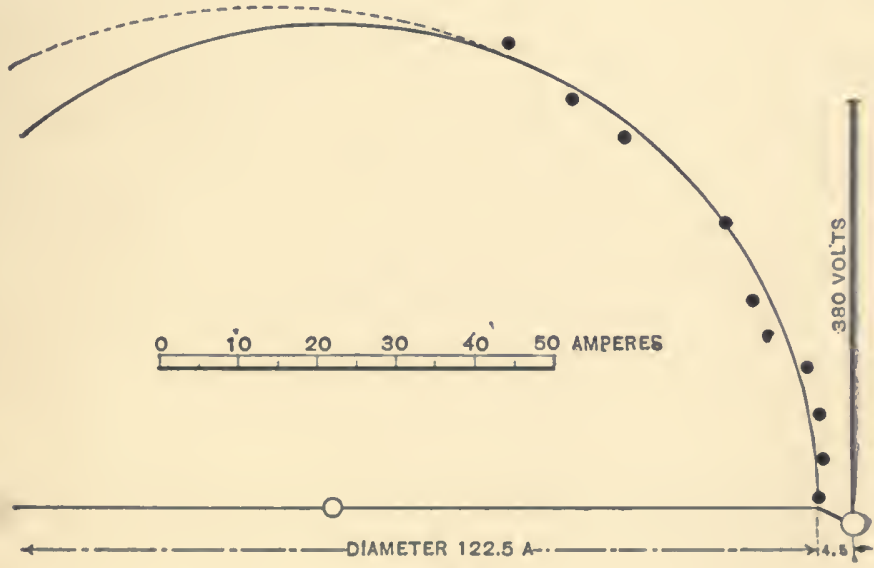

FIG. 15

cent of the output. The load loss increases rapidly with increasing load, until it becomes equal to all other losses taken together. 


\section{THE INDUCTION MOTOR.}

Opening the slots has a decided tendency to diminish the load loss considerably, therefore it is probable that the seat of this waste of energy is in the bridges.

38. It has often been adrocated to calculate the leakage fields from the dimensions of the slots, of the air-gap, of the pole-pitch, and so forth, and it has been claimed that great accuracy is thus obtainable. I am not of that opinion. Though I am perfectly aware that it is possible -at least theoretically-to calculate the leakage, yet I cannot close my eyes to the fact that such calculations are, of necessity, based upon a good deal of guesswork; the designer who chooses this path is like a man groping in the dark with here and there a guiding light, or, as I should rather say, a will-o'-the-wisp, sometimes guiding him aright, but much oftener leading him astray. I am suspicious of the a priori method; it has proved utterly vicious in all departments of human knowledge. Upon a sound experimental foundation any mathematical superstructure may be safely reared; and no desire to obtain a knowledge of things, which are in their very nature not yet clearly understood, should mislead us to build upon the quicksand of imagined data.

The succeeding chapter will be devoted to an exposition of the factors which enter into the equation for the leakage coefficient. 


\section{CHAPTER IV.}

\section{The Leakage Factor.}

$\mathrm{T}^{\mathrm{n}}$ HERE are two questions of the most vital interest which intrude themselves at every step upon the designer. The first is, How does the maximum output a polyphase motor is capable of yielding, depend upon the air-gap? In other words, if I increase the air-gap, does this to any great extent decrease the output? And does a decreased air-gap increase the output of the motor? The second question is this, If a motor is wound for four poles, and we want to wind it for eight poles, provided the frequency and the induction in the air-gap remain the same, does the output decrease in the ratio of $4 \div 8$, or, what relation exists between the maximum output of the motor and the number of poles? I shall now proceed to answer these questions.

THE INFLUENCE OF THE AIR-GAP UPON THE LEAKAGE FACTOR.

39. In order to determine the interdependence between the magnetic reluctance of the main field and the leakage factor, the following experiment was made: The magnetic field-the stator - of a three-phase current motor was provided with two armatures, the diameters of which were so chosen as to create an air-gap of $0.5 \mathrm{~mm}$, and one of 1.5 $\mathrm{mm}$. The magnetizing currents were then measured as well as the sliort-circuit currents. The following tables contain the results of the experiment :

Magnetizing Currents at 50

\begin{tabular}{|c|c||c|c|}
\hline \multicolumn{2}{|c||}{$\Delta=0.5 \mathrm{~m} . \mathrm{m}}$. & \multicolumn{3}{|c|}{$\Delta=1.5 \mathrm{~m} . \mathrm{m}}$. \\
\hline Volts. & Amperes. & Volts. & Amperes. \\
37 & 1 & 16.5 & 1.05 \\
56.5 & 1.5 & 34.7 & 2.25 \\
78 & 2.1 & 55.5 & 3.40 \\
95.5 & 2.55 & 75 & 4.70 \\
116 & 3.20 & 77 & 4.80 \\
& & 77.5 & 5.00 \\
& & 99 & 6.40 \\
& & 113 & 7.30 \\
\hline
\end{tabular}


THE INDUCTION MOTOR.

Short-circuit Currents at $50 \sim$

\begin{tabular}{|c|c||c|c|}
\hline \multicolumn{2}{|c||}{$\Delta=0.5 m . m}$. & \multicolumn{3}{|c|}{$\Delta=1.5 m . m}$. \\
\hline Volts. & Amperes. & Volts. & Amperes. \\
17.4 & 5.1 & 16.2 & 5.4 \\
36 & 12.5 & 36 & 14.85 \\
36.5 & 12.7 & 37.6 & 14 \\
58 & 20.3 & 55.5 & 22.5 \\
77 & 29.5 & 79 & 33.5 \\
\hline
\end{tabular}

Resistance of primary: Each phase, $0.05 \mathrm{ohm}$.

Resistance of secondary: Each phase, $0.50 \mathrm{ohm}$.

40. The data of these tables are graphically represented in Fig.I6 and Fig. 17. The most remarkable fact illustrated by these curves is that the short-circuit current remained almost unaltered for the two different air-gaps. We interpolate from these curves for 1 ro volts in each phase the respective short-circuit and magnetizing currents, and thus get the following values:

$\triangle=0.5 \mathrm{~m} . \mathrm{m}$.

Magnetizing current: 3 amperes.

Short-circuit current: 42 amperes.

Watts consumed: 8550 watts.

$\triangle=\mathrm{I} .5 \mathrm{~m} . \mathrm{m}$.

Magnetizing current: 7 amperes.

Short-circuit current: 47.5 amperes.

Watts consumed : 9100 watts.

41. With these data the semi-circles in Fig. I8 are drawn. We thus find for the leakage factor the following values:

$$
\begin{array}{llrl}
\triangle & =0.5 \mathrm{~m} . \mathrm{m} . & & \sigma=0.058 \\
\triangle & =1.5 \mathrm{~m} . \mathrm{m} . & & \sigma=0.128
\end{array}
$$

The leakage factor is, according to these experiments, directly proportional to the magnetizing current, or, in other words, to the magnetic reluctance of the main field. In our case the reluctance of the iron path is not negligible, as the air-gap of $0.5 \mathrm{~mm}$ is very small, 
THE LEAKAGE FACTOR.

otherwise the leakage factor would have been proportional to the airgap.

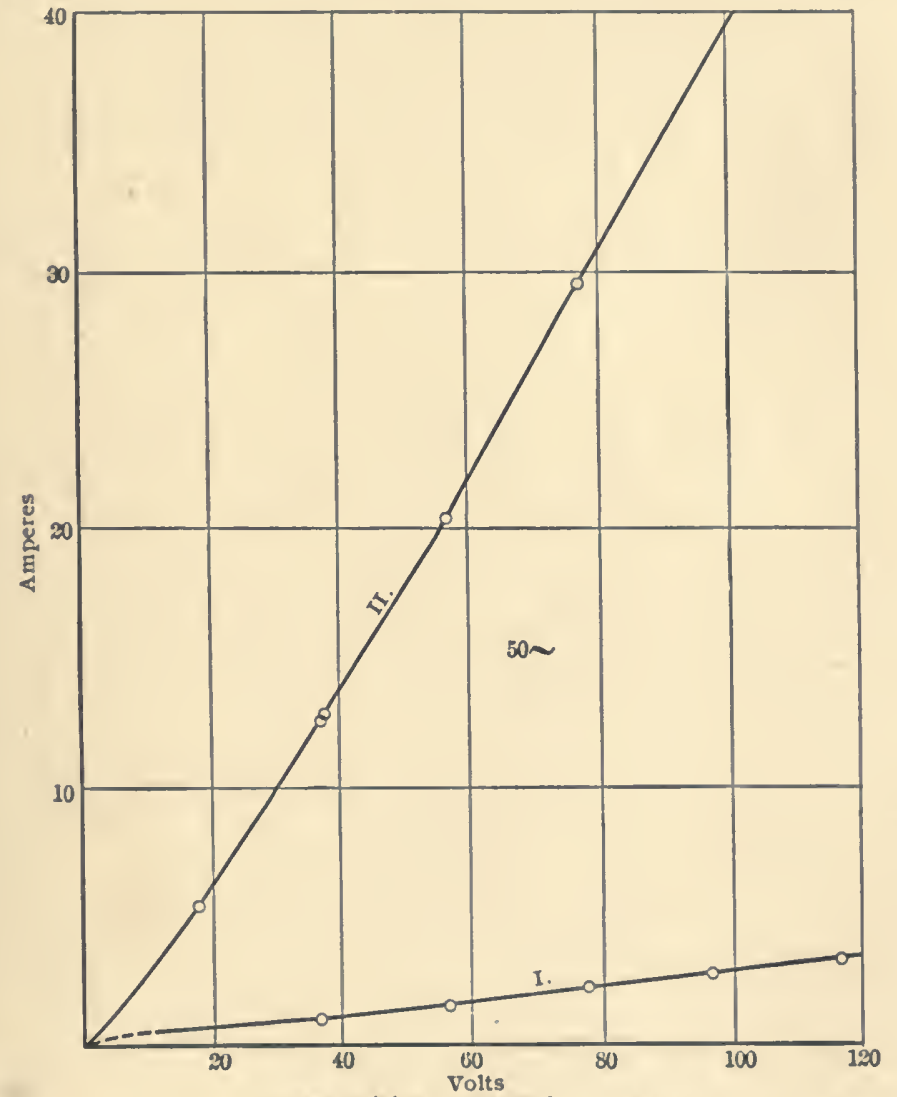

$\begin{aligned} & \text { I. Magnetizing Current. } \\ & \text { II. Short.-circuit Current. }\end{aligned} \Delta-0.5 \mathrm{~m} . \mathrm{m}$.

FIG. 16.

42. Now, this result is highly interesting. As a glance at Fig. 18 shows, the energy that the motor is capable of taking in at the rolt- 
THE INDUCTION MOTOR.

age of $\mathrm{IIO}$, is the same whether the air-gap is small or large. Hence;

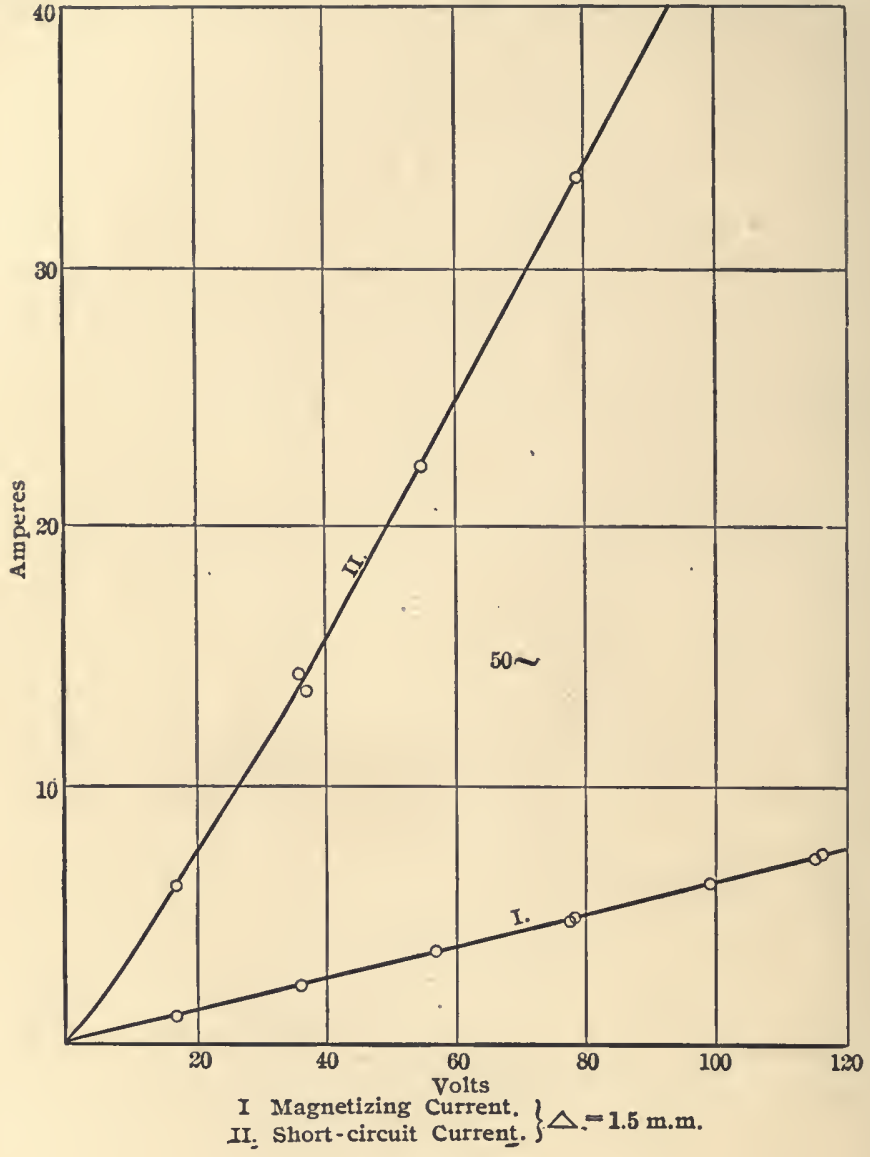

FIG. 17.

the overload that a motor is abre to stand is independent of the air-gap. This, of course, holds good only of small air-gaps. 


\section{THE LEAKAGE FACTOR.}

The air-gap influences merely the strength of the magnetizing current, but not the output.
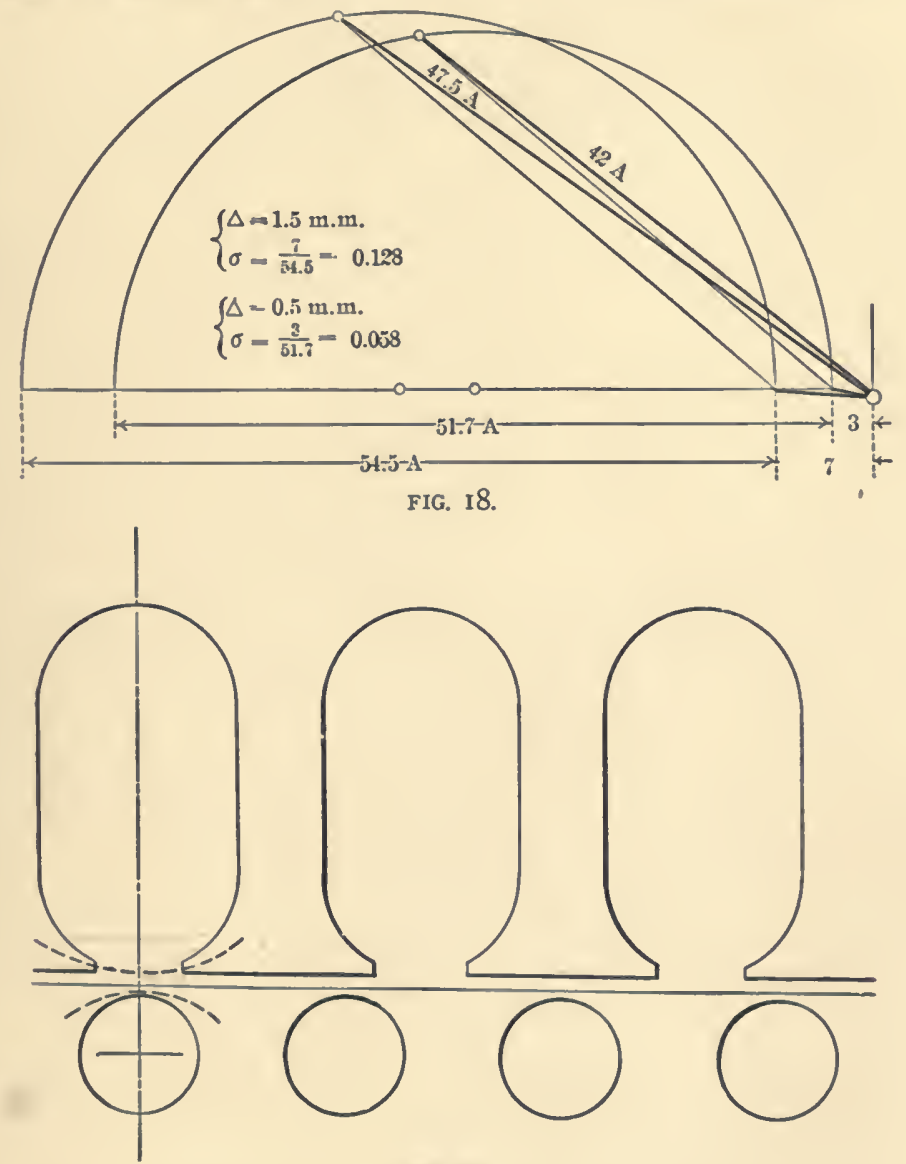

FIG. 19.

The curves of the short-circuit currents in Figs. 16 and 17 are almost straight lines owing to the open slots in the field of our motor. 


\section{THE INDÜCTION MOTOR.}

43. There remains to be answered the second question, How is the leakage factor dependent upon the pitch of the poles?

THE INFLUENCE OF THE POLE-PITCH UPON THE LEAKAGE FACTOR.

44. Before entering upon the experiments made to clear up this point, I shall attempt to show deductively how the leakage factor may be expected to vary with the pole-pitch.

Fig. 19 gives a view of the slots in a polyphase motor. The broken lines mark the leakage flux threading each slot. Now, let us assume that we have a motor with 48 slots in the field, which we want to wind as a two-pole, four-pole, or eight-pole motor, the armature being provided with 2 squirrel-cage winding, thus being suitable for any number of poles.

If the number of ampere-conductors per slot remains the same for any number of poles, the leakage flux per slot also remains constant.

The total number of ampere-turns spread over the circumference of the field is then constant whether the motor has two, four, or eight poles.

45. But the number of ampere-turns per pole is inversely proportional to the number of poles; hence, the induction produced by these ampere-turns in the air-gap is also inversely proportional to the number of poles. In other words, the magnetic field per pole, being proportional to the product of the induction in the air-gap into the polepitch, varies inversely with the square of the pole-pitch.

46. The leakage field, as we have seen, is constant for each slot. Hence, the total amount of leakage-the sum of all the leakage fields pertaining to each lot-is also constant. The number of leakage lines per pole is proportional to the number of slots per pole.

47. The ratio of leakage field $\div$ main field is therefore inversely proportional to the pole-pitch for the same number of ampere-turns per slot. 


\section{THE LEAKAGE FACTOR.}

48. This result is verified by the following series of tests:

A.-Three-phase current motor for 36 horse-power, 380 volts between the lines, six poles, $42 \sim$.

$$
\begin{aligned}
& \text { Air-gap } \triangle=0.62 \mathrm{~m} . \mathrm{m} . \\
& \text { Pole-pitch } t=30.5 \mathrm{~cm} .
\end{aligned}
$$

\begin{tabular}{|c|c|c|c|}
\hline Volts between the lines. & Amperes, field. & Amperes, armature. & Frequency. \\
81 & 36 & 95 & 42 \\
120 & 74 & 380 & \\
150 & 306 & 260 & 41 \\
170 & $\frac{335}{8.5}$ & 320 & $\frac{41}{43.2}$ \\
\hline 383 & 0 & 06 \\
\hline
\end{tabular}

If we draw the short-circuit curve, we can interpolate for 380 volts the short-circuit current of 380 amperes. We thus get for the leakage factor the value

$$
\sigma_{1}=\frac{8.5}{380}=0.0224
$$

49. B. - The same magnetic frame was wound for 24 horse-power, 190 volts between the lines, ten poles, $50 \sim$.

Air-gap $\triangle=$ I.I $\mathrm{m} . \mathrm{m}$.

Pole-pitch $t=18.3 \mathrm{~cm}$.

\begin{tabular}{|c|c|c|}
\hline Volts between the lines. & Amperes, field. & Frequency. \\
20 & 20 & 53 \\
25 & 31.5 & \\
33 & 50.5 & 51 \\
43.5 & 75 & \\
66 & 139 & \\
83 & 185 & \\
95 & 220 & \\
\hline
\end{tabular}

Magnetizing current: 31.2 amperes at 190 volts. The short-circuit current at 190 volts amounts to 470 amperes. Hence,

$$
\sigma_{11}=\frac{3^{1.2}}{470}=0.0664
$$

The following table shows the results of the tests in a perspicuous form:

\begin{tabular}{|c|c|c|}
\hline Air-gap cm. & Pole-pitch cm. & $\sigma$ \\
0.062 & 30.5 & 0.0224 \\
0.11 & 18.3 & 0.0664 \\
\hline
\end{tabular}




\section{THE INDUCTION MOTOR.}

50. For equal air-gaps we have

Hence,

$$
\begin{aligned}
& \sigma_{\mathrm{I}}=0.0224 \cdot \frac{0.1 \mathrm{I}}{0.062}=0.0396 \\
& \sigma_{1 \mathrm{II}}=0.0664
\end{aligned}
$$

$$
\frac{\sigma_{\mathrm{II}}}{\sigma_{\mathrm{I}}}=\frac{0.066_{4}}{0.0396}=\mathrm{I} .68,
$$

or, in other words,

$$
\sigma_{11}=\frac{t_{1}}{t_{11}}
$$

51. The leakage factor is inversely proportional to the pole-pitch, or directly proportional to the number of poles.

52. By the above experiments it has been demonstrated that the leakage factor is directly proportional to the air-gap, and inversely proportional to the pole-pitch. We may, therefore, write the formula for the leakage factor,

(I2) $\ldots \ldots \ldots \ldots \sigma=c \cdot \frac{\Delta}{t}$,

in which equation $c$ is a factor dependent upon the shape and size of the slots, and upon a great many other conditions of which we are still profoundly ignorant. For practical purposes, however, $c$ can be determined with satisfactory accuracy, though it will still be left to the designer to estimate the value of $c$ between certain limits. For slots, as shown in Fig. 19, $c$ varies between 10 and 15 .

WINDING THE SAME MOTOR FOR DIFFERENT SPEEDS.

53. Formula (12) permits us to determine the change in the output, power factor, and so forth, of a motor wound for a different number of poles, for instance, for eight, four, or two poles. If the field has 48 or 72 slots, it can easily be wound so as to satisfy this demand. We will assume the induction in the air-gap, or, which is the same, in the teeth, to remain constant for all three cases. We will further assume that the motors are to be wound for the same voltage. Then it is clear, according to equation (5), that the total number of active con- 


\section{THE LEAKAGE FACTOR.}

ductors must be proportional to the number of poles; in other words, if the eight-pole motor has, for instance, 720 conductors, or ten conductors in each of 72 slots, then the four-pole motor must have $36 \mathrm{n}$, and the two-pole motor 180 , in order to get the same induction in the air-gap. To calculate the relative value of the magnetizing current we need only know the number of active conductors $n$ per pole, see equation (6). We have for $n$ in the eight-pole motor $\frac{720}{8}=90$; in the four-pole motor $\frac{360}{4}=90$; and in the two-pole motor $\frac{180}{2}=90$. Hence, as $B$ and $n$ are the same in each of the three cases, it follows that the magnetizing current also remains the same. As the

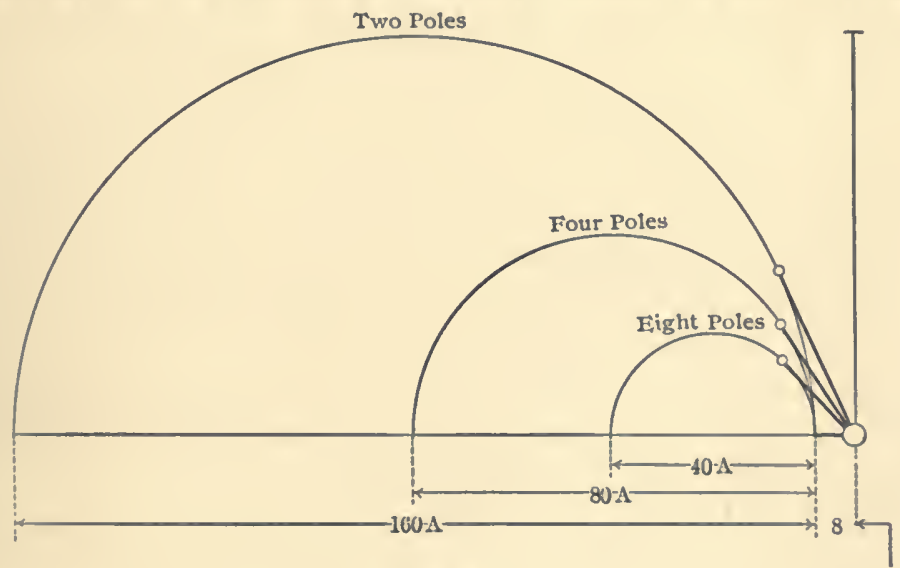

FIG. 20.

shape and size of the slots are the same in all three cases, the factor in equation (12) for the leakage coefficient also remains the same. Hence, as the leakage factor is proportional to the quotient of the airgap divided by the pole-pitch, we find the short-circuit current to be inversely proportional to the number of poles. This is graphically represented in Fig. 20. A glance at the diagram teaches us that the maximum energy that can be impressed upon the motor, and, there- 


\section{THE INDUCTION MOTOR.}

fore, also very nearly the output, vary in proportion to the polepitch. According to the diagram we find the leakage factor for the two-pole motor equal to $\frac{8}{160}=0.05$; for the four-pole motor equal to $\frac{8}{80}=0.10 ;$ and for the eight-pole motor equal to $\frac{8}{40}=0.20$. The power factor in each case can now be calculated with the help of formula (3). This is done in the following table:

\begin{tabular}{|c|c|c|c|c|}
\hline $\begin{array}{c}\text { Number of } \\
\text { Poles. }\end{array}$ & $\begin{array}{c}\text { Leakage } \\
\text { Factor. }\end{array}$ & $\begin{array}{c}\text { Maximum } \\
\text { Power Factor. }\end{array}$ & $\begin{array}{c}\text { Relative } \\
\text { Output. }\end{array}$ & R. P. M. \\
\cline { 1 - 2 } 2 & 0.05 & 0.91 & 80 & 3000 \\
4 & 0.10 & 0.835 & 40 & 1500 \\
8 & 0.20 & 0.715 & 20 & 750 \\
\hline
\end{tabular}

54. The output is therefore proportional to the number of r. p. m.

55. It may not be amiss here to remark that if the motor is ordinarily wound for four poles, the induction in the iron above the slots may for the same frame become too high in the two-pole motor, thus increasing the magnetizing current, and, possibly, creating undue heating.

\section{DRAWBACKS OF A HIGH FREQUENCY.}

56. If the circumferential speed of the armature is limited, and this is generally the case, then the pole-pitch is also limited for a given number of r. p. m. The air-gap cannot indefinitely be diminished, hence a high frequency necessitates a large leakage factor according to formula (12). We labor here under the same difficulties that we have met with in the design of alternators for high frequencies." It is doubtless possible to build motors for frequencies between 60 and Ioo, but the higher the frequency the lower will be the power factor, the larger will be the lagging currents. It has also to be borne in mind that motors for high frequencies, if they are to be as good as those for low frequencies, must be made not inconsiderably larger.

'See the author's papers in the Electrical World and Engineer, Jan. 20, 27 and Feb. 3, I900. 
Allowing again the induction in the air-gap to be the same for different frequencies, which is a more or less challengeable proposition, it follows from formula (5) that the total number of active conductors around the circumference of the field must also be the same, for the pole-pitch is inversely proportional to the frequency, hence the product of the frequency into the number of lines of induction per pole remains the same if the induction in the air-gap is the same.

57. The magnetizing current, however, being proportional to the quotient of the induction $B$ divided by the number of active conductors per pole, is thus inversely proportional to the frequency. The leak-

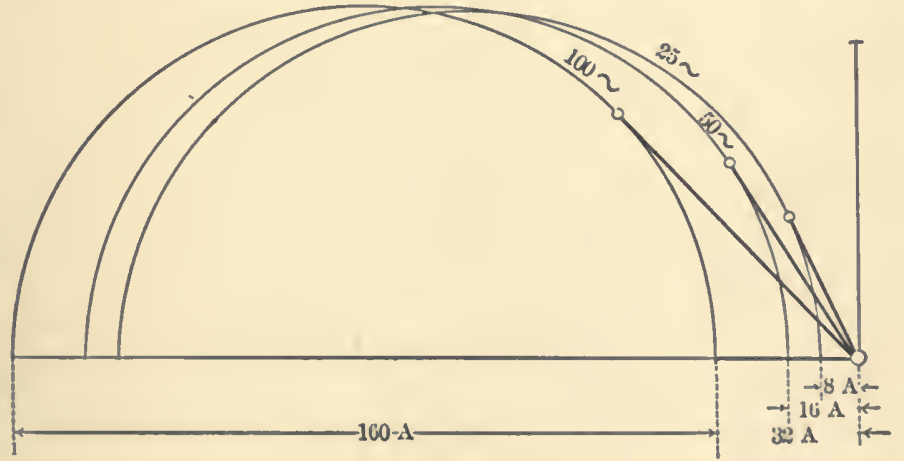

FIG. 21,

age factor is, according to formula (12), directly proportional to the pole-pitch, or inversely proportional to the frequency-because the pole-pitch is, in the case under consideration, inversely proportional to the frequency-hence it follows that, as the magnetizing current has been shown to be proportional to the frequency, the diameter of the semi-circle remains constant for all frequencies.

58. Fig.2I shows the clock diagram for the same motor, but for different frequencies. The maximum energy that the notor is capable of taking in, and, therefore, also the maximum output, is the same for 100 $\sim 50 \sim$, or $25 \sim$ But the maximum power factor is consider- 


\section{THE INDUCTION MOTOR.}

ably smaller for the high frequencies, as a glance at the diagram shows. The following table shows the leakage factor and the power factor in relation to the frequency:

\begin{tabular}{|c|c|c|}
\hline Frequency. & Leakage Factor. & Maximum Power Factor. \\
\cline { 2 - 3 } 25 & 0.05 & 0.91 \\
50 & 0.10 & 0.83 \\
100 & 0.20 & 0.715 \\
\hline
\end{tabular}

59. I wish to call attention to the fact that the motor for the higher frequencies is here represented less unfavorably than it really is, because the induction in the air-gap has to be reduced if the motor is to be wound for a higher frequency. The immense lagging currents invariably bound up with the higher frequency, are very clearly shown in the diagram.

60. It is to be remembered that the current in the armature is dependent upon the leakage factor, since the transformation factor $v_{1}$ forms part of the leakage factor, see Fig. 6 . The transformation factors $v_{1}$ and $v_{2}$ are connected with $\sigma$ through equation (2),

$$
\sigma=\frac{\mathrm{I}}{v_{1} v_{\imath}}-\mathrm{I}
$$

61. Hence it follows, as $i_{2}=\overline{A D} \cdot \frac{n_{1}}{n_{2}} \cdot \frac{\mathrm{I}}{v_{1}}$, see Fig. 6 , that the current in the armature is larger for the motor running at a high frequency than for that running at only $25 \sim$. In our case, setting $v_{1}=v_{2}$, we get for $v$ at $25 \sim 0.978$, and at $100 \sim 0.912$, therefore the current in the armature of the motor for Ioo $\sim$ is, for the same $\overline{A D}$, I.07 times larger than for $25 \sim$. This corresponds to an increased armature loss of about I4 per cent. But as the primary current is also larger for $100 \sim$ than for $25 \sim$, the armature loss is still greater than here calculated. Thus to the drawback of large lagging currents, it has to be added the further drawback of considerably larger losses.

62. The foregoing experiments and considerations are, within $\mathrm{my}$ knowledge, the first attempt to deal in a rational, systematic manner 


\section{THE LEAKAGE FACTOR.}

with the conditions underlying the leakage in polyphase motors. I am far from claiming for this treatment completeness or conclusiveness; on the contrary, I deem it a necessity to revise it by the light of forthcoming experience. I am tolerably confident that the main propositions will be proved true, while minor points may need some qualification.

63. Considering the immense complexity of the phenomena in poly. phase motors, the greater or less arbitrariness which hangs about most of our assumptions which have to be made in order to be able to calculate at all, I cannot forbear from wondering that so approximate a solution can be attained at all. It may be that there are errors inherent in our fundamental assumptions which all so counteract one another as to cause the result of calculation to deviate but little from experiment and observation. This view will commend itself to those who are familiar with any branch of physiology, for instance, physiological optics; here we have the testimony of Helmholtz that the eye, having "every possible defect that can be found in an optical instrument," yet gives us a fairly accurate image of the outer world because these various defects balance one another almost completely.

64. The above remarks will be distasteful to those who have accustomed themselves to look upon only one side of a question, and try to shut their eyes to the inevitable uncertainties that beset us in all intellectual problems. I was once taken to task by a critic for having adduced experimental evidence qualifying my theory, and narrowing the limits of its application, and I was told that these experiments invalidated my argument, while my intention-to lay stress upon the incompleteness and the shortcomings of the theory-was obviously not even thought of by my critic. Lawyers may have to hide the weak sides and spots of their arguments, but men of science are bound to point them out and expose them.

The formulx and rules of the preceding articles will now be turned to account in the following part by applying them to the calculation of a motor. 


\section{CHAPTER V.}

\section{Design of a Three-Phase Current Motor for 200 Horse-Power.}

\section{$\mathrm{T}$}

$\mathrm{HE}$ application to practice of the theory expounded in the preceding chapters will best be illustrated by a concrete case. To this end I propose to calculate a three-phase current motor for an output of 200 horse-power at 440 r. p. m. for a frequency of $60 \sim$. Voltage between the lines 2000. I have chosen a rather extraordinary case, the speed of $440 \mathrm{r}$. p. m. being comparatively low, while the frequency is unfavorably high, in order to show that it is yet possible to build a satisfactory motor for such conditions.

65. The following are further conditions for the design :

(I.) Normal output, 200 horse-power.

(2.) Maximum torque, 400 synchronous horse-power.

(3.) The motor must be able to start with the maximum torque.

66. The torque of a motor is measured in mkg. or foot-pounds. The product of the number of mkg. into the angular velocity of the rotor, divided by 76 , yields the number of horse-power available at the shaft of the motor. The unit of horse-power used in America and England is slightly greater than the unit used on the Continent of Europe. To get "European horse-power," we should have to divide by 75 . As, in a great many cases, we do not care much about the absolute value of the torque, we speak of torque corresponding to a certain number of horse-power at a certain speed. The most natural speed is offered us by the speed at synchronism. If we thus speak of a torque of 400 synchronous horse-power, this torque may be developed at any speed, but the product of it into the angular velocity of the rotor at synchronism is proportional to 400 horsepower. This very convenient mode of expressing torque in "synchronous horse-power" has been introduced by Mr. Steinmetz; at 


\section{THREE-PHASE CURRENT MOTOR.}

least the author first saw it some years ago in a short paper of this gentleman in the German Elektrotechnische Zeitschrift.

67. The motor must be wound for 16 poles, which gives a synchronous speed of 450 r. p. m.

68. The circumferential speed of the revolving armature should not exceed $7000 \mathrm{ft}$. p. m. A high speed is necessary in order to get a large pole-pitch upon which, as we have seen, the leakage factor is greatly dependent. So high a speed as this is not always favorable to a cheap, commercial design. Indeed, it may be urged that by choosing so high a speed as $7000 \mathrm{ft}$. p. m. we have overstepped the most favorable limit. Had $\mathrm{I}$, in this work, set myself the task of designing a cheap motor, as the market may here and therc require, I should have yielded to this objection from economy and adopted a slower speed. It is still a much vexed question whether, in the long run, the greatest commercial economy is not identical with excellence of quality. I therefore prefer to make the motor as good as possible without giving undue regard to cheapness.

69. The motor receives a diameter of $150 \mathrm{~cm}$, corresponding to a circumferential speed of $6960 \mathrm{ft}$. p. m.

The pole-pitch is equal to $\frac{150 \cdot \pi}{16}=29.5 \mathrm{~cm}$.

The air-gap will be made equal to $0.15 \mathrm{~cm}$.

70. The coefficient $c$ in formula (12) may be estimated for the shape of the slots which we are going to adopt at 12 ; we then have for the leakage factor according to formula (12):

$$
\sigma=12 \cdot \frac{0.15}{29.5}=0.061
$$

71. With this leakage factor a maximum power factor of $\cos \phi_{0}=$ $\frac{1}{2 \sigma+1}=0.89$ is attainable.

72. The motor will take from the mains a current of about 54 amperes per phase at an output of 200 horse-power. 


\section{THE INDUCTION MOTOR.}

73. In order to develop a maximum torque equal to 400 synchronous horse-power, the maximum ordinate or the radius of the semi-circle in the diagram must be equal to

$$
\frac{400 \cdot 746}{\sqrt{3} \cdot 2000 \cdot 0.85}=102 \text { amperes, }
$$

assuming the efficiency to be 85 per cent at this output. Hence follow3 that the diameter of the semi-circle must be equal to 200 amperes.

74. The no-load current $i_{0}$ can now immediately be calculated, if we remember that the quotient of it and the diameter of the semicircle must be equal to $\sigma=0.06 \mathrm{r}$. We thus get

$$
i_{0}=12 \text { amperes. }
$$

75. From formula (6) follows the number of conductors per pole and phase, if a value for $B$ is assumed. We make $B$, the maximum induction in the air-gap, equal to 5600 , and we have then

$$
\begin{aligned}
& i_{0}=12 \text { amperes. } \\
& \triangle=0.15 \mathrm{~cm} . \\
& B=5600 \mathrm{c.g} . \mathrm{s} .
\end{aligned}
$$

76. Inserting these values into the formula

(6) $\ldots \ldots \ldots \ldots \ldots \ldots, i_{0}=\frac{B \cdot 1.6 \triangle}{2 n \sqrt{2}}$

we get

$$
n=40
$$

77. The total number of active conductors per phase, $z$, is equal to $n$ multiplied by the number of poles. Thus we have

$$
z=16.40=640
$$

78. We can now calculate the number of lines of induction per pole with the help of formula (5). It is

(5) $\ldots \ldots \ldots \ldots \ldots \ldots, e=2 \cdot 12 \cdot \sim \cdot z \cdot \Phi \cdot 10^{-8}$

Hence,

$$
\begin{aligned}
e & =\frac{2000}{\sqrt{3}} \text { volts. } \\
\sim & =60 \\
z & =640
\end{aligned}
$$

$$
\Phi=\mathrm{I} .42 \cdot 10^{6} \mathrm{c} . \mathrm{g} \cdot \mathrm{S} \text {. }
$$




\section{THREE-PHASE CURRENT MOTOR.}

79. We found in the second chapter that

$$
\Phi=\frac{7}{12} \cdot b \cdot t \cdot B,
$$

where $b$ is the width of the motor, and $t$ the pole-pitch. This formula is correct only if the slots in the field and the armature are prac-

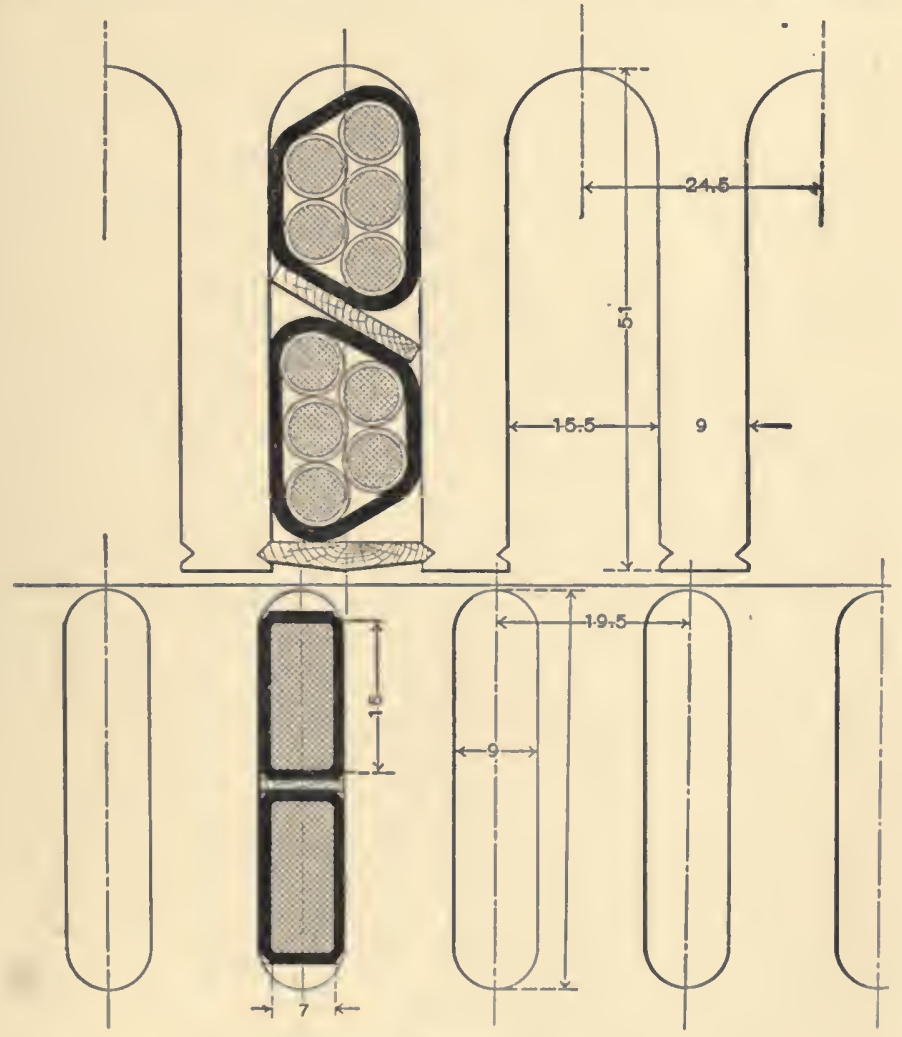

FIG. 22.

tically closed. As we intend to keep the slots in the field entirely open in order to be able to exchange the coils easily, $N$ will be about 


\section{THE INDUCTION MOTOR.}

85 per cent smaller than according to the formula. By taking this in to account, we find for

$$
b=17.0 \mathrm{~cm} \text {. }
$$

80. We leave in in the middle of the iron a space of $1.0 \mathrm{~cm}$ for radial ventilation, so that the width of the iron becomes $18.0 \mathrm{~cm}$.

81. The slots are represented in Fig. 22. The slots in the field are 2 ins. deep; in the armature $15 / 8$ ins. These slots represent about the
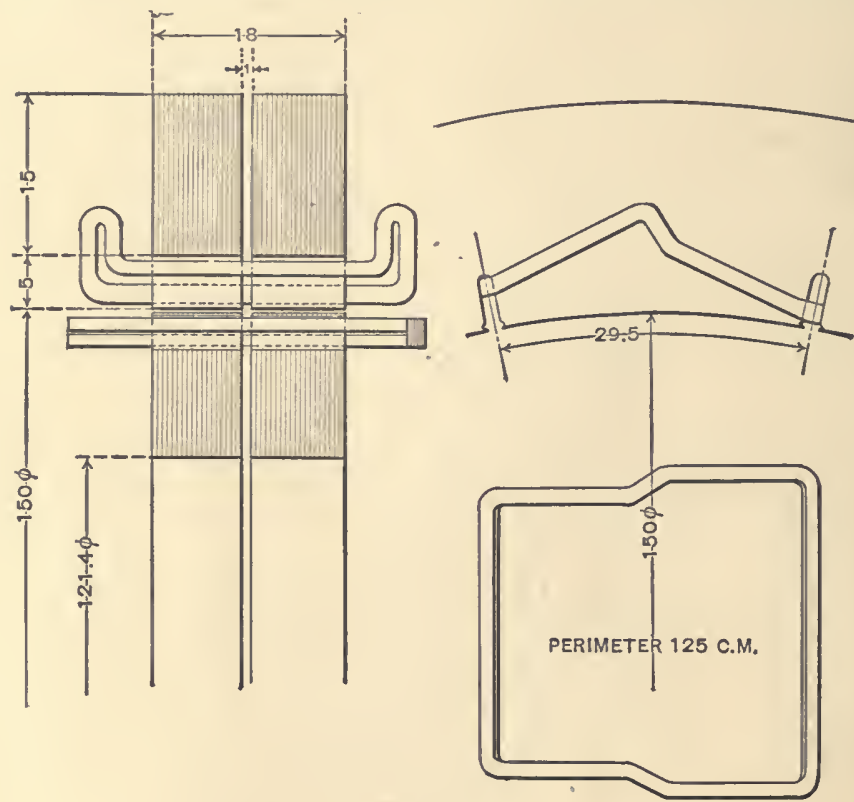

FIG. 23.

largest size that should be used in polyphase motors. If possible, it is preferable to keep the slots smaller than those in Fig. 22. The wire used for the field coils is No. 3 of B. \& S. wire gauge, having a diameter of 0.229 in.

The maximum induction in the iron teeth is 13000 . 


\section{THREE-PHASE CURRENT MOTOR.}

The induction in the iron above the teeth should be no higher than 3000 ; this gives $15.0 \mathrm{~cm}$ of iron above the slots.

The main dimensions of the motor are inscribed in Fig. 23.

The resistance of each phase of the field is $0.28 \mathrm{ohm}$, hot.

The resistance of each phase of the armature is $0.016 \mathrm{ohm}$, hot.

The loss through hysteresis and eddy currents is 1100 watts, of which 530 watts is dissipated in the iron ring, and 570 watts in the teeth.

82. We are now in possession of all the data necessary to predetermine the behavior of the motor under load and at starting.

This has been done in the following table. After the explanation given in the preceding chapters, it would be superfluous here to enter

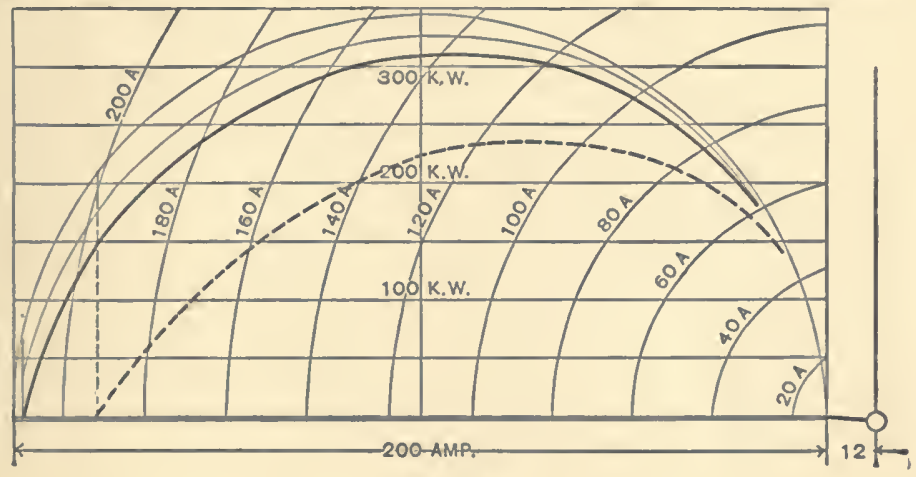

FIG. 24 .

upon the manner in which these figures were derived partly from Fig. 24, partly from the foregoing formula. A word, however, has to be said about the way in which the loss by friction is taken into account. With sufficient accuracy we may assume that the torque necessary to overcome the friction is constant at different speeds. By drawing a line parallel to the basis upon which the semi-circle is described, we find in the length of the ordinates lying between this line and the curve which lies next to the semi-circle in Fig. 24, a 


\section{THE INDUCTION MOTOR.}

measure for the torque and synchronous kilowatts available at the pulley of the motor.

83. For the calculation of the efficiency $\eta$ I have assumed that the

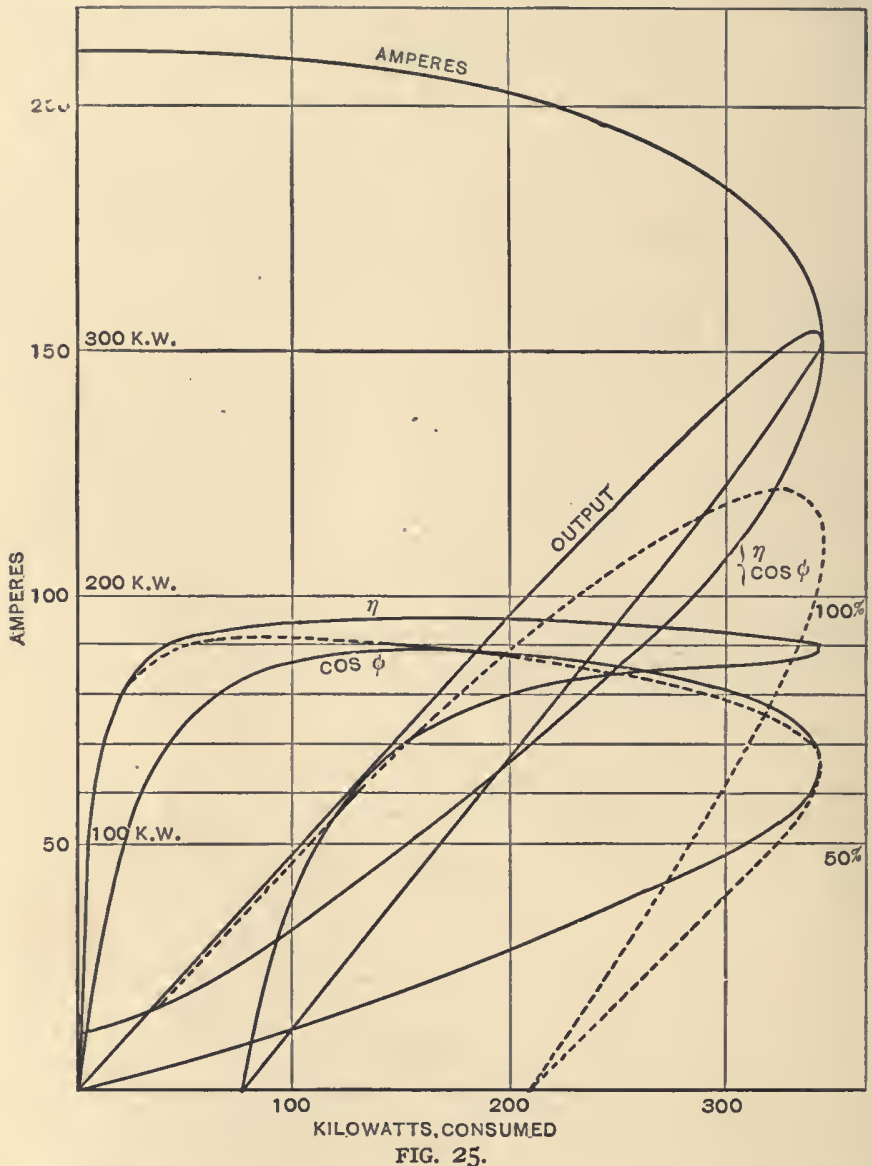

loss through friction and air resistance is practically constant at all speeds. That this is not accurately so, I need hardly remark. 


\section{THREE-PHASE CURRENT MOTOR.}

84. The ordinates of the full line curve in Fig. 24 measure the output of the motor for an armature of small resistance, provided with external starting resistance.

85. The ordinates of the broken line curve measure the output of the motor having a squirrel-cage armature with considerable resistancesix times larger than that of the armature with external resistancein order to start under load. A glance at the curves shows the tremendous reduction of the output with which we have to buy the advantage of dispensing with slide rings. This is even more conspicuous in the curves of Fig. 25. The abscissæ here represent the energy in kilowatts consumed by the motor, while the ordinates represent the field current, the output, the efficiency, and the power factor as functions of the energy consumed. As in Fig. 24, the full line curves represent the different quantities for the motor with external starting resistance, while the broken line curves show these quantities for the motor with squirrel-cage armature.

86. The field current, of course, remains unaltered, and so does the power factor. But the output, and therefore the efficiency, of the motor with squirrel-cage armature are powerfully influenced by the high resistance of the armature. For a starting torque equal to the tcrque at normal load, we need a current which is almost four times as large as the current at normal load; indeed, a poor result.

87. To emphasize this point once more, the abolition of an external starting resistance-either revolving with the armature, or placed outside the armature and being connected to it by means of slide rings-brings with it inevitably a considerable reduction of the output, and a lowering of the efficiency. The reduction of the output, as a glance at Figs. 24 and 25 shows, is equivalent to a reduction of the overloading capacity of the motor, diminishing the margin of power and thus tending to pull the motor out of step at a small temporary overload. For these reasons European designers have abandoned the squirrel-cage armature in all larger motors. 


\section{THE INDUCTION MOTOR.}

88. In the calculation of the efficiency the load losses have not been taken into account. As I have said before, they greatly influence the efficiency, but it is extremely difficult to predetermine them for va-

Data of 200 h. p. Polyphase Motor for 2000 Volts, 60 Periods, 440 R. P. M.

\begin{tabular}{|c|c|c|c|c|c|c|}
\hline 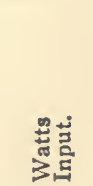 & ن & 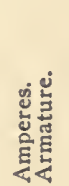 & 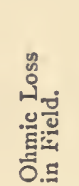 & 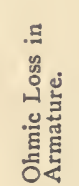 & 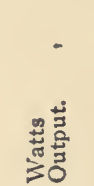 & 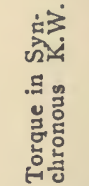 \\
\hline 52,600 & 20 & 60.5 & 336 & 175 & 48,790 & 48,965 \\
\hline 124,000 & 40 & 148 & 1,350 & $1,05^{\circ}$ & I 18,300 & $\times 19,350$ \\
\hline I 59,000 & 51 & 193 & 2,190 & 1,790 & $\mathrm{I}_{5} \mathrm{I}, 720$ & I 53,4 I \\
\hline $\begin{array}{l}185,000 \\
\end{array}$ & 60 & 230 & 3,040 & 2,550 & $\begin{array}{l}176,100\end{array}$ & $\begin{array}{r}38,650 \\
178,\end{array}$ \\
\hline 240,000 & 80 & 307 & 5,400 & 4,530 & 226,770 & $23 \mathrm{I}, 300$ \\
\hline 287,000 & 100 & 386 & 8,400 & 7,150 & 268,150 & 275,300 \\
\hline 322,000 & I 20 & 465 & 12,000 & I 0,400 & 296,200 & 306,600 \\
\hline 343,000 & 140 & 545 & 16,500 & I 4,300 & 309,000 & 323,300 \\
\hline 346,000 & 160 & 623 & 21,500 & I 8,800 & 302,400 & 321,200 \\
\hline 315,000 & 180 & 700 & 27,300 & 23,600 & 260,800 & 284,400 \\
\hline 325,000 & 200 & 780 & 33,600 & 29,800 & I 58,800 & 188,100 \\
\hline
\end{tabular}

Data of 200 h. p. Polyphase Motor for 2000 Volts, 60 Periods, 440 R. P. M.

\begin{tabular}{|c|c|c|c|c|c|c|c|}
\hline$\stackrel{\dot{q}}{\sqrt{2}}$ & 它 & 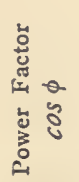 & 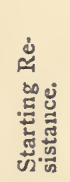 & 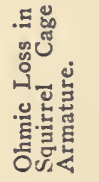 & 劳 & $\stackrel{\dot{\vartheta}}{\tilde{v}}$ & 思 \\
\hline 0.0030 & 0.927 & 0.76 & 4.44 & 1,100 & 47,855 & 0.0225 & 0.94 \\
\hline 0.0088 & 0.955 & 0.89 & 1.80 & 6,300 & 113,050 & 0.0528 & 0.911 \\
\hline 0.0117 & 0.954 & 0.90 & 1.35 & 10,740 & 142,770 & 0.07 & 0.897 \\
\hline 0.0143 & 0.952 & 0.89 & I.I I & 15,350 & 163,300 & 0.086 & 0.882 \\
\hline 0.0196 & 0.947 & 0.868 & 0.80 & 27,130 & 204,170 & 0.117 & 0.852 \\
\hline 0.026 & 0.935 & 0.83 & 0.60 & 43,150 & 231,150 & 0.157 & o/895 \\
\hline 0.0333 & 0.920 & 0.78 & 0.459 & 62,400 & 244,200 & 0.203 & 0.76 \\
\hline 0.0443 & 0.90 & 0.705 & 0.346 & 85,600 & 237,700 & 0.265 & 0693 \\
\hline 0.0585 & 0.875 & 0.625 & 0.260 & I 12,800 & 208,400 & $0.35^{\mathrm{I}}$ & 8.603 \\
\hline 0.083 & 0.828 & 0.505 & 0.178 & 141,600 & 141,800 & 0.497 & 0.45 \\
\hline 0.156 & 0.705 & 0.325 & 0.07 & $\begin{array}{r}75,300 \\
\end{array}$ & I 2,800 & 0.93 & 0.057 \\
\hline
\end{tabular}

rious loads. Here is a field full of practical and theoretical interest which has been sadly neglected by investigators, but promises a rich harvest. 


\section{THREE-PHASE CURRENT MOTOR.}

The Starting Resistance.-89. In order to calculate the resistance of the starting box, it is advisable to plot a curve representing the torque, the amperes and the volts in the armature as a function of the resistance of the starting box." This can easily be done if we remember that at starting the energy available at the shaft of the motor, when running with the same torque, must be dissipated into heat. We find, therefore, the starting resistance necessary to enable

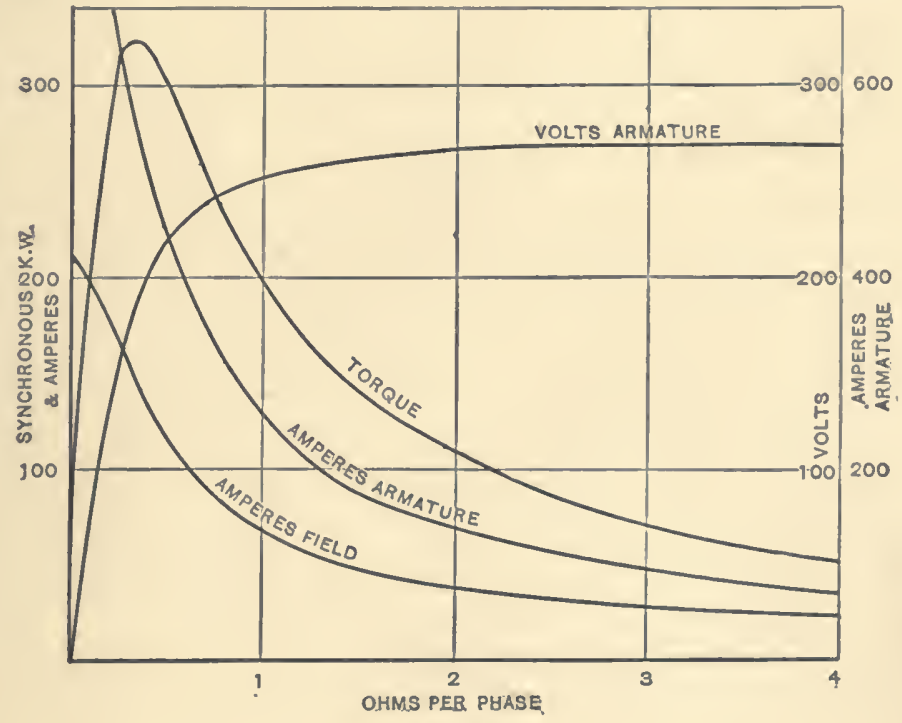

FIG. 26.

the same torque to be generated in the motor, by dividing the output by the square of the armature current. In this way the curve for the torque, in Fig. 26, has been drawn. From this curve we can find the starting current, the torque, and the voltage at the slide rings of the armature. The latter is considerable at a small starting torque, and the armature conductors must, therefore, be carefully insulated.

-This method was first recommended by Dr. Behn-Eschenburg, Oerlikon. 


\section{THE INDUCTION MOTOR.}

Slip and Torque.-90. Lastly, Fig. 27 represents the torque as afunction of the slip. The curves demonstrate that the maximum torque attainable is entirely independent of the armature resistance. The cffect of a great armature resistance consists in shifting the same torque from a small slip to a large one. Again, the full line curve gives the torque for the armature with a resistance of $0.016 \mathrm{ohm}$ per phase, while the broken line curve shows the torque for the squirrel..

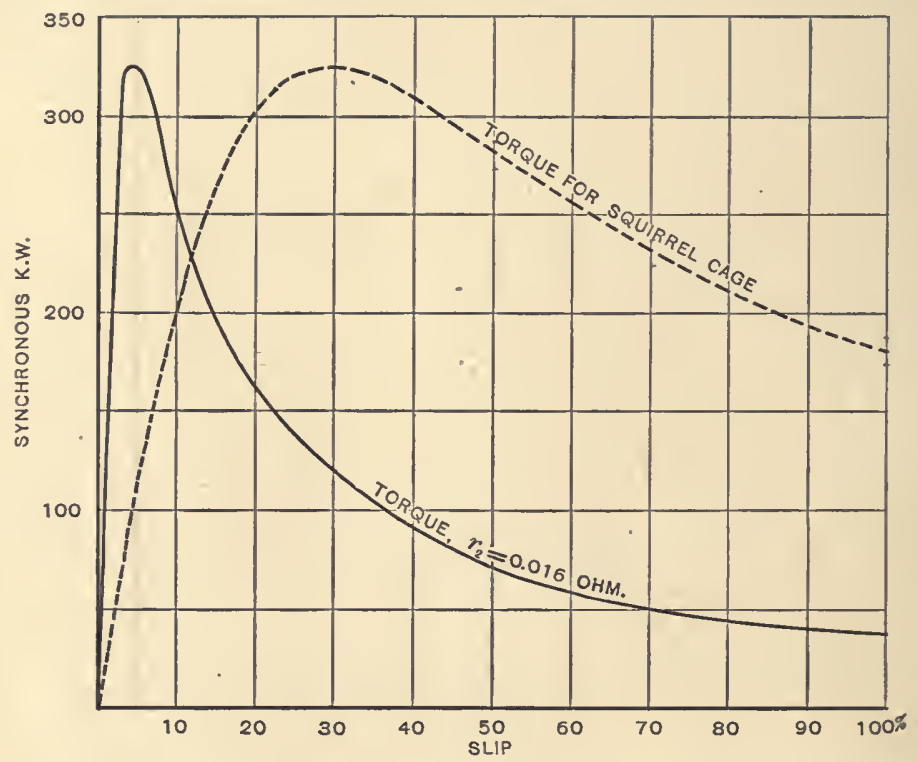

FIG. 27.

cage armature having a resistance equivalent to six times that of the armature with external starting resistance.

91. Having thus finished the theory and calculation of the polyphase motor, it behooves us to glance back upon the comparatively easy road by which we have reached a complete solution of a problem which, if treated merely by mathematics, appears to be one of the 


\section{THREE-PHASE CURRENT MOTOR.}

most abstruse problems in natural philosophy. More and more we begin to realize the truth of the words with which Kelvin and Tait prefaced their lucid treatise on "Natural Philosophy," that "simplification of modes of proof is not merely an indication of advance in our knowledge of a subject, but is also the surest guarantee of readiness for farther progress."

92. Time was-and that not very long ago-when theories in which mathematical methods were restricted to a minimum, were glibly labeled "popular," with that fine flavor of contempt that hangs about this term. Slowly but surely graphical methods have supplanted, and will supplant in the future, highly analytical methods, ${ }^{7}$ as in the graphical method the development of the idea can be followed stage by stage, thus furnishing a means of constantly checking the process oi reasoning and keeping the attention of the mind concentrated upon the development of the thought. While a long analytical argument, after starting out from certain premises, leaves us in large measure in the dark until the result is reached. In my opinion the didactic value of graphic methods is vested in the difference traced out in the above comparison.

93. These remarks must not be misconstrued. In many cases the graphical treatment turns out to be far more complicated and wearisome than the analytical treatment, and I need hardly say that in such cases the latter is preferable. Whichever method is the simpler, i: 1 the case under consideration, deserves preference.

\footnotetext{
'One of the most complex problems in natural philosophy is the theory of the tides, on which the greatest mathematicians from the time of Newton until today have tried their powers. This is what one of the workers in this field, Prof. George Howard Darwin, himself one of the most powerful mathematicians of this age, reared in the very lap of mathematics, in Cambridge, England, says of graphic methods: "In my paper on the 'Precession of a Viscous Spheroid,' I ob. tained the quartic equation from this last point of view only, and considered analytically and numerically its bearings on the history of the earth.

"Sir William Thomson, having read the paper, told me that he thought much light might be thrown on the general physical meaning of the equation, by a comparison of the equation of conservation of moment of momentum with the energy of the system for various configurations, and he suggested the appropriateness of geometrical illustration for the purpose of this comparison.

"The simplicity with which complicated mechanical interactions may be thus traced out gcometrically to their results appears truly remarkable."
} 


\section{CHAPTER VI.}

\section{The Single-Phase Motor.}

\section{$\mathrm{T}$}

HE simplified and improved transformer diagram which has stood us in good stead in understanding the phenomena in polyphase motors, will serve our purpose equally well in the treatment of the single-phase motor. The method here employed* is based upon the well-known theorem first made prominent by the late Galileo Ferraris and André Blondel, that an oscillating magnetic field can, in all its effects, be replaced by two revolving fields, the amplitude of each of which is equal to half the amplitude of the oscillating field; the two fields revolve in opposite directions at a frequency equal to that of the oscillating alternating field.

94. A two-pole armature revolving at a speed of $\sim_{2}$ in an oscillating magnetic field of the frequency $\sim_{1}$, has relative to the one magnetic field, which we will call $I$, a slip of $\sim_{1}-\sim_{2}$, relative to the other, $I I$, a slip of $\sim_{1}+\sim_{2}$.

95. Let us now consider the field $I I$. At the immense slip of $\sim_{1}+\sim_{2}$ the secondary ampere-turns act almost exactly in an opposite direction to the primary ampere-turns; they thus neutralize each other, leaving only a small field-the vector of which coincides with the vectors of the primary and secondary ampere-turns-just large enough to balance the voltage which drives the magnetizing current through the field-coils.

96. We have dissolved the amplitude of the impressed alternating current flowing through the primary into two components of half the amplitude revolving in opposite directions. This is equivalent to having two polyphase motors, the field-coils of which are coupled in

"See the author's article on "Asynchronous Alternating-Current Motors," in the Elektrotechnische Zeitschrift, Berlin, March 25, I897. 


\section{THE SINGLE-PHASE MOTOR.}

series, but in such a manner that an observer looking at the fields in the direction of the axes of the rotors, would call the one revolving clockwise, the other counter-clockwise. The armatures of both motors are rigidly connected. $\dagger$ The field $I$ would then try to turn the armatures in a clock-wise direction, while the field $I I$, if left to itself, would try to turn them in a counter-clockwise direction. The motor $I$ would take the larger share of the voltage, since we have seen that the reactance of a polyphase motor is great for a small slip, and small for a great slip. Hence, the voltage which is necessary to drive the current, that comes from motor $I$, through motor $I I$, is small in comparison with that consumed by motor $I$.

97. In order, then, to draw a diagram of the single-phase motor we should have to find out by trying how the voltage is distributed between the two motors. This is a very wearisome procedure. We arrive at a sufficiently accurate and simple solution if we remember that the resultant magnetic field in motor $I I$ will always, with very little inaccuracy, coincide with the impressed magnetic field of motor $I$. But this means nothing else than that the effect of motor II may be taken into account by considering it as an apparent increase of the primary leakage field of motor $I$.

98. According to the above considerations it is clear that currents will be induced by the field $I I$ in the armature, even if running almost synchronously. Synchronism, of course, can never be reached by the armature unless an external force is applied to its shaft. These armature currents react upon the primary and must, obviously, about double the magnetizing current; in other words, the single-phase motor running idle, takes a current about twice as large as the magnetizing current. The accurate relation between magnetizing current and "idle current" depends upon the leakage factor, and can be calculated as follows. Each of the motors $I$ and $I I$ receives one-half the idle current $i_{0} . \quad \frac{i_{0}}{2}$ is the magnetizing current in motor $I$, and the

tThe author is indebted for this helpful comparison to a conversation with Mr. Herrmann Cahen in 1895 . 


\section{THE INDUCTION MOTOR.}

voltage necessary to drive this current through the field coils $n f$ motor $I$ is proportional to $-\frac{i_{0}}{2}$.

99. The magnetizing current of motor $I I$, running at a slip of $2 \sim$ may be called $i_{11}$, then we have for the magnetizing current of the single-phase motor:

$$
i_{m}=\frac{i_{0}}{2}+i_{11}
$$

For $i_{11}$ we have

hence

$$
i_{11}=\left(i_{0}-i_{m}\right) \sigma,
$$

$$
\begin{aligned}
& i_{m}=\frac{i_{0}}{2}+i_{0} \sigma-i_{m} \sigma \\
& i_{m}(\mathrm{I}+\sigma)=i_{0} \cdot \frac{\mathrm{I}+2 \sigma}{2} \\
& \text { (13) } \ldots \ldots \ldots \ldots \ldots \frac{i_{m}}{i_{0}}=\frac{1+2 \sigma}{2+2 \sigma}
\end{aligned}
$$

For $\sigma=0$, that is, for a motor without leakage, we have:

$$
\begin{aligned}
\frac{i_{m}}{i_{0}} & =\frac{\mathrm{I}}{2}=0.500 \\
\text { For } \sigma & =0.05 \text { we have } \\
\frac{i_{m}}{i_{0}} & =0.525
\end{aligned}
$$

Fig. 28 shows the diagram resulting from these considerations.

$\overline{O A}$ is the idle current.

$\overrightarrow{O B}$ is the magnetizing current.

The point $C$ bisects $\overline{O A}$. $B^{\prime}$ lies upon the semi-circle $B B^{\prime} G, G$ being the centre of the semi-circle $B L, O B \div B L$ being equal to $\sigma . B^{\prime}$ divides the total primary current $\overline{O A}^{\prime}$ in the ratio of

$$
\frac{O B^{\prime}}{O A^{\prime}}=\frac{\mathrm{I}+2 \sigma}{2+2 \sigma},
$$

hence the locus of $A^{\prime}$ is the semi-circle $A A^{\prime} L$. 


\section{THE SINGLE-PHASE MOTOR.}

\section{THE CURRENTS IN TIE ARMATURE.}

100. The current in the armature of the single-phase current motor is equal to the vector sum of the secondary currents $\frac{1}{v_{1}} \cdot B B^{\prime}$ and $\frac{\mathrm{I}}{v_{1}} \cdot A^{\prime} B^{\prime}$ of the two polyphase motors, hence equal to $\frac{1}{v_{1}} \cdot A^{\prime} B$.

A glance at Fig. 28 shows us that only one-half of the energy dissipated in the armature can be utilized for the production of the torque. We see, namely, that at all loads the secondary currents represented by $A^{\prime} B^{\prime}$ and $B^{\prime} B$ remain very nearly equal, and as only motor $I$ is do-

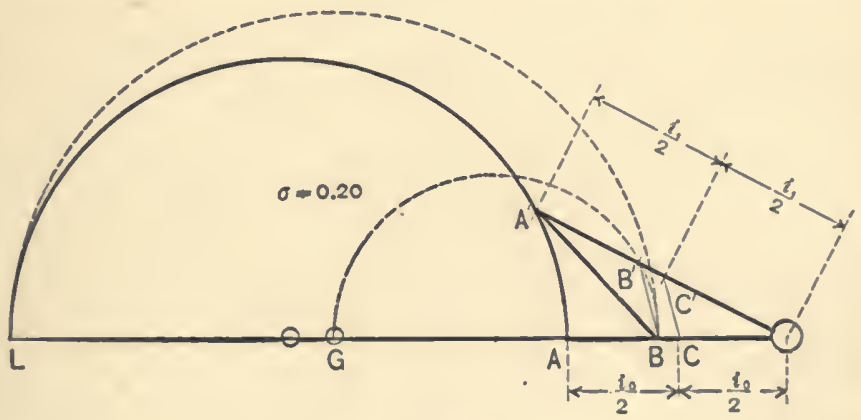

FIG. 28.

ing useful work, the armature currents in motor II represent a loss almost exactly equal to the loss in the armature of the working motor I. The slip in a singlc-phase motor indicatcs, thcrcforc, only onehalf of the energy dissipatcd in the armature, hence the loss in the armature of a single-phase motor is twice as large as that in a polyphase motor, provided the slip be equal in the two motors.

Torque. - 101. The torque can be calculated as follows: Suppose the armature is wound in thrce phases, cach having the resistance $r_{2}$. The output of the motor is then:

$$
P=c_{1} i_{1} \cdot \cos \phi-i_{1}^{2} \cdot r_{1}-3 i_{2}^{2} r_{2}
$$




\section{THE INDUCTION MOTOR.}

whence follows

$$
\text { (14)...6.61.6 D mkg }=\frac{p}{\sim_{2}} \cdot P_{\text {watts }}
$$

in which equation $D_{m k g}$ is the torque in $m . k g$., and $p$ the number of north or south poles.

102. The following reasoning yields a value for $\sim_{2}$ :

We have for motor $I$,

and for motor $I I$,

$$
9.8 \mathrm{I} \cdot D_{1}\left(\omega_{1}-\omega_{2}\right)=\frac{3 i_{2}^{2} \cdot r_{2}}{2},
$$

$$
\text { 9.8I } \cdot \mathrm{D}_{\mathrm{II}}\left(\omega_{1}+\omega_{2}\right)=\frac{3 i_{2}^{2} \cdot r_{2}}{2}, .
$$

in which equations $\omega_{2}$ is the angular velocity of the revolving field, $\omega_{2}$ that of the armature.

Hence,

$$
9.8 \mathrm{I} \cdot\left(D_{\mathrm{I}}-D_{\mathrm{II}}\right) \omega_{2}=3 i_{2}^{2} r_{2} \cdot \frac{\mathrm{I}}{\left(\frac{\omega_{1}}{\omega_{2}}\right)^{2}-\mathrm{I}}
$$

or

$$
\begin{aligned}
3 i_{2}^{2} r_{2} & =P_{\text {watts }}\left(\left(\frac{\omega_{1}}{\omega_{2}}\right)^{2}-\mathrm{I}\right) \\
(\mathrm{I} 5) \ldots \ldots \ldots \ldots \ldots \ldots \ldots+3 i_{2}{ }^{2} r_{2} & =P_{\text {weatts }}\left(\left(\frac{\sim_{1}}{\sim_{2}}\right)^{2}-1\right)
\end{aligned}
$$

903. To illustrate: Let us assume $\sim_{1}=50$, and $\sim_{2}=45$; then we have

$$
\begin{aligned}
3 i_{2}{ }^{2} r_{2} & =P_{\text {watts }}\left(\left(\frac{50}{45}\right)^{2}-\mathrm{I}\right) \\
& =0.23 \text { Pwatts }
\end{aligned}
$$

In words, if the slip is ro per cent, the loss of energy in the arma." ture amounts to 20 per cent.

104. It is instructive to compare with (14) the formula (7) for the polyphase motor, which reads after some transformations,

$$
\text { (16)..................3 } i_{2}^{2} r_{2}=P_{\text {watts }} \cdot \frac{\sim_{1}}{\sim_{2}}\left(\frac{\sim_{1}}{\sim_{2}}-1\right)
$$

This is in words that the slip in per cent is equal to the armature loss in per cent, setting $P+3 i_{2}^{2} r_{2}$ equal to 100 . 
Ratio of Transformation. - 105. We shall see that it is not advisable to cover the whole circumference of the field with windings. In general, it will be advantageous to wind but two-thirds of it. The ratio of transformation in this case is not equal to the quotient of the number of conductors in the field divided by the number of conductors in the armature. With sufficient accuracy we may consider the ratio of trans-

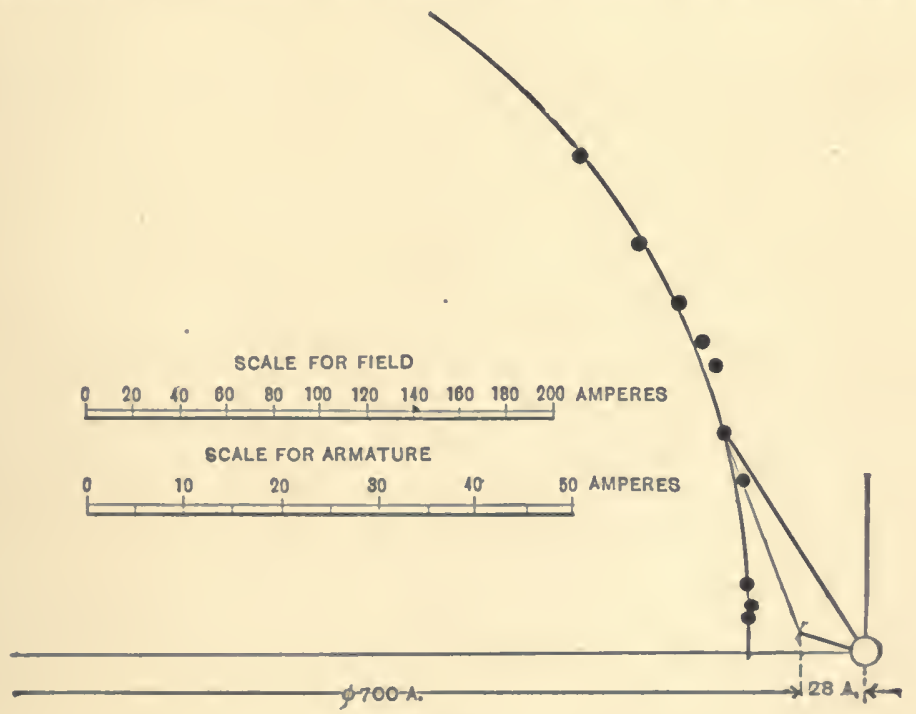

FIG. 29.

formation to be equal to the number of active conductors in the field divided by only five-sixths of the total number of active conductors in the armature.

\section{EXPERIMENTAL CORROBORATION.}

106. The data given in the following table, and graphically represented in the polar diagram, Fig. 29, belong to a 10-lp, single-plas: current motor for 110 volts, $50 \sim$, and 1500 r. p. m. The number of conductors in the field was 120 ; the number of conductors in the 


\section{THE INDUCTION MOTOR.}

armature was 312. The resistance of the field was $0.015 \mathrm{ohm}$; of each of the three phases of the armature, $0.08 \mathrm{ohm}$.

TESTS OF $10 . \mathrm{HP}$ MOTOR.

\begin{tabular}{|c|c|c|c|c|c|c|c|c|}
\hline $\begin{array}{l}\Sigma \\
\dot{\Sigma} \\
\dot{\alpha}\end{array}$ & & 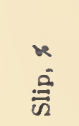 & 选 & 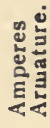 & 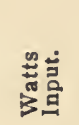 & 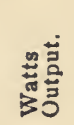 & 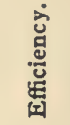 & 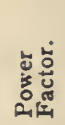 \\
\hline & 51.5 & 100 & 29 & 0 & 900 & 0 & 0 & 0.283 \\
\hline 1553 & 51.5 & .. & 51.5 & . & 1700 & 0 & 0 & 0.30 \\
\hline $\begin{array}{l}1579 \\
\end{array}$ & 52.8 & $\therefore$ & 54 & . & 2250 & 700 & 0.31 & 0.379 \\
\hline 1572 & 52.4 & .. & 58 & .. & 3300 & 1770 & 0.536 & 0.518 \\
\hline I 554 & 52.4 & .. & 90 & .. & 8100 & 6300 & 0.778 & 0.82 \\
\hline 1547 & 51.4 & .. & 112 & 21 & 10,500 & 8100 & 0.77 & 0.85 \\
\hline 1525 & 51.5 & 3.30 & 138 & 29 & 13,500 & 10,600 & 0.785 & 0.89 \\
\hline 1517 & 50.8 & 0.52 & 150 & 31 & 14,700 & 11,400 & 0.775 & 0.89 \\
\hline 1483 & 50.2 & 1.80 & 169 & 35 & 16,500 & 13,000 & 0.788 & 0.888 \\
\hline 1430 & 48.8 & 2.40 & 200 & & I 9,400 & & 0.765 & 0.882 \\
\hline 1460 & 49.9 & 2.66 & 245 & 55 & 23,500 & 16,830 & 0.716 & 0.873 \\
\hline
\end{tabular}

107. It is instructive to calculate the armature loss in watts for the greatest load. We find this to be $55^{2} \cdot 0.24=730$ watts, corresponding according to (I5), to a slip of 2.1 per cent. The discrepancy between this and the measured value of 2.66 per cent is doubtless mainly due to the difficulty of measuring a small slip.

\section{CALCULATION OF THE INDUCTANCE OF THE SINGLE-PHASE MOTOR}

108. We must now turn to the calculation of the counter e. m. f. induced by the oscillating field upon itself. We shall consider two cases, viz., first, the case in which the field-coil is spread over twothirds of the pole-pitch; secondly, the case in which the field-coil covers the whole pole-pitch.

First-We saw in the second chapter of this article that the e. $\mathrm{m}$. $\mathrm{f}$. induced by a field $\Phi$ in a coil of the width $b$ is two-thirds as large as the e. $\mathrm{m}$. f. which would be induced by the same field in a coil which is not distributed but lodged in only one groove. For the latter case we have,

$$
e=2.22 \sim \cdot z \cdot \Phi \cdot 10^{-8} \text { volts. }
$$

Fig. 30 shows the shape of the field for a coil the width of which is equal to two-thirds of the pole-pitch. We call the number of ac- 
THE SINGLE-PHASE MOTOR.

tive conductors per pole $n$, then we have for the induction in the airgap :

$$
\text { (17) } \ldots \ldots \ldots \ldots \ldots \ldots, B=\frac{n \cdot i_{m} \cdot \sqrt{2}}{1.6 \cdot \Delta}
$$

In this formula $i_{m}$ is the effective value of the magnetizing cur-
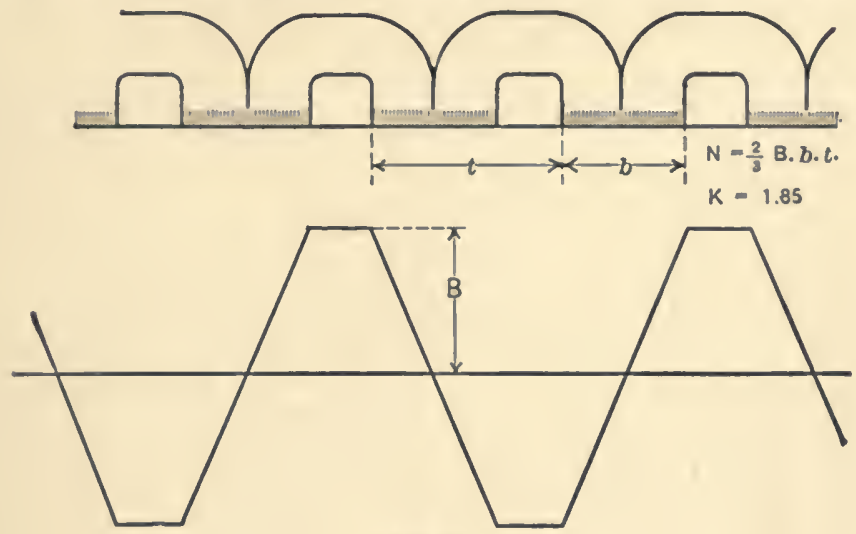

FIG. 30 .

rent, while $\Delta$ is the air-gap. If $b$ is the width of the iron of the motor in $\mathrm{cm}, t$ the pole-pitch, then we have,

$$
\text { (18) } \ldots \ldots \ldots \ldots \ldots \ldots \ldots+. \ldots=\frac{2}{3} b \cdot t \cdot B
$$

Instead of a coefficient of 2.22 we get, as will easily be scen, a coefficient of 1.85 ; therefore, we have the formula:

$$
\text { (19) } \ldots \ldots \ldots \ldots \ldots \ldots e=1.85 \cdot \sim 2 \cdot \Phi \cdot 10^{-8}
$$

Secondly_Fig. 31 shows this case. For the induction formula (16) holds good.

The mumber of lines of induction is equal to

$$
\text { (20) } \ldots \ldots \ldots \ldots \ldots \ldots . . .+1=\frac{1}{2} b \cdot t \cdot B .
$$

as may be seen at a glance. 


\section{THE INDUCTION MOTOR.}

For the e. m. f. we have:

$$
e=\frac{2}{3} \cdot 2.22 \cdot \sim \cdot z \cdot \Phi \cdot 10^{-8}
$$

$$
\text { (21) } \ldots \ldots \ldots \ldots \ldots \ldots, e=1.48 \cdot \sim \cdot z \cdot \Phi \cdot 10^{-8}
$$

109. It will readily be seen from these formulæ that it is not advantagcous to use a coil spread over the whole pole-pitch.
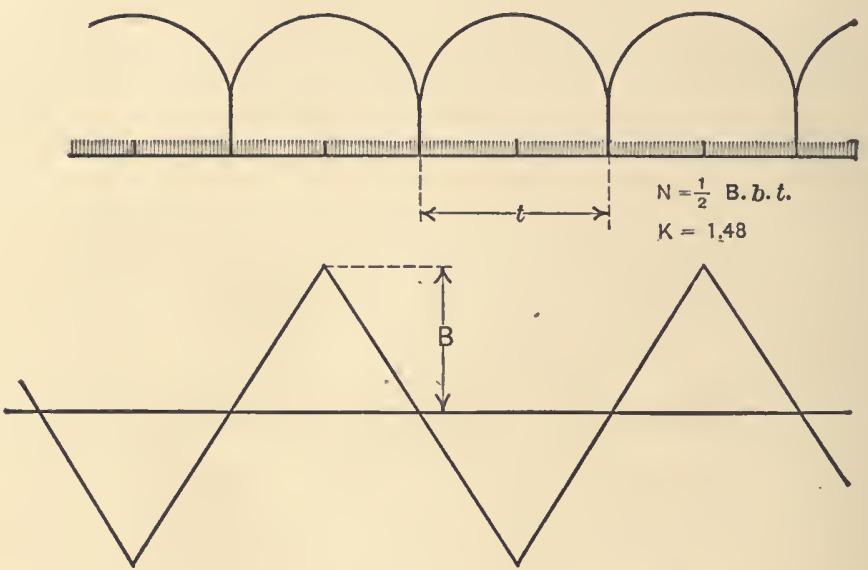

FIG. 3I.

110. We can now proceed to study in detail the qualities of the single-phase motor; to this purpose we shall devote the next chapter, taking the iron frame of the three-phase motor designed in chapter $\mathrm{V}$, and winding it as a single-phase current motor. 


\section{CHAPTER VII.}

\section{Calculation of a Single-Phase Current Motor.}

7 HE three-phase current motor, the design of which was given in chapter $\mathrm{V}$, is reproduced in Fig. 32. We shall now proceed to examine the behavior of this motor if running as a singlephase motor. For simplicity's sake we shall retain the winding, and
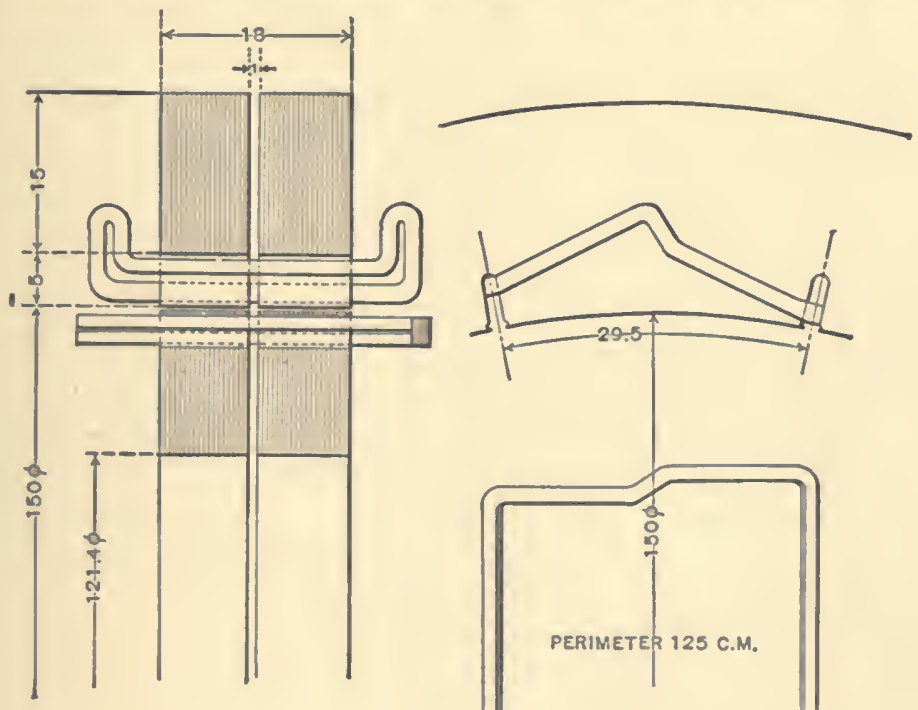

FIG. 32 .

investigate what voltage is most suitable for it. The motor, as will be remembered, has 16 poles, and is to work again at 60 p. p.s.

III. Field Winding.-128 slots, ro conductors in each slot; diameter of wire, $0.229^{\prime \prime}$; resistance hot, $0.28 \mathrm{ohm}$. 


\section{THE INDUCTION MOTOR.}

Armature Winding.-240 slots, 2 conductors in each slot; wound in three phases in star connection; resistance of each plase, 0.015 ohm.

112. E. M. F.-According to (18) we have:

$$
\begin{aligned}
(18) \ldots \ldots \ldots \ldots \ldots \ldots . \Phi & =\frac{2}{3} b \cdot t \cdot B . \\
b & =17 \mathrm{~cm} . \\
t & =29.5 \mathrm{~cm} . \\
B & =5600 .
\end{aligned}
$$

The diminution of the air-gap through the open slots is taken into account by reckoning only 85 per cent of the surface of the air-gap. Thus, we find:

$$
\Phi=1.58 \cdot 10^{\circ} \text { c. g. S. }
$$

113. In the three-phase current motor we had:

$$
\Phi_{3}=1.42 .10^{\circ} \mathrm{c} . \mathrm{g} . \mathrm{s} \text {. }
$$

We insert $N=1.58 \cdot 10^{\circ}$ in formula (19) and get

$$
100 \cdot e=1.85 \cdot \sim \cdot z \cdot \Phi \cdot 10^{-6}=2250 \text { volts. }
$$

Therefore, the terminal voltage should be equal to 2250 volts.

114. Hysteresis.-The loss through hysteresis and eddy currents amounts to 1150 watts, of which 570 is dissipated in the teeth, and 580 in the iron ring.

Magnetizing Current.-From (17) follows

$$
i_{m}=\frac{B \cdot \mathrm{r} .6 \triangle}{n \sqrt{2}}
$$

We insert the following values:

and find

$$
\begin{aligned}
& B=5600 \text { c. g. s. } \\
& \Delta=0.15 \text { cm. } \\
& n=80 .
\end{aligned}
$$

$$
i_{m}=12 \text { amperes. }
$$


CALCULATION OF A SINGLE-PHASE CURRENT MOTOR.

115. Lcakage.-The leakage coefficient is $0.06 \mathrm{I}$ for the iron frame.

116. Idle Current.-We have according to (13):

$$
\begin{aligned}
& \text { (13)........... } \frac{i_{m}}{i_{0}}=\frac{1+2 \sigma}{2+2 \sigma}=\frac{1+0.122}{2+0.122} \\
& i_{0}=\frac{12}{0.576} \\
& i_{0}=20.8 \text { amperes. }
\end{aligned}
$$

117. Friction.-Loss through friction and air resistance, 2150 watts.

118. We can now draw our standard diagram. This has been done in Fig. 33. The ordinates measured between the full line curve and

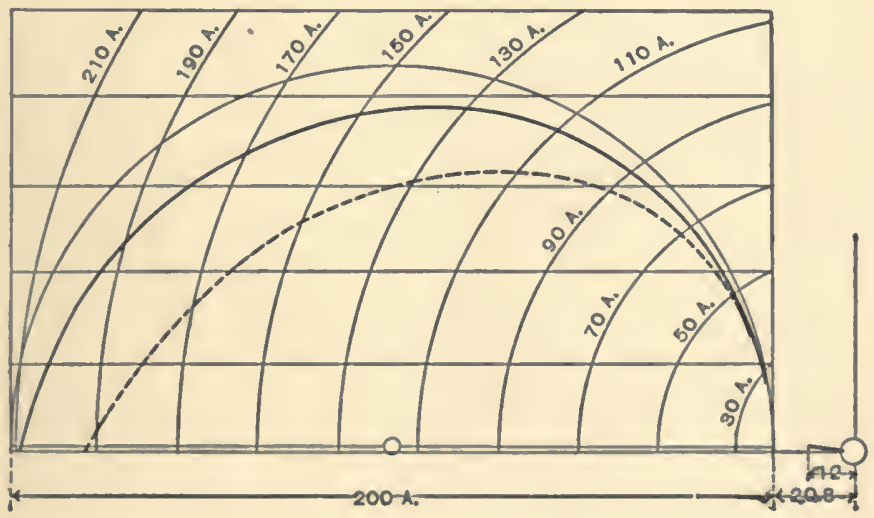

FIG. 33 .

the basis of the semi-circle measure the output of the motor for the armature with small resistance. The ordinates between the broken line curve and the basis of the semi-circle measure the output of the motor for the squirrel cage armature. 
THE INDUCTION MOTOR.

From this diagram the following table has been compiled.

DATA OF 180-HP SINGLE-PHASE CURRENT MOTOR.

2250 Volts, 60 P. P. S., 450 R. P. M.

\begin{tabular}{|c|c|c|c|c|c|c|}
\hline 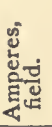 & 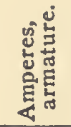 & 대 & 돌 & 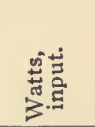 & 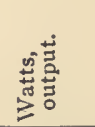 & 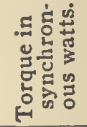 \\
\hline 30 & 66.6 & 500 & 212 & 43,900 & 39,888 & \\
\hline 50 & 135 & 1,400 & 874 & 91,000 & 85,426 & 85,800 \\
\hline 70 & 195 & 2,740 & $\mathrm{I}, 820$ & I 29,000 & I $2 \mathrm{I}, \mathrm{I} 4 \mathrm{O}$ & ... \\
\hline 90 & 256 & 4,530 & 3,150 & 163,000 & I 52,020 & ... \\
\hline IIO & 316 & 6,800 & 4,800 & 190,000 & I 75, 100 & 177,500 \\
\hline 130 & 375 & 9,500 & 6,750 & 209,000 & I 89,450 & 193,000 \\
\hline 150 & 436 & 12,600 & 9,100 & 217,000 & I 92,000 & I 97,000 \\
\hline 170 & 495 & 16,200 & I 1,700 & 209,000 & 177,800 & I 83,000 \\
\hline 190 & 583 & 20,200 & 14,700 & 173,000 & I 34,800 & 141,000 \\
\hline 200 & 583 & 22,400 & 16,300 & I 37,000 & 95,000 & 103,000 \\
\hline 208 & 608 & 24,200 & 17,700 & 83,000 & 37,800 & 45,900 \\
\hline
\end{tabular}

DATA OF I80-HP SINGLE-PHASE CURRENT MOTOR. 2250 Volts, 60 P. P. S., 450 R. P. M.

\begin{tabular}{|c|c|c|c|c|c|c|c|}
\hline 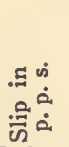 & 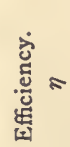 & 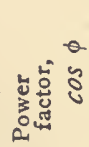 & 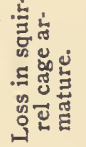 & 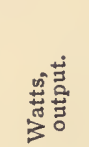 & 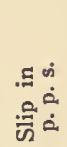 & 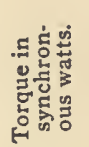 & 灾 \\
\hline & 0.91 & 0.65 & $\mathrm{I}, 270$ & 38,830 & $59 . \mathrm{I}$ & 39,500 & $0.88 \overline{5}$ \\
\hline 59.73 & 0.938 & $0.8 \mathrm{I}$ & 5,250 & $8 \mathrm{r}, 050$ & 58 & 84,000 & 0.89 \\
\hline & 0.94 & 0.82 & 10,900 & I 12,060 & 57.3 & II 7,500 & 0.87 \\
\hline ..... & 0.933 & 0.805 & I 8,900 & I 36,270 & 56.3 & 145,000 & 0.837 \\
\hline 59.2 & 0.922 & 0.768 & 28,800 & I 51,100 & 55 & 165,000 & 0.795 \\
\hline 59 & 0.907 & 0.715 & 40,500 & I 55,700 & 53.5 & 175,000 & 0.745 \\
\hline 58.6 & 0.885 & 0.645 & 54,600 & I 46,500 & $5 \mathrm{I} .3$ & I $7 \mathrm{I}, 000$ & 0.675 \\
\hline 58.2 & 0.85 & 0.547 & 70,200 & 123,800 & 48 & 155,000 & $0.59^{2}$ \\
\hline 57.4 & 0.78 & 0.405 & 88,200 & 61,300 & 38.4 & 96,000 & 0.355 \\
\hline 55.4 & 0.694 & 0.305 & 97,800 & I 3,500 & 20.9 & 38,800 & 0.0985 \\
\hline 49.5 & 0.455 & 0.177 & & & 20.9 & & ... \\
\hline
\end{tabular}

119. A few words may be said as to the calculation of the slip, which is here expressed in p. p. s., and the calculation of the torque.

120. Slip.-The slip can easily be found with the help of formula (15), as all quantities, with the exception of $\sim_{2}$ are known.

121. Torque.-The torque in synchronous watts is then obtained by multiplying the output in watts by the ratio of $\sim_{1} \div \sim_{2}$. 
CALCULATION OF A SINGLE-PHASE CURRENT MOTOR.

122. Fig. 34 shows the field current and the output as a function of the energy consumed. The full line curves represent again the output

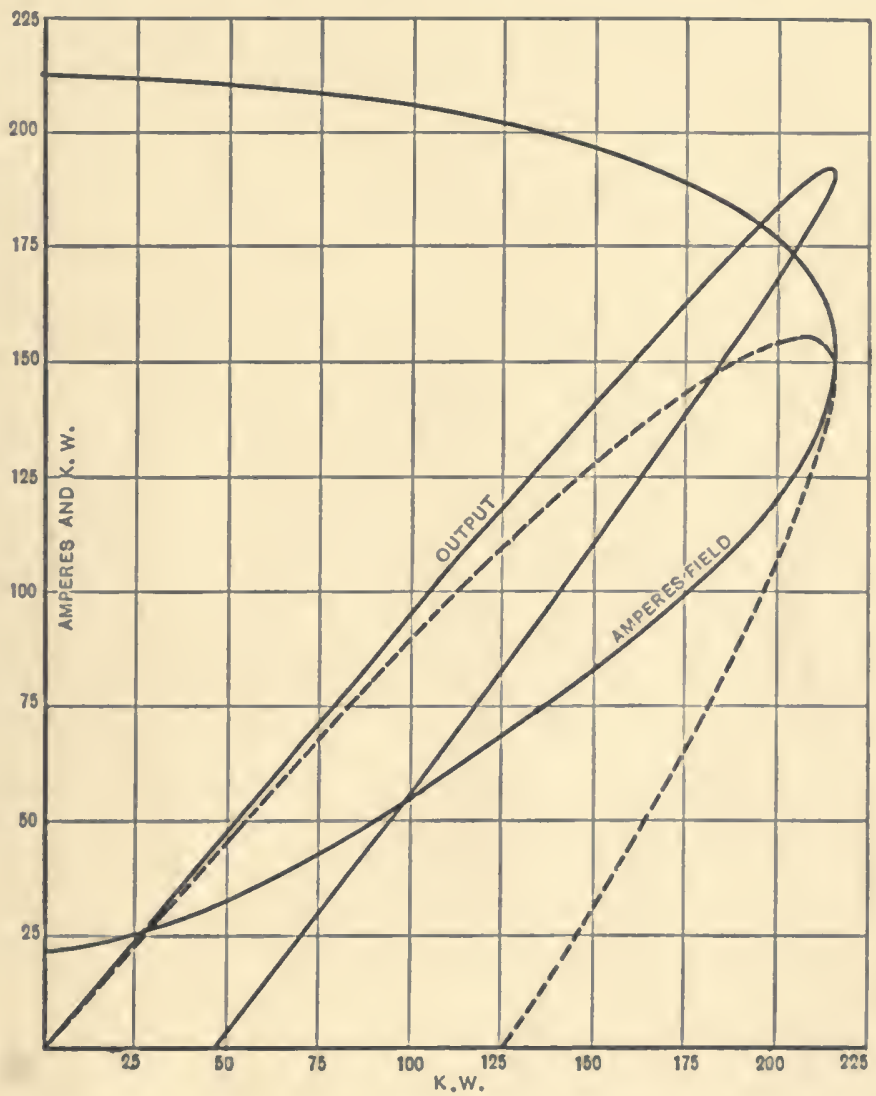

FIG. 34 .

of the armature with small resistance, while the broken line curve shows the output of the motor with squirrel cage armature, the re- 
THE INDUCTION MOTOR.

sistance of which is six times as large as that of the armature with external starting resistance.

123. Fig. 35 shows the power factor and the efficiency for the two cases. The power factor is, of course, the same in either case. In the calculation of the efficiency the load-losses have not been taken into account.

124. Finally, we have in Fig. 36 a graphic representation of the output and the torque in watts as a function of the slip in p. p. s., or rath-

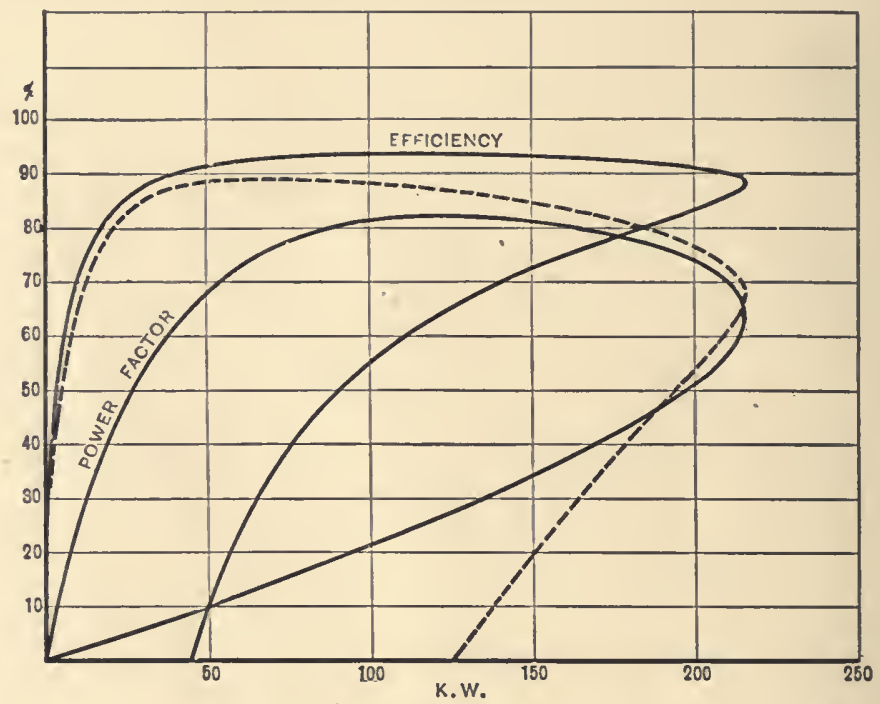

FIG. 35 .

er, of the number of revolutions of the armature expressed in p. p.s. The broken line curves reier as usual to the squirrel cage armature. Little need be said about these curves. It is plain that for the armature with a small resistance the starting torque is still exceedingly small at $\sim_{2}=40$. Such a motor will never start well without extra resistance in the armature, whatever starting arrangement be made. 


\section{CALCULATION OF A SINGLE-PHASE CURRENT MOTOR.}

125. The effect of armature resistance consists in reducing the capacity of the motor, and in shifting the maximum torque toward the starting point.

126. In designing the three-phase current motor, we had made the condition that the motor should start with a torque equal to twice the normal running torque. As all the starting devices that have been tried for single-phase motors are not worth very much, such a condition can, at present, not be fulfilled. W'e rate the motor, therefore,

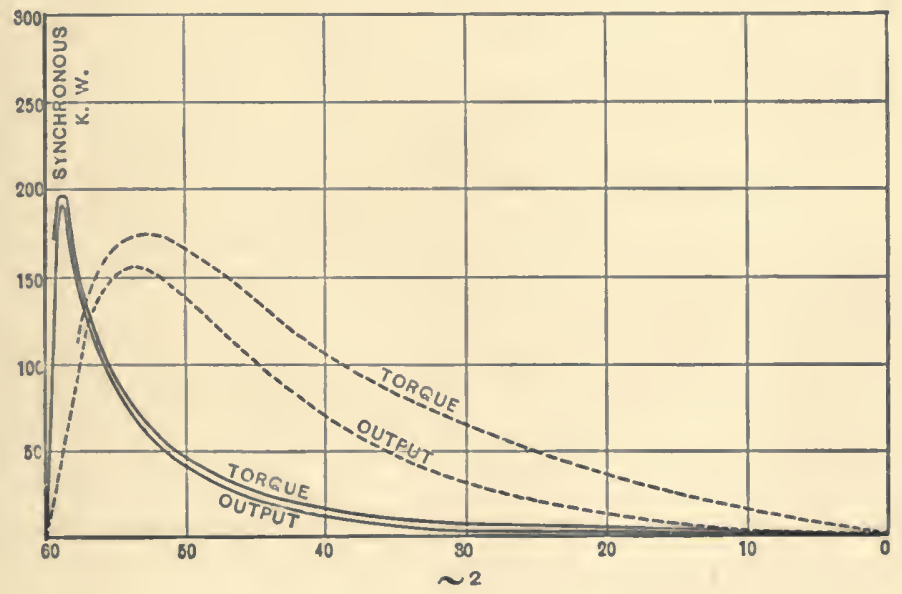

FIG. 36 .

according to its most favorable efficiency and power factor. For I35 kilowatts we have an efficiency of 94 per cent and a power factor of 82 per cent, corresponding to an apparent efficiency of 77 per cent. The motor will safely yield 180 horse-power at 2250 volts.

127. It is instructive to compare the current in the three phases of the three-phase current motor reduced to the voltage of the single-phase current motor with the current in the singlephase motor. The three-phase motor took a magnetizing cur- 


\section{THE INDUCTION MOTOR.}

rent of 12 amperes, corresponding to $12 \cdot 2000 \sqrt{ } \overline{3}$ volt-am peres. This divided by 2250 volts yields a magnetizing current equivalent to 18.4 amperes. The leakage factor being $0.06 \mathrm{I}$, we can draw our standard diagram whence the curves in Fig. 37 are derived.

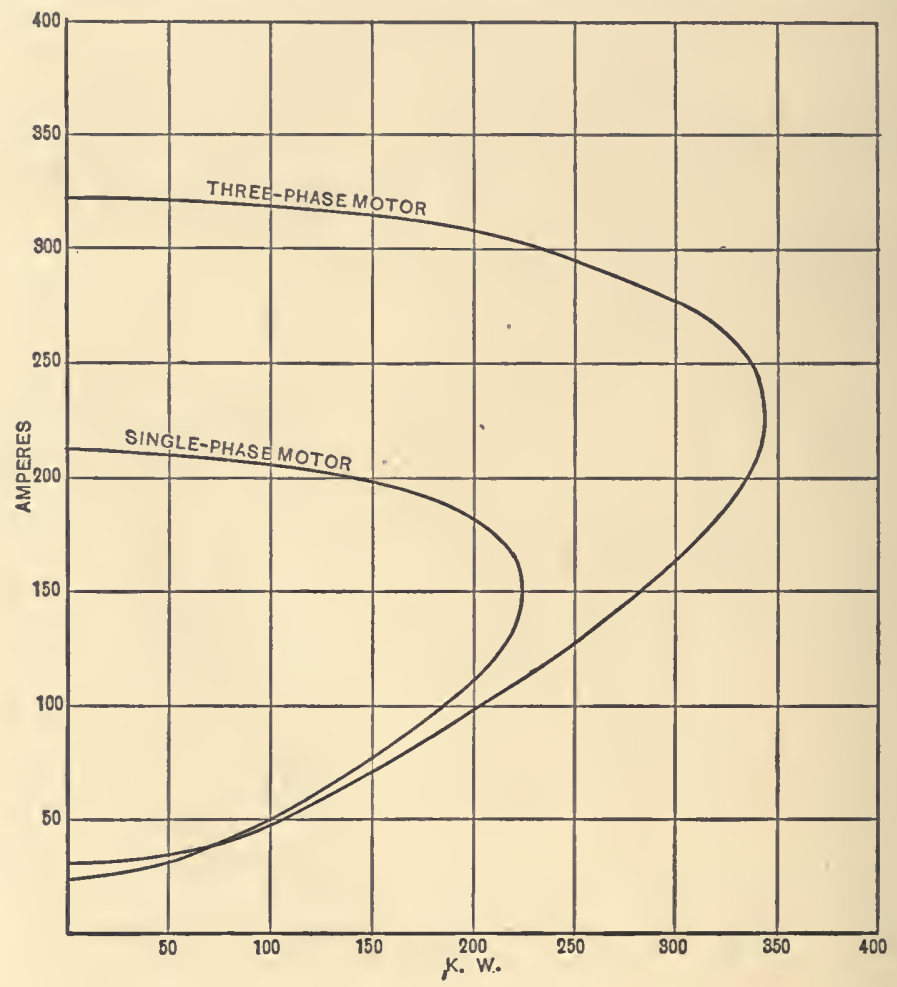

FIG. 37.

These curves clearly show that the maximum output of the singlephase current motor is only 0.65 the maximum output of the threephase current motor. 


\section{CALCULATION OF A SINGLE-PHASE CURRENT MOTOR.}

STARTING ARRANGEMENTS.

128. A few words may fitly be added about the methods of starting single-phase motors. It has generally been found advantageous to use two-thirds of the pole-pitch for the main winding, and to leave the remaining third for the starting phase. The motor thus starts as an imperfect two-phase current motor. An external armature re-

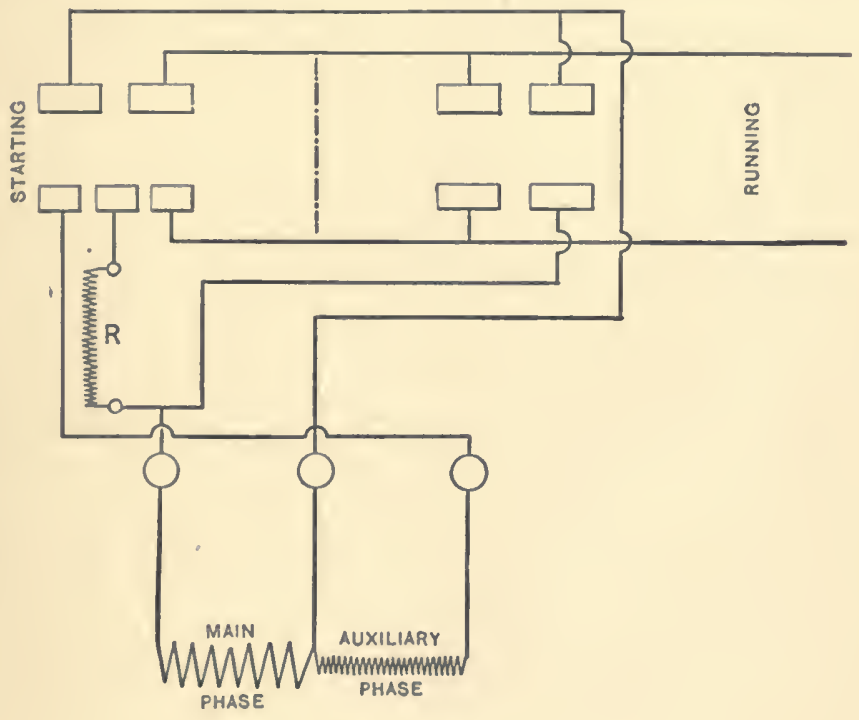

FIG. 38 .

sistance is to be recommended for large sizes, say, for an output above 15 horse-power.

129. The starting phase receives generally either half the number of convolutions as the main phase, or twice as many. The latter method seems to be preferable. Figs. 38 and 39 show the switch used by the Oerlikon Engineering Works for their single-phase motors. 


\section{THE INDUCTION MOTOR.}

130. In Fig. $3 \&$ the resistance or condenser $R$ is, at starting, in series with the main phase, the auxiliary phase being directly between the terminals.

131. In Fig. 39 the resistance $R$ is in parallel with the auxiliary phase, which is in series with the main phase.

During the throwing-over of the switch from the starting position

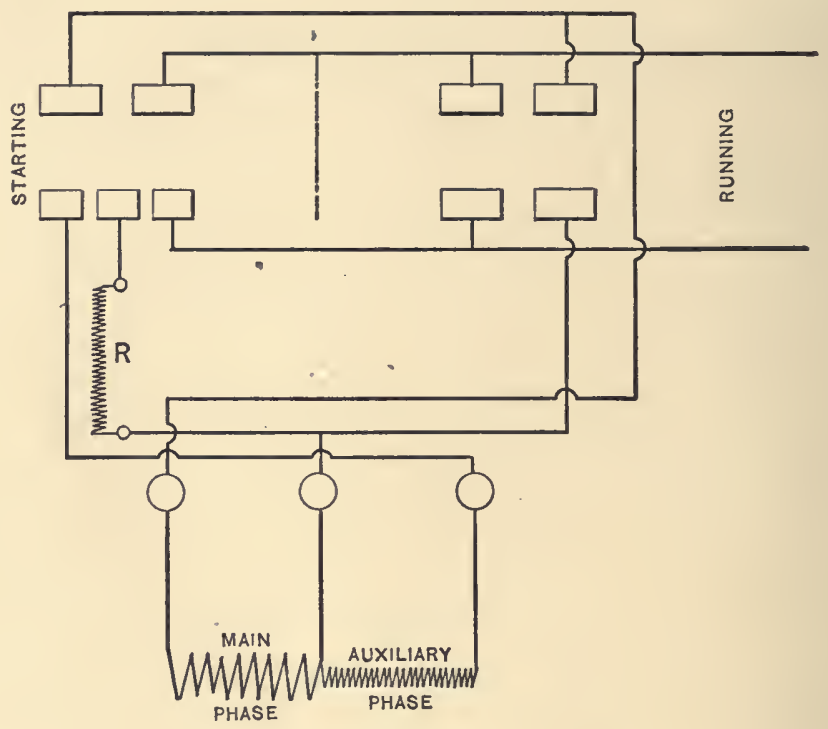

FIG. 39 .

to the running position, the motor is temporarily disconnected from the mains.

The last chapter we shall devote to a more general and broadetreatment of the polar diagrams of the general alternating-current transformer. 


\section{CHAPTER VIII.}

\section{The Polar Diagrams of the General Alternating- Current Transformer.}

$I^{N}$ $\mathrm{N}$ this last chapter it is my aim to present, in as simple and lucid a manner as possible, the general theory of the alternating-current transformer, taking also the resistance of the primary into account. The results of this consideration are partly known, but as the road by which they can be reached, is a very easy one, it may deserve some consideration. I shall make use in my treatment of the problem of the theorem of reciprocal vectors, known in kinematics and geometry as the theorem of inverse points, and I will here make good a sin of omission, of which I became aware only when by clance glancing over the pages of Dr. Bedell's book, "The Principles of the Transformer," in November, 1900. As early as I893 Messrs. Bedell and Crehore gave the theoretical proof of the fact that the locus of the primary voltage in a transformer at constant current is a semi-circle, " and in his paper on "Transformer Diagrams Experimentally Determined," read at the Electrical Congress in Chicago, 1893 , Dr. Bedell gave also the experimental proof for the constant-current transformer that the potential at its terminals can be represented by chords in a semi-circle. To develop the diagram for the constant potential transformer was, however, reserved to European physicists.

\section{DIAGRAM OF FLUXES AND MAGNETOMOTIVE FORCES.}

132. The principle of the conservation of energy requires that the magnetomotive forces $X_{1}$ and $X_{2}$ of the primary and secondary of the transformer tend to magnetize the core in opposite directions. $X_{1}$

-See a series of ten articles on the "Theory of the Transformer," Electrical World, May, 1893, and later. 


\section{THE INDUCTION MOTOR.}

and $X$, may be considered to be magnetic cells producing, as it were, magnetomotive forces $X_{1}$ and $X_{2}$. The reluctance of the circuit com-
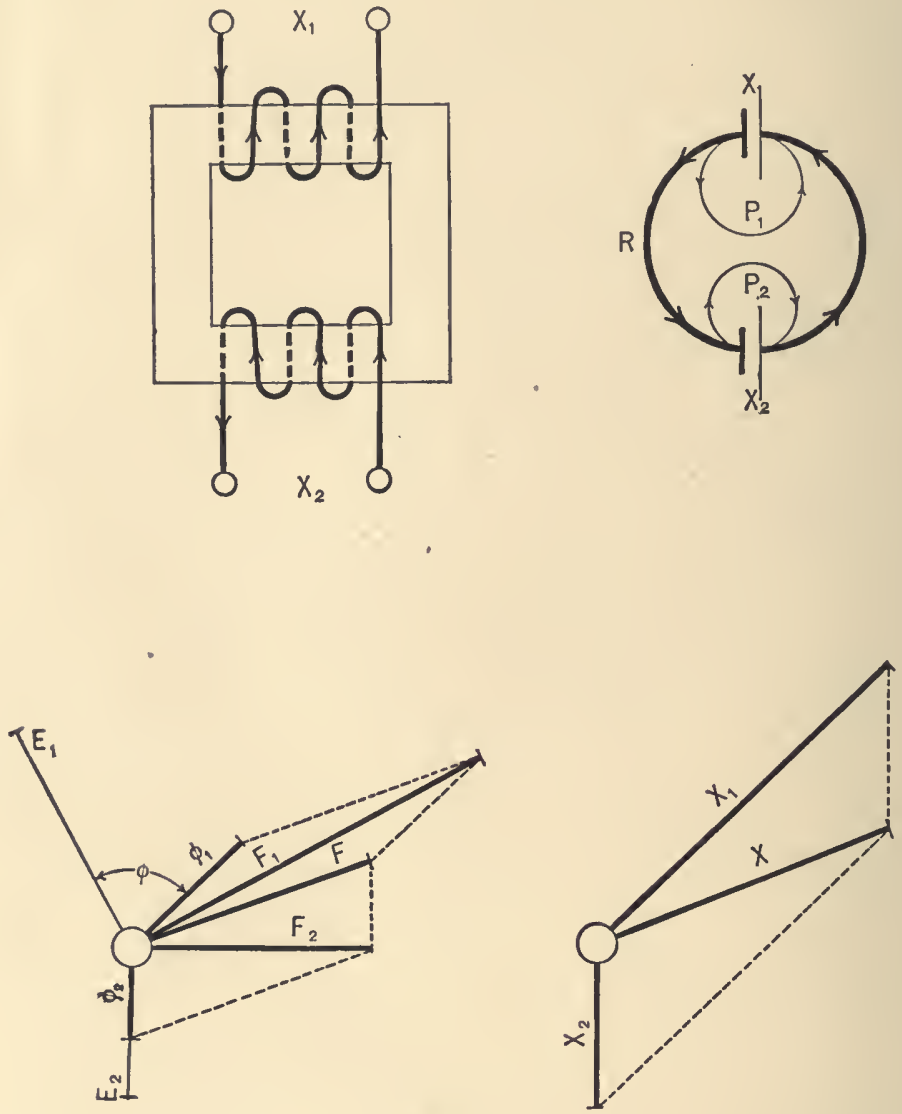

Fig. 40.

mon to both be $R$, the reluctance of the stray-fields that naturally form about $X_{1}$ and $X_{2}$, be $\rho_{1}$ and $\rho_{2}$. Let us call the flux flowing 


\section{ALTERNATING-CURRENT TRANSFORMER.}

through $X_{1}$ and $X_{2}, F$, and the leakage-fluxes $\phi_{1}$ and $\phi_{3}$ respectively.* We have then,

(1) $\ldots \ldots \ldots \ldots \ldots \ldots \ldots X_{1}=\phi_{1} \rho_{1}$

(2) $\ldots \ldots \ldots \ldots \ldots \ldots \ldots \ldots X_{z}=\phi_{2} \rho_{2}$

Treating $X_{2}$ and $X_{2}$ not as scalar quantities but as vectors, we may write,

(3) $\ldots \ldots \ldots \ldots \ldots \ldots \ldots \ldots X_{1}-X_{2}=F \cdot R$.

133. The phase of the leakage-fields $\phi_{1}$ and $\phi_{2}$ is the same as that of the magnetomotive forces which produce them, hence they are in phase with the currents.

134. Let $E_{2}$, Fig. 40, represent the voltage at the terminals of a noninductive resistance in the secondary of the transformer, then the current will be in phase with $E_{2}$. The magnetic field which is required to produce $E_{2}$ by its variation, is $F_{2}$, in quadrature with $E_{2}$. The lines of induction in phase with the secondary current, whose e. $m$. $f$. is in quadrature with the current, are represented by $\phi_{2}$. We shall first treat the case in which these lines are all within the transformers, and next we shall deal with the case of an external inductance or capacity.

135. The flux $F$, as mentioned above, links together the primary and secondary coils. The vector-sum of $\phi_{3}$ and $F_{2}$ is equal to $F$.

136. If we neglect for the moment the lag of phase between the magnetomotive force and the fux, then the magnetomotive force of the magnetizing current is in phase with the flux $F$. It may be represented by the vecior $X$.

137. $X$ must be the vector-difference between $X_{1}$ and $X_{2}$

138. $X_{1}, X_{2}$, and $X$ have real existence.

139. The leakage-flux $\phi_{1}$ of the primary is in plase with the primary magnetomotive force $X_{1}$, and may be represented in the diagram by $\phi_{1}$. The vector-sum of $\phi_{2}$ and $F$ is equal to the total primary flux $F_{1}$.

-The notation of fluxes in this chapter is different from that of the preceding chapters, the main flux being called $F$ instead of $\$$. I hope that this reference will prevent readers from making a mistake. 


\section{THE INDUCTION MOTOR.}

Let us now choose our scale for $X, X_{1}$ and $X_{2}$ so that $X$ is equal to $F$; then, Fig. 4I, $\overline{O A}=X_{1}$, and $\overline{O B}=X_{2}$.

THE DIAGRAM FOR THE CONSTANT-CURRENT TRANSFORMER.

140. Let us keep $\overline{O A}=X_{1}$ still and constant, then we see at a

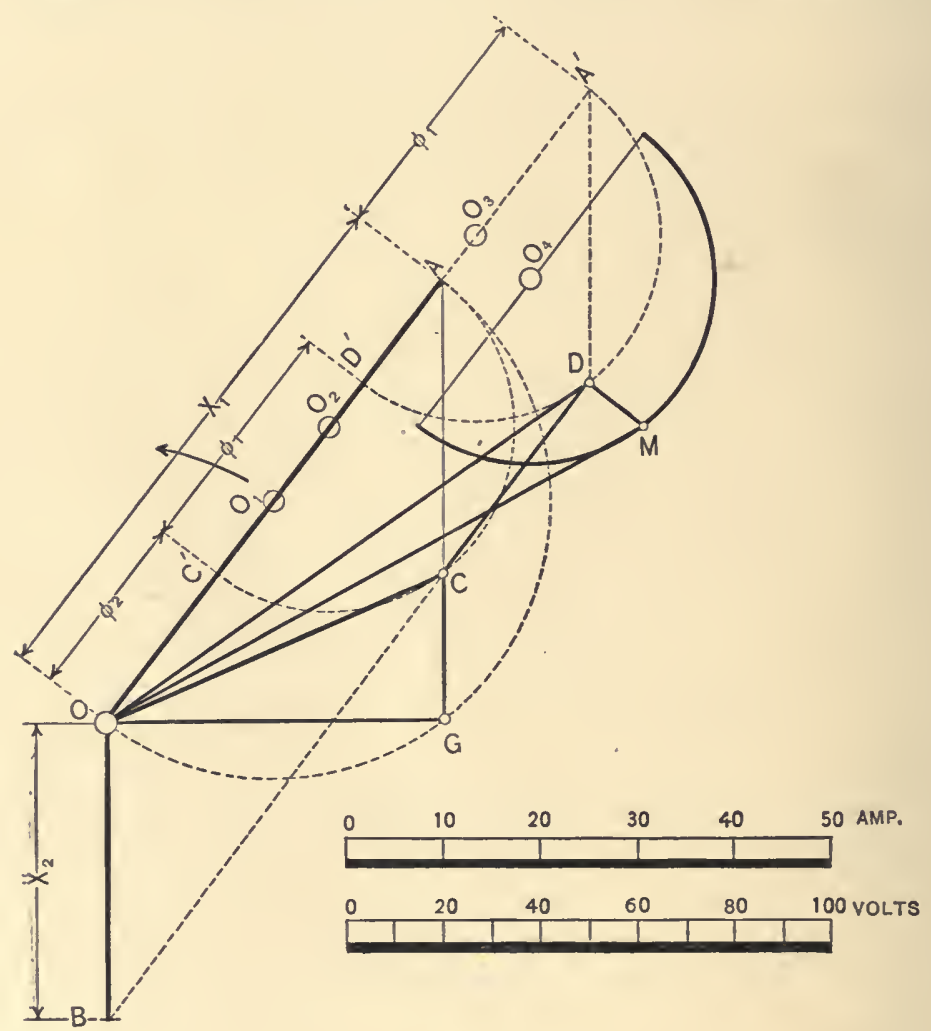

Fig. 41.

glance that the point $G$ will move in the semi-circle $O_{1} . \overline{G C}=\phi_{2}$, is always a constant portion of $\overline{A C}=\overline{O B}=X_{2}$, because of equation (2). 


\section{ALTERNATING-CURRENT TRANSFORMER.}

$\phi_{2}=\frac{X_{2}}{\rho_{2}}$. A very useful way of defining $\phi_{1}$ and $\phi_{2}$ is that of A. Heyland, who writes,

$$
\phi_{2}=\tau_{2} \cdot X_{2} .
$$

Here $\tau_{2}$ is obviously the magnetic conductivity or reluctivity of the leakage-path.

Similarly he writes,

$$
\phi_{1}=\tau_{1} \cdot X_{1} \text {. }
$$

According to the notation which $I$ have used in the preceding chapters, we define $\phi_{1}$ and $\phi_{2}$ by saying that $\overline{A G}=\frac{X_{2}}{v_{2}}$, and $\overline{O A^{\prime}}=\frac{\overline{O A}}{v_{1}}$.

141. If $G$ mores in the circle $O_{1}, C$, which divides $\overline{A G}$ in the ratio $\overline{A C}: \overline{A G}:: v_{2}: 1$, also moves in a circle, which is determined by $C^{\prime}$ dividing $\overline{O A}$ in the ratio $\overline{A C^{\prime}}: \overline{O A}:: v_{2}: \mathrm{I}$.

142. It is just as simple to find the locus of the primary flux $F_{1}$, since, by our assumption, the primary current is constant, the leakagefield $\phi_{1}$ is also constant. We have, therefore, only to transfer the senicircle $\mathrm{O}_{2}$ to $\mathrm{O}_{3}, \overline{\mathrm{O}_{2} \mathrm{O}_{3}}$ being equal to $\phi_{1}$, or, to put it differently, $\overline{\mathrm{OA}}$ : $\overline{U d^{\prime}}:: v_{1}:$ s.

143. The primary resistance can easily be taken into account as we may imagine that the drop caused by the ohmic resistance is equivalent to the e. m. f. produced by a magnetic ficld of constant magnitude, lagging behind the current by 90 degs. This field is represented by $\overline{D M}$.

The locus of the primary field is, therefore, the semi-circle $O$, $\overline{O_{3} O}$, being equal to $\overline{D M}$.

144. The potential at the terminals, necessary to drive a current proportional to $X_{1}$ through the transformer, is proportional to $\overline{O M}$.

From $\overline{O M}$, the potential at the terminals is calculated from the formula

$$
100 e=k \sim z F 10^{-6} \text { volts, }
$$

in which $k$ is generally equal to 2.22 , if $z$ is the number of conductors, and equal to 4.44 , if $z$ is the number of convolutions. 


\section{THE INDUCTION MOTOR.}

145. The position of the semi-circle can now easily be determined, either by the use of complex imaginary numbers, or graphically, as I prefer.

The ratio $\overline{O D^{\prime}}: \overline{A^{\prime} D^{\prime}}$ can be found at once. We have:

$$
\begin{aligned}
& \overline{O D^{\prime}}=\frac{X_{1}}{v_{1}}-\overline{A^{\prime} D^{\prime}} \\
& \overline{A^{\prime} D^{\prime}}=X_{1} \cdot v_{2}, \text { hence } \\
& \frac{\overline{O D^{\prime}}}{\overline{A^{\prime} D^{\prime}}}=\frac{\frac{\mathrm{I}}{v_{1}}-v_{2}}{v_{2}}=\frac{\mathrm{I}}{v_{1} v_{2}}-\mathrm{I}
\end{aligned}
$$

146. This constant ratio we call the leakage factor of the transformer, and denote it by $\sigma$.

$$
\text { (4) } \ldots \ldots \ldots \ldots \ldots \ldots, \sigma=\frac{I}{v_{1} v_{2}}-I
$$

In Heyland's notation we should have:

$$
\sigma=\left(\mathrm{I}+\tau_{1}\right)\left(\mathrm{I}+\tau_{2}\right)-\mathrm{I}=\tau_{1}+\tau_{2}+\tau_{1} \tau_{2}
$$

147. To recapitulate: In a constant-current transformer whose secondary resistance is varied from naught to open-circuit, the terminal voltage varies in such a manner that the vector of the field to which it is proportional and with which it is in quadrature, has for its locus the semi-circle, determined by $O_{*}$ as centre. The position of this circle is perfectly defined if the primary resistance and the leakage factor are known.

\section{THE CONSTANT-POTENTIAL TRANSFORMER,}

148. If, in Fig. 4I, we wanted to know what current would flow through the transformer at a certain difference in phase between $O M$ and $O A$, if $\overline{O M}$ were $n$-times as large as in the diagram, we should simply reason that, the counter e. m. f. being $n$-times as large, only $\frac{\mathrm{r}}{n}$ times as much current could flow through the transformer. Hence, if we kept $\overline{O M}$ constant, varying only its phase relative to $\overline{O A}$, the 


\section{ALTERNATING-CURRENT TRANSFORMER.}

current would vary in inverse proportion to the magnitude of the field-vectors. If we kept $\overline{O M}$ not only constant, but also in the same position, the locus of the vector $\overline{O A}$ would also be a semi-circle. This is a very fertile principle, and it was called by Dr. Bedell the method of reciprocal vectors.

Let, in Fig. 42, the semi-circle having $O_{1}$ as centre, represent the locus of the primary field of the constant-current transformer, $\overline{O r}$ being the primary current. Let $\overline{O_{4}}$ be numerically equal to $20, \overline{O r^{\prime}}$ to 50 , and $\overline{O r}$ to 60 .

A current $\overline{O I^{\prime}}=50$ produces a field equal to $\overline{O I}=60$, hindering

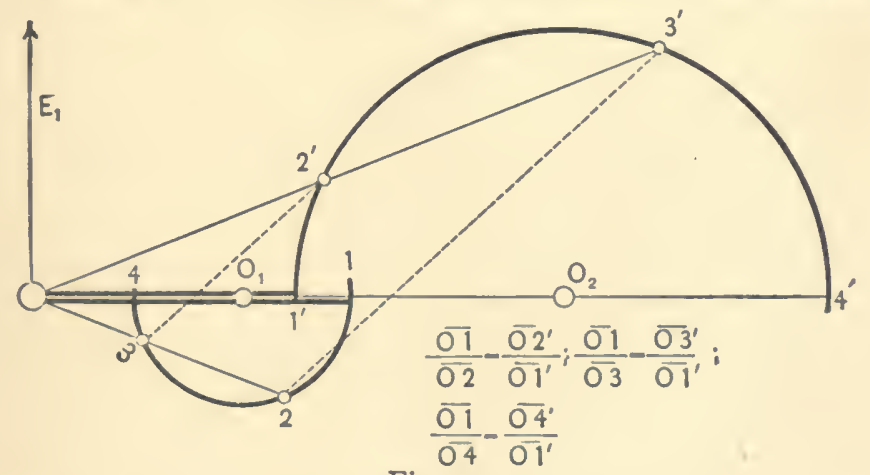

Fig. 42.

the flow of the current. Hence, if the field is only $\overline{O_{4}}=20$, then a current of $\frac{60}{20} \times 50=150$ can flow through the transformer. This current is represented by $\overline{\mathrm{O}^{\prime}}$. It can easily be shown that the points $I, 2,3,4$ correspond point for point to the points $I^{\prime}, 2^{\prime}, 3^{\prime}, 4^{\prime}$, the angle $30 \mathrm{r}$ being equal to 2 'or.

Fig. 43 represents the circle $O{ }^{\prime}$, reciprocal to $O_{4}$. Angle $O{ }^{\prime} O A$ is equal to angle $0,0 \mathrm{~A}$.

A concrete case will bring the matter into a more palpable form.

149. A transformer or induction motor requires a magnetizing current $i_{0}=5 \mathrm{amp}$. We assume $v_{1}=0.91$ and $v_{2}=0.80$. The constant 


\section{THE INDUCTION MOTOR.}

potential of the transformer be IIo volts. The resistance of the primary be 2 ohms. The semi-circle $O_{4}$ can then easily be constructed.

All that remains to be done is to construct the semi-circlef for the constant-potential transformer. $\overline{O I}$, Fig. 44 , is a field equivalent to I Iovolts. $\overline{O_{2}}$ is a field equivalent to 3 I.5 volts; hence, if the potential is kept constant at IIO volts, $\frac{110}{31.5} \times 5=174$ amp. will flow through the

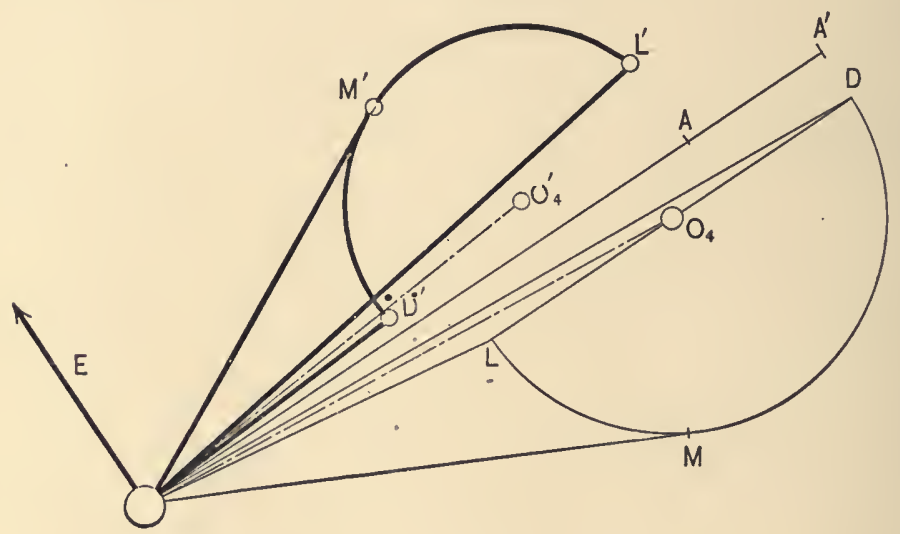

DIAGRAM ILLUSTRATING METHOD OF RECIPROCAL VECTORS.

Angle $\mathrm{O}_{4}^{\prime} O \mathrm{~A}_{1}-$ Angle $\mathrm{O}_{4} \bigcirc \mathrm{A}_{1}$; Angle $M^{\prime} O{ }^{\prime \prime} A_{1}=$ Angle $M O A_{1}$; Angle $L^{\prime} \circ A_{1}$-Angle $L O A_{1}$ : $\overline{O M} \cdot \overline{O M^{\prime}}=\overline{O D} \cdot \overline{O D^{\prime}}-\overline{O L} \cdot \overline{O L^{\prime}}$

Fig. 43.

transformer at the same phase-angle. We thus get point 2. The centre of the semi-circle can at once be.found, points I and 2 being determined, as angle $O_{1}^{\prime} O A$ is equal to angle $0 . O A$.

150. The ordinates of the semi-circle $O_{4}^{\prime}$ represent the watt-current of the transformer, the ordinate of point I being equal to $5^{2} \times 2 \div$ IIo 


\section{ALTERNATING-CURRENT TRANSFORMER.}

$=0.455$, and the ordinate of 2 being equal to $174^{2} \times 2 \div 110=5.5$ amp.

$\overline{O_{1}} ; \overline{O_{2}}$, represent directly the primary currents.

To find the secondary currents I have redrawn the same diagram in Fig. 45. $\overline{O A}$ is the primary current, or, to be more strictly correct, the primary $\mathrm{m} . \mathrm{m}$. $\mathrm{f}$.

$\overline{O M}$ is proportional to the terminal voltage of 310 volts in our case.
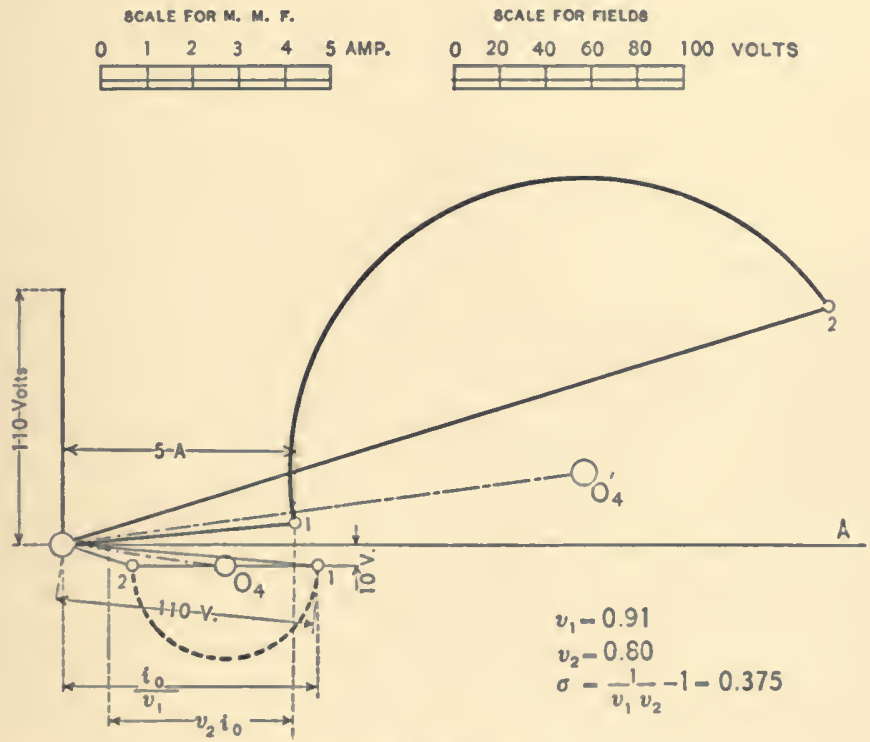

Fig. 44.

$\overline{M D}$ is proportional to $i_{1} r_{1}$, the ohmic drop in the primary. It is drawn perpendicular to $X_{1}$, as the field that would be equivalent to the throttling action of the ohmic resistance must be in quadrature with the voltage necessary to overcome it.

$\overline{O D}$, then, is the primary flux $F_{\mathrm{s}}$. 


\section{THE INDUCTION MOTOR.}

$\overline{C D}$ is the primary leakage-field $\phi_{1}$.

$$
\overline{C D}=\left(\frac{1}{v_{1}}-1\right) \overline{O A}
$$

$\overline{C G}$ is the secondary leakage-field $\phi_{2}$.

$$
\overline{C G}=\left(\frac{1}{v_{2}}-1\right) \overline{A C}
$$

$\overline{\mathrm{OG}}$ is the secondary field $F_{2}$. By means of the scale for the fields the secondary voltage can at once be determined. It must be borne in SCALE FOR M.M.F. SCALE FOR FIELDB
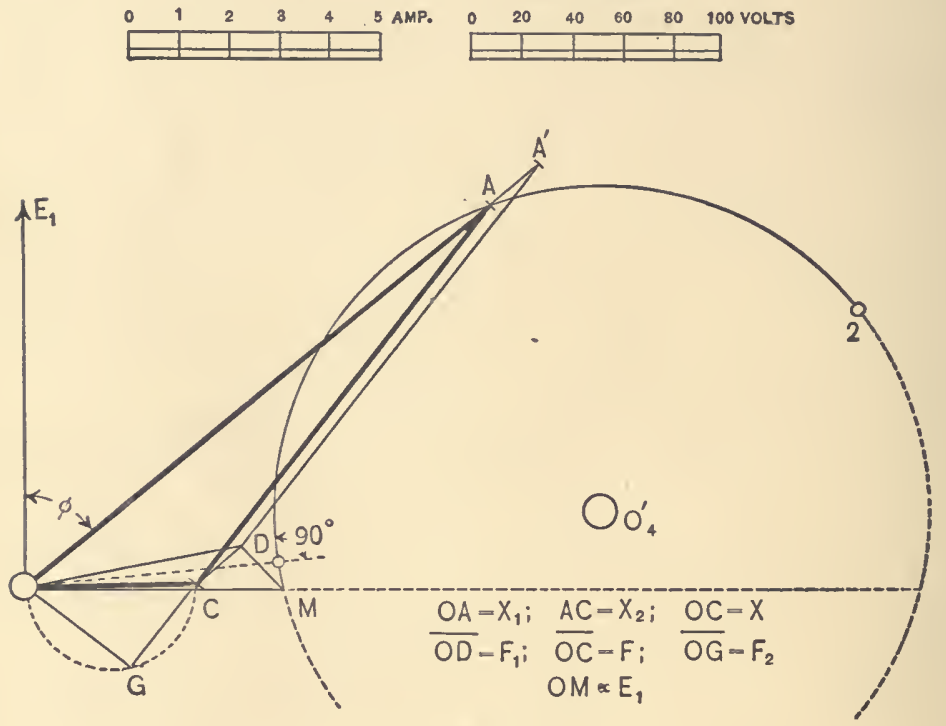

Fig. 45 .

mind that $\overline{O G}$ is not proportional to the voltage at the secondary terminals, but that it includes the ohmic drop in the secondary.

151. Though the preceding considerations offer no great difficulty in understanding them clearly, yet the transformer diagram becomes surprisingly simple if we neglect the resistance of the primary. And not only the diagram, but also its evolution, become so perspicuous 


\section{ALTERNATING-CURRENT TRANSFORMER.}

that it seems peculiar that it has taken such a long time to arrive at this solution.

That the locus of the vector of the primary $\mathrm{m} . \mathrm{m}$. f. must be $a$ semi-circle, follows directly from the diagram of Fig. 4I. This circle is reproduced in Fig. 46. The thick lines show the triangle of the magnetomotive forces.

152. $\overline{O C}$ is the magnetizing current. If the transformer runs on open-circuit, $\overline{O C}$ becomes equal to $\overline{O K}$. We see, therefore, that the

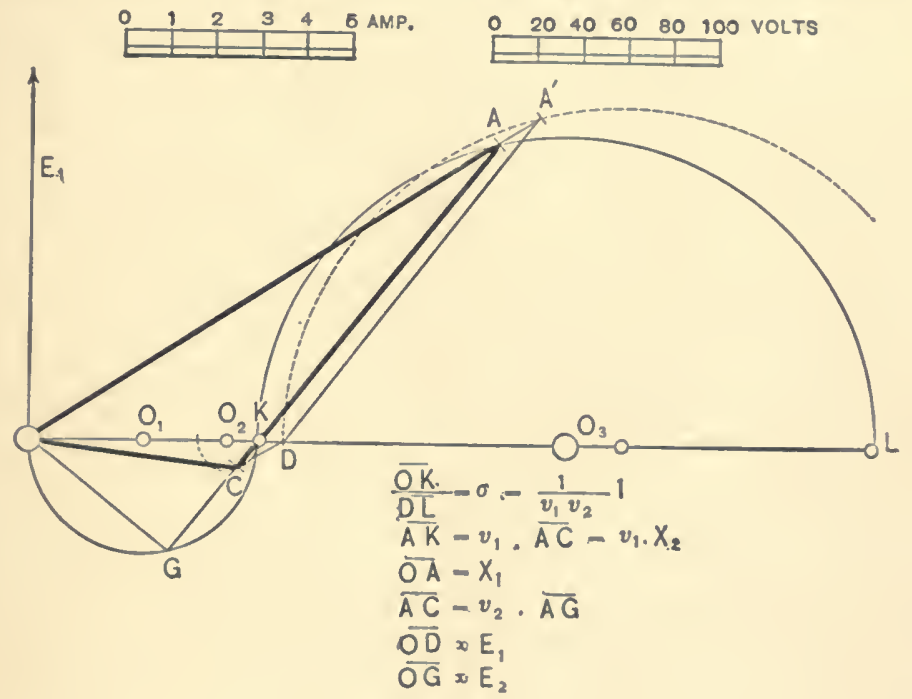

Fig. 46.

magnetizing current is not constant for all loads, but decreases with the diminution of the secondary resistance. What remains constant is the primary magnetic field $F_{1}$, which is composed of the common field $F$ and the leakage-field $\phi_{1}, F$ is constantly diminishing, while $\phi_{1}$ is increasing, their vector-sum being constant.

153. $K$ divides $\overline{O D}$ in a constant ratio, $\overline{O K}=v_{1} . \overline{O D}$. Hence, drawing a line through $K$, for instance, $\overline{A K}$, and producing it until it 


\section{THE INDUCTION MOTOR.}

intersects the semi-circle in $G$, yield us all the data of the transformer that we are interested in.

INDUCTANCE IN SECONDARY.

154. There is no difficulty in drawing the diagram for a transformer working on an inductive load of constant power-factor. The devel-

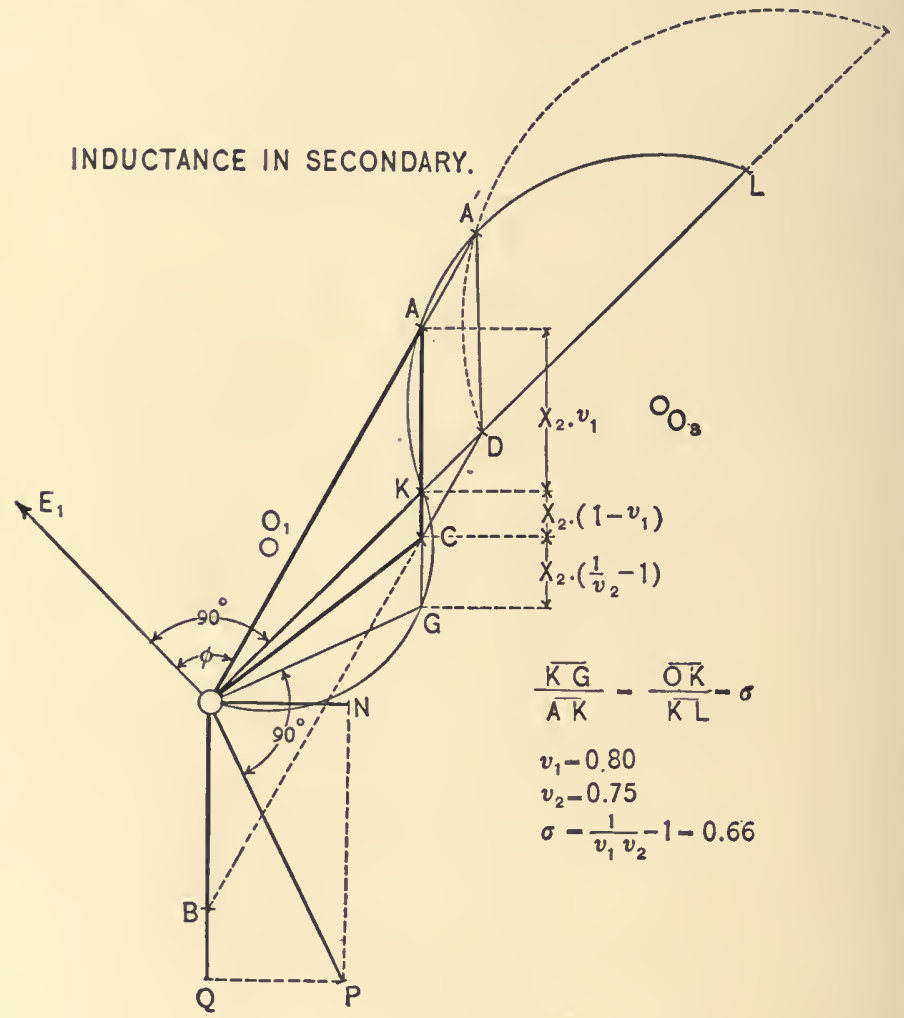

Fig. 47.

opment of the diagram is of the simplest if we neglect the primary resistance, which is generally perfectly permissible. Afterwards it 


\section{ALTERNATING-CURRENT TRANSFORMER.}

is easy to correct the diagram with regard to the ohmic resistance of the primary, if this should be desired.

155. Let $\overline{O Q}$, Fig. 47 , be the e. m. f. necessary to overcome the ohmic resistance of the secondary circuit, including the resistance of the coils of the transformer, and $\overline{O N}$ the e. m. f. required to overcome the external inductance in the secondary circuit, then $\overline{O P}$ is equal to the e. $\mathrm{m}$. f. required to drive the current through the whole secondary of the transformer. The field necessary to do this is $\overline{O G}$, in quadrature with $E_{2} . \overline{C G}$ is the leakage field of the secondary, $\overline{C A}$ is the secondary m. m. f. $X_{3}, \overline{O A}$ the primary m. m. f. $X_{1} . \overline{C D}$ is the primary leakage field. $\overline{O C}$ is the common magnetic field, and the scale of $X_{1}$ and $X_{2}$ is so chosen as to give a resultant equal to $\overline{O C}=$ $F$. $\overline{O K}$ is constant as $\overline{O D}$ is constant, $\overline{O K}$ being equal to $v_{1} . \overline{O D}$.*

It follows at once from the diagram,

$$
\begin{gathered}
\overline{A K}: X_{2}:: X_{1}: \frac{X_{1}}{v_{1}} \\
\overline{A K}=v_{1} \cdot X_{2} .
\end{gathered}
$$

As angle $O G K$ remains constant and equal to $180^{\circ}-P O N, G$ moves in the arc $\overline{O G K}$. If the diagram is constructed for one point, the locus of $G$ is determined.

156. To determine the locus of $A$ we have to consider the ratio between $\overline{G K}$ and $\overline{A K}$, which we have called $\sigma$.

$$
\begin{aligned}
& \overline{G C}=X_{2}\left(\frac{\mathrm{I}}{v_{3}}-\mathrm{I}\right) \\
& \overline{K C}=X_{2}\left(I-v_{1}\right)
\end{aligned}
$$

For $\overline{A K}$ we have $v_{1} . X_{1}$, hence

$$
\sigma=\frac{\overline{G K}}{\overline{A K}}=\frac{\frac{\mathrm{I}}{v_{2}}-\mathrm{I}}{v_{1}}=\frac{\mathrm{I}}{v_{1} v_{2}}-\mathrm{I}
$$

- This diagram is identical with that given by Hers Emde in the Elektrolech. nische Zeitschrift, Oct. 11, 1900 . I refer the reader to Herr Emde's important contributions on this subject, as well as to his valuable criticism of my paper of 3896 on the general transformer. See also Herrn Heubach's, Kuhlmann's, and Sumec's letters on the same subject there. 


\section{THE INDUCTION MOTOR.}

Hence the locus of $A$ is an arc the chord of which is determined by the ratio.

$$
\text { (5) } \ldots \ldots \ldots \ldots \ldots . .6=\frac{\mathrm{r}}{v_{1} v_{3}}-\mathrm{I}=\frac{\overline{O K}}{\overline{K L}}
$$

157. The centre of this arc is determined by the angle $O_{3} K L$, which is equal to $Q O P$, the angle of lag in the secondary. Angle $O_{2} O K$ is equal to $Q O P$.

\section{CAPACITY IN THE SECONDARY.}

158. Fig. 48 is constructed for a capacity in the secondary in series with the resistance. Angle $\overline{P O B}$ is the secondary lead, $F_{z}$ is the secondary field, triangle $\overline{O A K}$ is the triangle of the $\mathrm{m}$. $\mathrm{m}$. ff. We find exactly as before:

$$
\frac{\overline{O K}}{\overline{O L}}=\sigma=\frac{1}{v_{1} v_{2}}-\mathbf{I}
$$

Bearing in mind that angle $O G K$ is constant and equal to angle $N O P$, it follows at once that the locus of $G$ and that of $A$ are circles.

159. Again angle $O_{3} K L$ is equal to angle $O_{1} O K$, equal to argle $P O Q$, the angle of the secondary lead.

\section{HYSTERESIS AND EDDY CURRENTS.}

160. A word about the way in which hysteresis and eddy currents should be taken into account. Assuming them to be constant for all loads-which they are not, as, if the leakage-path is slightly saturated, the leakage-flux becomes greater with larger currents, and the greater loss in the leakage-path may outdo the decrease of the loss in the main field-it seems most logical to take these losses into account by assuming a lag between the common field $\overline{O C}$ and the magnetizing current. This lag diminishes the secondary current. Draw a line parallel with $\overline{L D}$, the distance of which from $\overline{L D}$ being equal to the loss in watts through hysteresis and eddies divided by the primary voltage, then the secondary currents must be measured between this line and the semi-circle $\mathrm{O}_{2}$. 


\section{ALTERNATING-CURRENT TRANSFORMER.}

16I. I wish to impress upon the reader that there is little in this contribution that I can claim specially my own. I have merely combined the diagrams of Kapp, Steinmetz, and Blondel, simplifying wherever it was possible. The application of the principle of reciprocal vectors* enables us in a surprisingly simple manner to trace out the intricate phenomena in the transformer for constant potential, if CAPACITY IN SECONDARY.

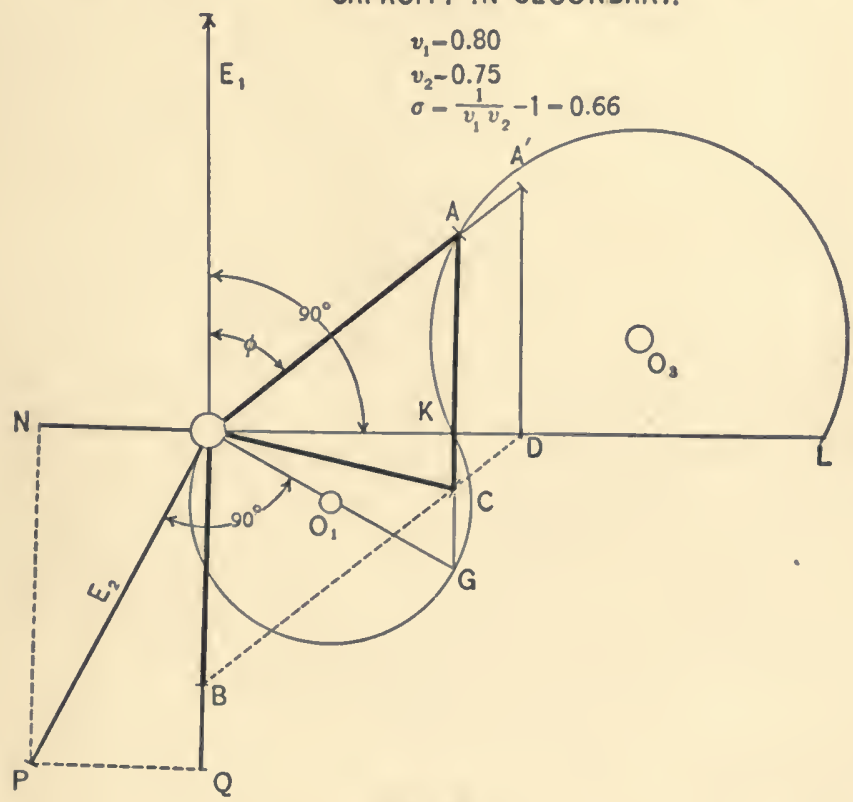

Fig. 48.

we want to include the primary resistance. My method of arriving at the diagram of the general transfomer is different from Dr. Be dell's in so far as he uses the coefficients of self- and mutual induction, a method which I cannot advocate.

- The method of reciprocal vectors was admirably treated in 8878 by Prof. W. K. Clifford in the chapter on "Pedal and Reciprocal Curves" in his work on "Elements of Dynamic." But Dr. Bcdell first applied the principle to the transformer. 


\section{THE INDUCTION MOTOR.}

162. A very beautiful and simple diagram can be drawn, showing in polar co-ordinates the locus of the primary current for a lag, noninductive load, and a lead in the secondary, as for the same transformer or motor $\overline{K L}$ is a constant if $\overline{O K}$ is constant. Neglecting the primary resistance, a diagram can be constructed for constant terminal voltage by erecting arcs over $\overline{K L}$ as chord. Arcs flatter than the semi-circle correspond to an inductance in the secondary, the semi-circle corresponds to a non-inductive load, and an arc whose inscribed angle is smaller than a right angle, standing on $\overline{K L}$ as chord, determines the locus of the primary current for a condenser in the secondary. As the secondary terminal voltage is determined by the circle $O_{1}$, in the most simple and beautiful manner the phenomena of resonance and kindred phenomena may at a glance be qualitatively and quantitatively understood. But I must leave the construction to the reader, who will find no difficulty in building up the diagram synthetically with the help of Figs. 46,47 , and 48 . It is worthy of notice how injurious an inductance in the secondary is with regard to the maximum energy the transformer or motor is capable of taking in, and how much a condenser in the armature of the motor would increase the power of the motor to do work. 


\section{A PPENDIX I.}

The following presentation by Mr. Gisbert Kapp of the elementary phenomena in the induction motor is reprinted from his book, "Electric Transmission of Energy," because, in the author's opinion, it is the clearest and most concise logical evolution of the principles underlying the theory set forth in the preceding pages. It will repay the student to go over Mr. Kapp's presentation of the subject, and he will understand the vector diagram much more clearly after having become thoroughly familiar with this extract from the work of a master of the art of exposition.

\section{Extract from Gisbert Kapp's Electric Transmission of Power-On the Induction Motor.}

$\mathrm{T}$

$\mathrm{HE}$ armature conductors may be connected so as to form single loops, each passing across a diameter, or they may all be connected in parallel at each end face by means of circular conductors, somewhat in the fashion of a squirrel cage. Either system of winding does equally well, but as the latter is mechanically more simple, we will assume it to be adopted in Fig. 49. The circular end connections are supposed to be of very large area as compared with the bars, so that their resistance may be neglected. The potential of either connecting ring will then remain permanently at zero, and the current passing through each bar from end to end will be that due to the c. $\mathrm{m}$. f. acting in the bar divided by its resistance. It is important to note that the e. $\mathrm{m}$. f. here meant is not only that due to the bar cutting through the lines of the revolving field, but that which results when armature reaction and self-induction are duly taken into account. 


\section{THE INDUCTION MOTOR.}

Let us now suppose that the motor is at work. The primary field produced by the supply currents makes $\sim_{1}$ complete revolations per second, whilst the armature follows with a speed of $\sim_{2}$ complete revolutions per second. The magnetic slip $s$ is then

$$
s=\frac{\sim_{1}-\eta}{\sim_{1}}
$$

If the field revolves clockwise, the armature must also revolve clockwise, but at a slightly slower rate. Relatively to the field, then, the

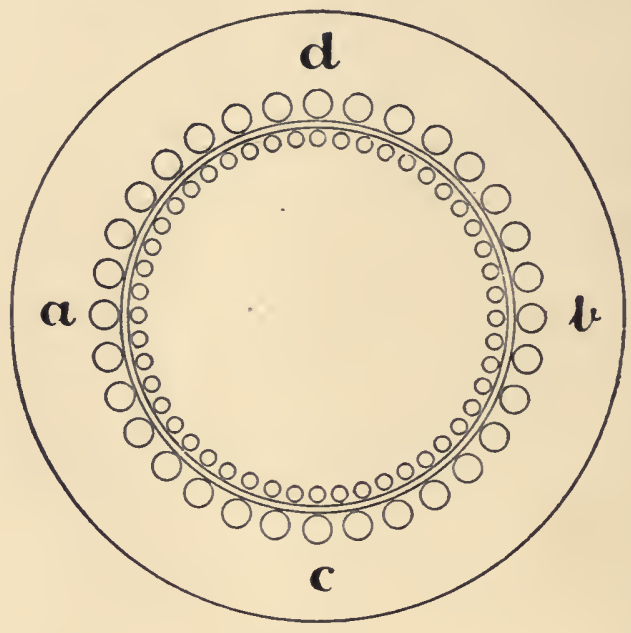

FIG. 49.

armature will appear to revolve in a counter clockwise direction, with a speed of

$$
\sim=\sim_{1}-\sim_{2}
$$

revolutions per second. As far as the electro-magnetic action within the armature is concerned, we may therefore assume that the primary field is stationary in space, and that the armature is revolved by a belt in a backward direction at the rate of $\sim$ revolutions per second. The effective tangential pull transmitted by the belt to the 


\section{APPENDIX I.}

armature will then be exactly equal to the tangential force which in reality is transmitted by the armature to the belt at its proper working speed, and we may thus calculate the torque exerted by the motor as if the latter were worked as a generator backward at a much slower speed, the whole of the power supplied being used up in heating the armature bars. The object of approaching the problem from this point of riew is, of course, to simplify as much as possible the whole investigation. If we once know what torque is required to work the machine slowly backward as a generator, it will be an easy matter to find what power it gives out when working forward as a motor at its proper speed.

Let in Fig. 105 the horizontal $a, c, b, d, a$ represent the interpolar space straightened out, and the ordinates of the sinusoidal line. $B$, the induction in this space, through which the armature bars pass with a speed of $\sim$ revolutions per second. We make at present no assumption as to how this induction is produced, except that it is the resultant of all the currents circulating in the machine. We assume, however, for the present that no magnetic flux takes place within the narrow space between armature and field wires, or, in other words, that there is no magnetic leakage, and that all the lines of force of the stationary field are radial. The rotation being counter clockwise, each bar travels in the direction from $a$ to $c$ to $b$, and so on. The lines of the field are directed radially outwards in the space $d a c$, and radially inward in the space $c b d$. The c. m. f. will, therefore, be directed downwards in all the bars on the left, and upwards in all the bars on the right of the vertical diameter in Fig. 49. Let E represent the curve of e. $\mathrm{m}$. f. in Fig. 5o, then, since there is no magnetic leakage the current curve will coincide in phase with the e. $\mathrm{m}$. f. curve, and we may represent it by the line $\mathrm{I}$. It is important to note that this curve really represents two things. In the first place it represents the instantaneous value of the current in any one bar during its advance from left to right; and in the second place, it represents the permanent effect of the current in all the bars, provided, 


\section{THE INDUCTION MOTOR.}

however, the bars are numerous enough to permit the representation by a curve instead of a line composed of small vertical and horizontal steps. The question we have now to investigate is: what is the magnetizing effect of the currents which are collectively represented by the curve I? In other words, if there were no other currents flowing but those represented by the curve $\mathrm{I}$, what would be the disposition of the magnetic field produced by them? Positive ordinates of I represent currents flowing upwards or towards the observer in Fig.

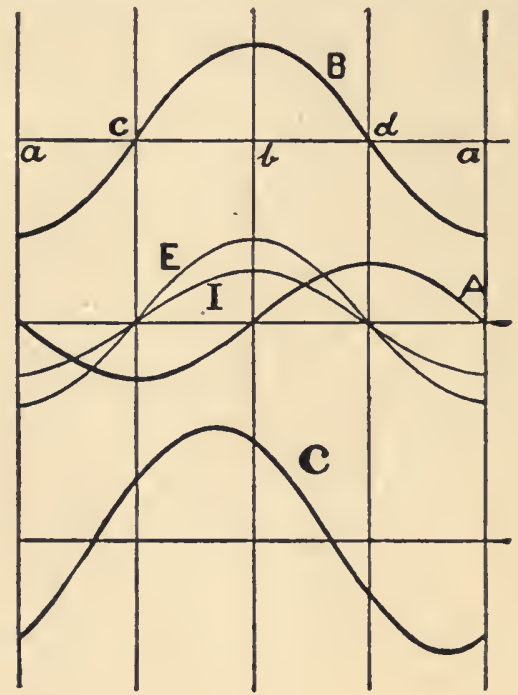

FIG. 50 .

49, negative ordinates represent downward currents. The former tend to produce a magnetic whirl in a counter clockwise direction, and the latter in a clockwise direction. Thus the current in the bar which happens at the moment to occupy the position $b$, will tend to produce a field, the lines of which flow radially inwards on the right of $b$, and radially outwards on the left of b. Similarly the current in the bar occupying the position $a$, tends to produce an inward 


\section{APPENDIX I.}

field, i. e., a field the ordinates of which are positive, in Fig. 105, to the left of $a$, and an outward field to the right of $a$. It is easy to show that the collective action of all the currents represented by the curve $I$ will be to produce a field as shown by the sinusoidal line $A$. This curve must obviously pass through the point $b$, because the magnetizing effects on both sides of this point are equal and opposite. For the same reason the curve must pass through $a$. That the curve must be sinusoidal is easily proved, as follows: Let $i$ be the current per centimetre of curcumference in $b$, and let $r$ be the radius of the armature; then the current through a conductor distant from $b$ by the angle $\alpha$, will be $i \cos a$ per centimetre of circumference. If we take an infinitesimal part of the conductor comprised within the angle $d a$, the current will therefore be

$$
d i=i r \cos a d a,
$$

and the magnetizing effect in ampere-turns of all the currents comprised between the conductor at $b$, and the conductor at the point given by the angle $a$ will be

$$
\int_{0}^{a} d i=-i r \sin a,
$$

and since the conductors on the other side of $b$ act in the same sense, the field in the point under consideration will be produced by $2 \mathrm{ir}$ $\sin a$ ampere-turns, $i$ being the current per centimetre of circumference at $b$.

Since for low inductions, which alone need here be considered, the permeability of the iron may be taken as constant, it follows that the field strength is proportional to ampere-turns, and that consequently $A$ must be a true sine curve.

When starting this investigation, we had assumed that the field represented by the curve $B$ is the only field which had a physical existence in the motor; but now we find that the armature currents induced by $B$ would, if acting alone, produce a second field, represented by the curve $A$. Such a field, if it had a physical existence, would, however, be a contradiction of the premise with which we 


\section{THE INDUCTION MOTOR.}

started, and we see thus that there must be another influence at work which prevents the formation of the field $A$. This influence is exerted by the currents passing through the coils of the field magnets.

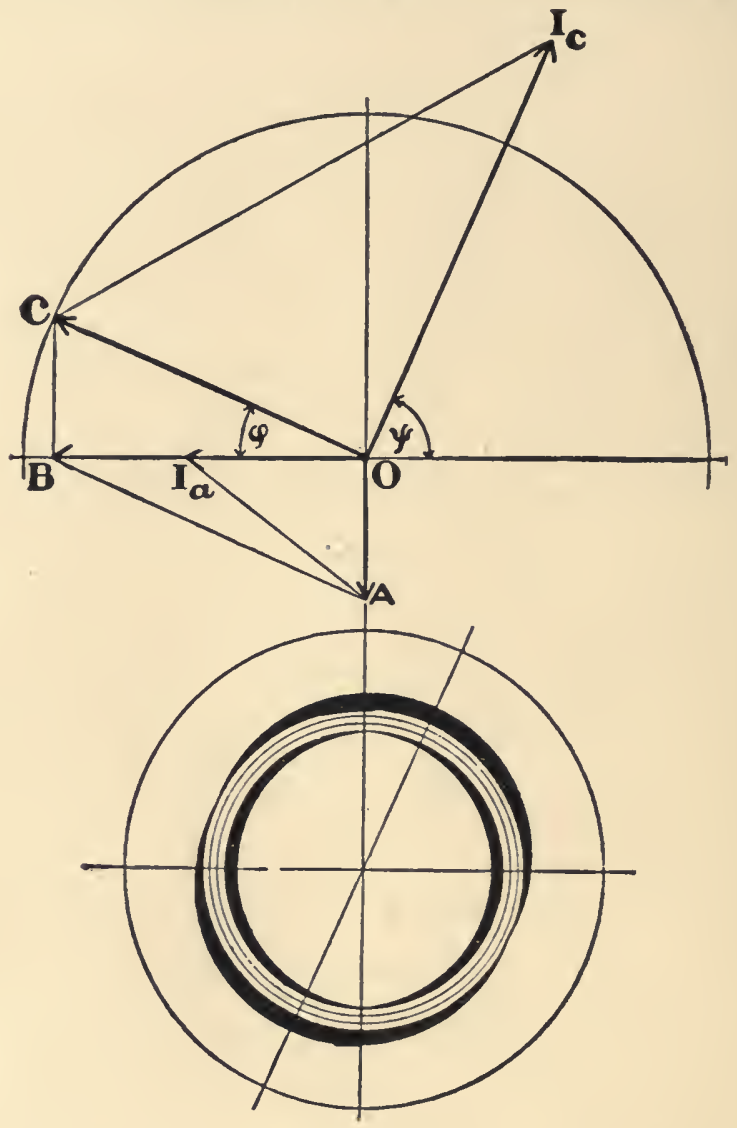

FIG. 5I.

The primary field must therefore be of such shape and strength, that it may be considered as composed of two components, one exactly 


\section{APPENDIX I.}

equal and opposite to $A$, and the other equal to $B$. In other words, $B$ must be the resultant of the primary field and the armature field $A$. The curve $C$ in Fig. 50 gives the induction in this printary field or as it is also called, the "impressed field," being that field which is impressed on the machine by the supply currents circulating through the field coils. It will be noticed that the resultant field lags belind the impressed field by an angle which is less than a quarter period.

The working condition of the motor, which has here been investigated by means of curves, can also be shown by a clock diagram. Let in Fig. 106, the maximum field strength within the interpolar space (i. e., number of lines per square centimetre at $a$ and $b$ of Fig. I04, be represented by the line $O B$, and let $O I_{a}$ represent the total ampere-turns due to armature currents in the bars to the left or the right of the vertical, then $O A$ represents to the same scale as $C B$ the maximum induction due to these ampere-turns. We need not stop here to inquire into the exact relation between $O I_{a}$ and $O A$, this will be explained later on. For the present it is only necessary to note that under our assumption of no magnetic leakage in the machine, $O A$ must stand at right angles to $O I_{a}$, and therefore also to $O B$, and that the ratio between $O I_{a}$ and $O A$ (i. e., armature ampere-turns and arnature field) is a constant. By drawing a vertical from the end of $B$ and making it equal to $O A$, we find $O C$ the maximum induction of the impressed field. The total ampere-turns required on the field magnet to produce this impressed field are found by drawing a line from $C$ under the same angle to $C O$, as $A I_{a}$ forms with $A O$, and prolonging this line to its intersection with a line drawn through $O$ at right angles to $O C$. Thus we obtain $O I_{c}$, the total ampere-turns to be applied to the field. The little diagram below shows a section through the machine, but instead of representing the conductors by little circles as before, the armature and field currents are shown by the tapering lines, the thickness of the lines being supposed to indicate the density of current per centimetre of circumference at each place. 


\section{A P PENDIX II.}

The following is a very simple and elegant method of arriving graphically at the results of the integrations in Sections 19, 20, 108 and 109.

Consider a winding ag, Fig. 52, extending over an arc of 180 degs., that is all over the pole-pitch. In each element, extending over an infinitesimally small arc, there is an e. $\mathrm{m}$. $\mathrm{f}$. induced which we shall

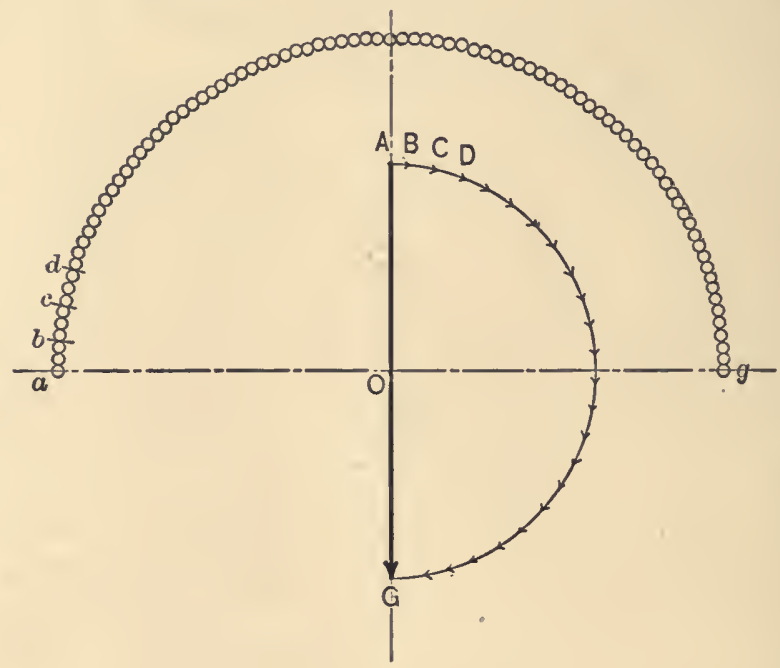

FIG. 52.

call $d e$, represented by the infinitesimally small vector $\overline{A B}$ perpendicular to the element of the winding $a b$. We can see at a glance that the vector-sum, or the expression $\int d e$, is equal to $\overline{A G}$, and that the algebraic sum of the e. m. f.'s induced in the elements is equal to the arc $\widehat{A B C D-G}$, since in the latter case the elements have to 


\section{APPENDIX II.}

be added independently of their phase relation. But we know that the algebraic sum of the e. m. f.'s of all the elenents is equal to

$$
e=\frac{\pi}{\sqrt{2}} \sim z \Phi 10^{-8} \text { volts, }
$$

hence we may conclude that in a distributed winding the e. $\mathrm{m}$. f. induced is equal to $\overline{A G} \div \widehat{A B C D-G}$ multiplied by e. This is,

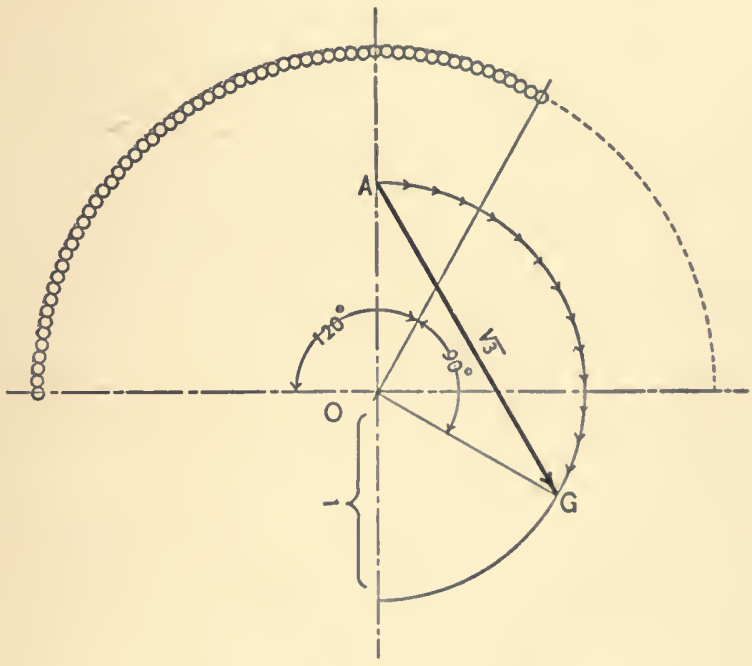

FIG. 53 .

however, equal to $\frac{2}{\pi} \cdot \frac{\pi}{\sqrt{2}} \sim z \Phi 10^{-8}=\sqrt{2} \sim z \Phi 10^{-8}$ volts.

This formula differs slightly from (21) as in our graphic representation we have assumed a sinusoidal field the lines of which are cutting the winding, whereas fields with straight contours have been considered in Sections 19, 20 and 108.

If the coil covers an angle of 120 degs., (Fig. 53), the e. m. f. in- 
THE INDUCTION MOTOR.

duced in it is equal to $\frac{\pi}{\sqrt{2}} \sim z \Phi 10^{-8}$ multiplied by $\overline{A G} \div \overline{A B C D-G}$, that is to say, equal to

$$
\frac{3 \sqrt{3}}{2 \sqrt{2}} \sim z \Phi 10^{-8}=1.836 \sim z \Phi 10^{-8} \text { volts. }
$$

For a coil extending over an angle of 90 degs. (Fig. 54), we find

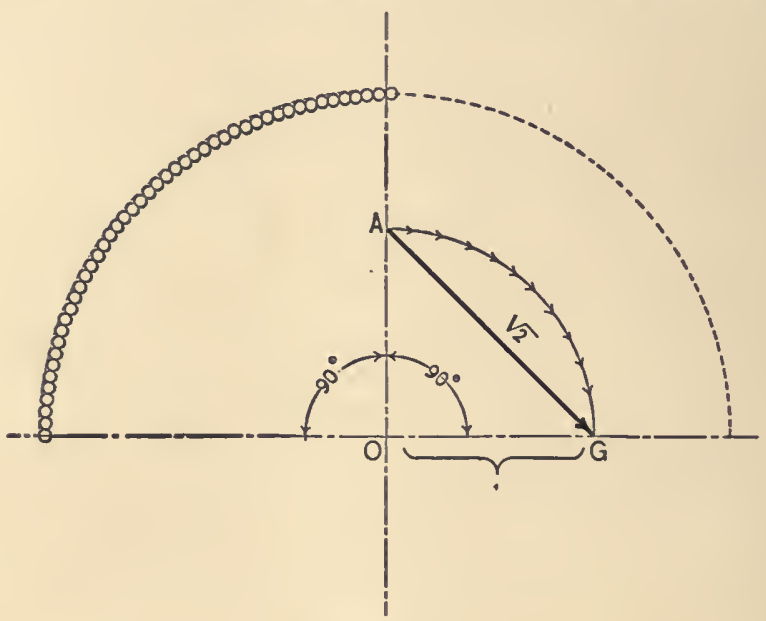

FIG. 54 .

at once the co-efficient entering into the general equation for the e. $m$. f. to be

$$
\frac{\pi \sqrt{2}}{\sqrt{2}} \div \frac{\pi}{2}=2
$$

Let the coil cover an angle of 30 degs. (Fig. 55), and we have at once for the co-efficient

$$
\frac{\pi}{\sqrt{2}} \div \frac{2 \pi}{6}=\frac{3}{\sqrt{2}}=2.12
$$

as found in Section 20. 
APPENDIX II.

The foregoing is again an illustration of the ease with which graphic methods lead to results otherwise attainable only by lengthy integrations.

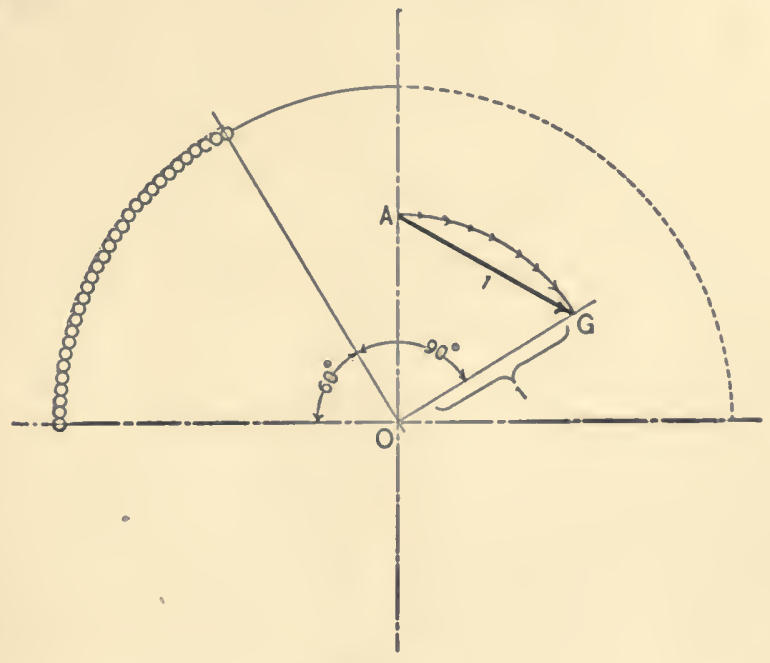

FIG. 55 .

In Appendix III. we shall describe a way in which to take into account the ohmic losses in field and armature much simpler than that adopted in Figs. 5, 24, and 33. 


\section{APPENDIX III.}

Figs. 5, 24, and 33 can be greatly simplified if the watt component corresponding to the $C^{2} R$ losses in the primary and secondary of the rotatory transformer are set off from $\overline{D L}$ instead of from the semicircle. For it can easily be proved (Fig. 56 ) that the ordinates between $\overline{R C}_{1}$ and $\overline{R C}_{2}$ are exactly proportional to $C_{2}^{2} R_{2}$, while the ordinates between $\overline{D L}$ and $\overline{R C}_{1}$ represent, with extremely little inaccuracy, the watt component corresponding to the ohmic loss in the primary, $C_{1}{ }^{2} R_{1}$. The proof of this is very simple, for let $b_{0}$ be the ordinate between $\overline{R C}_{1}$ and $\overline{R C}_{2}$, or a current $C_{0}$, then we have

$$
C_{0}^{2}=m b_{0} \text {, }
$$

where $m$ is a constant.

Calling the projection of $C_{0}$ on $\overline{D L}, a_{0}$, and that of $C$ on $\overline{D L}, a$, then we have

We also have

$$
\overline{D N}^{2}=C^{2}=a^{2}+\overline{M N}^{2}
$$

$$
\frac{a}{a_{0}}=\frac{b}{b_{0}}, \text { and } \overline{M N^{2}}=a(\overline{D L}-a)
$$

Hence follows

$$
\begin{aligned}
& C^{2}=\left(\frac{a_{0}}{b_{0}} \cdot b\right)+\frac{a_{0}}{b_{0}} \cdot b\left(\overline{D L}-\frac{a_{0}}{b_{0}} \cdot b\right)
\end{aligned}
$$

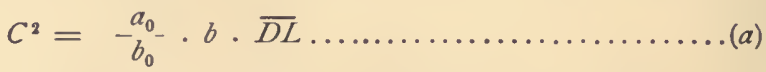

In a similar manner it can be proved that the ohmic loss in the primary may be represented by the ordinates between $\overline{D L}$ and $\overline{R C}_{1}$, $\overline{R D}$ being equivalent to the ohmic loss produced by the current $\overline{O R}$.

It is now evident that the output $P$ of the motor is represented by the ordinates between the circle and $\overline{R C}_{2}$, while the ordinates between the circle and $\overline{R C}_{1}$ represent the torque $D$ of the motor. 


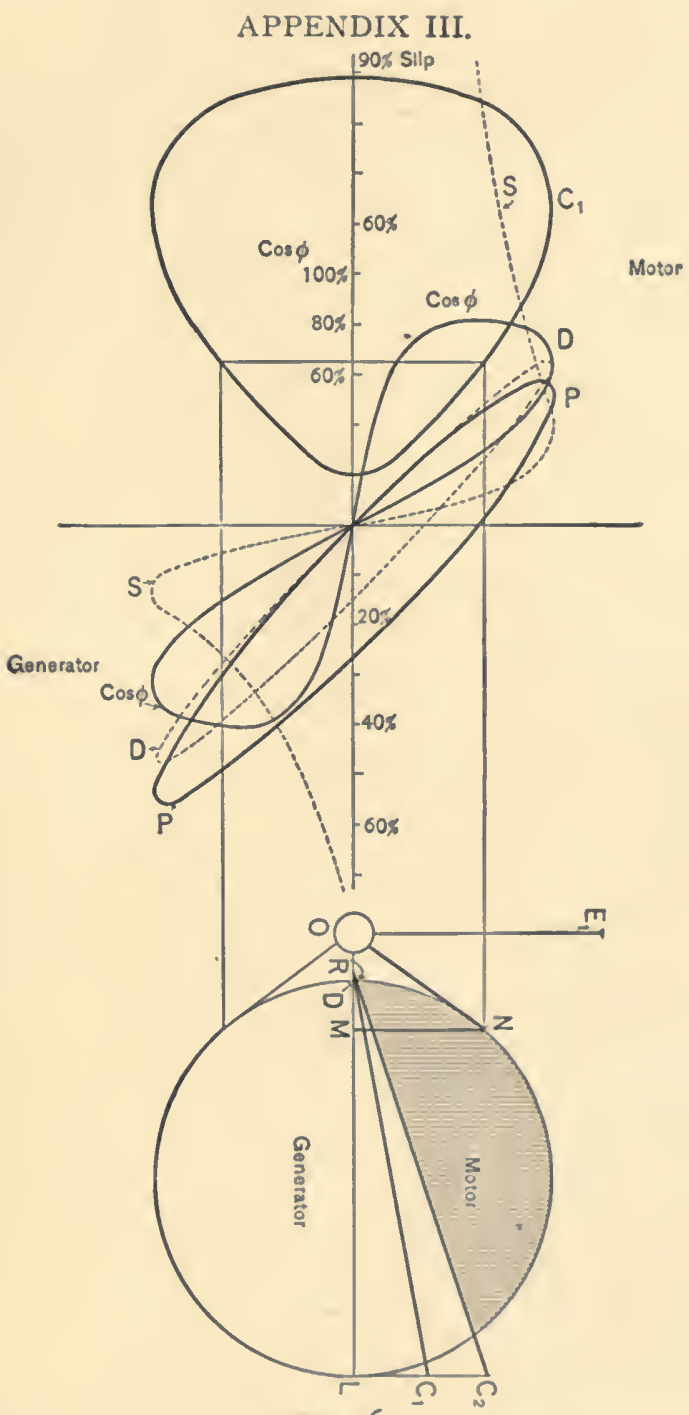

FIG. 56 .

ror 


\section{THE INDUCTION MOTOR.}

The slip is equal to the ratio of the loss in the armature divided by the total energy developed in the secondary, hence equal to the ratio of the ordinates between $\overline{R C}_{1}$ and $\overline{R C}_{2}$, divided by the ordinates between the circle and $\overline{R C_{1}}$.

Mr. Heyland has shown that the diagram may be used to represent the action of the motor when running at a speed above synchronism, i. e., at a negative slip. The motor then gives energy back upon the line, requiring mechanical energy to drive it. The simplification that I have just introduced, by which the ohmic losses can be taken into account by merely drawing two straight lines, enables us to plot at once the current, $C_{1}$, the torque $D$, the output $P$, the power factor $\cos \phi$, and the slip $S$, in rectangular co-ordinates as functions of the electrical energy consumed by the motor, and as functions of the electrical energy given back by the generator.

Fig. 56 illustrates these curves, the plotting of which takes but a few minutes. 


\section{NDEX.}

(The numbers refer to the pages.)

A mpere-Conductors per Slot, Their Influence on Leakage.... 24

Ampere-Conductors per Slot ..................... 23

Armature Currents it Different Frequencies ............ 40

Bedell, Dr. Fred............................... $8_{7}$

Bedell \& Crehore ............................... 73

Behn-Eschenburg, Dr. Hans. ...................... 5I

Blondel, Prof. André .......................... 15

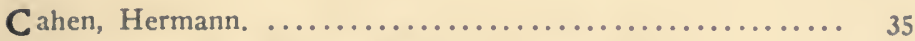

Calculation of Single-Phase Motor, Chapter VII. .......... 63

Capacity in Secondary of Transformer ...............85, 86

Character of Magnetic Field....................... II

Characteristic Curves of Single-Phase Motor........60,67, 68, 69

Clifford, W. K. ............................ 87

Constant-Current Transformer .................... 76

Comparison of Single-Phase and Three-Phase Motor ....... 70

Conductors, Number of, per Slot ................... 24

Constant Potential Transformer .................... $\quad 78$

Corroboration of Theory ......................... 5

Counter-E. M. F. in Three-Phase Motor...............13,14

Counter-E. M. F. in Single-Phase Motor.............61, 62

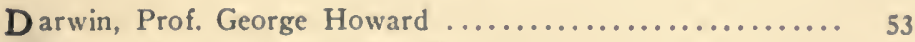

Design of 200-hp Threc-Phase Motor ............... ${ }_{42}^{2}$

Determination of Characteristic Curves of $200-h p$ Motor......47, 48

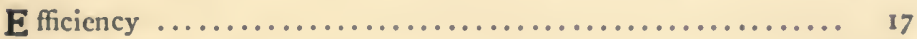

Ende, Fritz ............................... 85

Exciting Current; Its Determination .................. 15 


\section{THE INDUCTION MOTOR.}

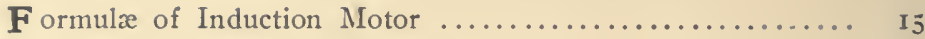

Frequency, Drawbacks of High ................... ${ }_{3} 8$

General Alternating-Current Transformer, Chapter i ...... I

Graphic Integration, Appendix II. .................. 96

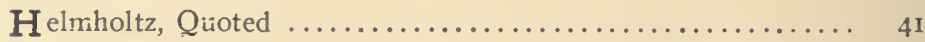

Heubach ..................................... 85

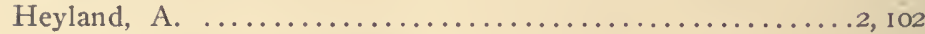

Hysteresis and Eddy Currents ..................... 87

Inductance in Secondary of Transformer .............. 84

Induction Generator, Appendix III. ................. I00

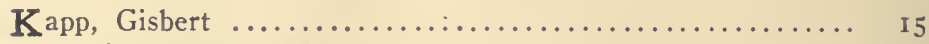

" On Induction Motor, Appendix I. ............... 89

Kuhlmann $\ldots \ldots \ldots \ldots \ldots \ldots \ldots \ldots \ldots \ldots \ldots \ldots \ldots \ldots, \quad 85$

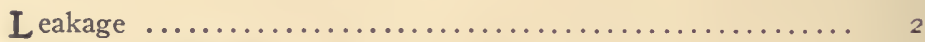

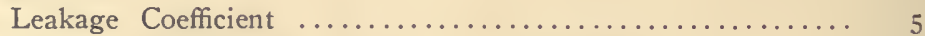

Leakage Coefficient; Its Theoretical Predetermination ....... 28

Leakage Factor, Chapter IV. ..................... 29

Leakage Factor, as Dependent on Air-Gap and Pole-Pitch....32, 36

Leakage Factor, Influence of Air-Gap on ..............29, 30

Leakage, How Influenced by Pole-Pitch ............... 34

Load Losses ............................... 27

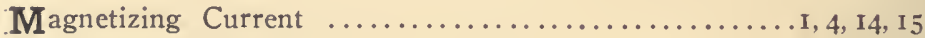

Maximum Power Factor ........................ I8

No-Load Current, Relation Between No-Load and Magnetizing Current in Single-Phase Motors ............... 56

Ohmic Resistance of Primary $\ldots \ldots \ldots \ldots \ldots \ldots \ldots \ldots \ldots, 7$

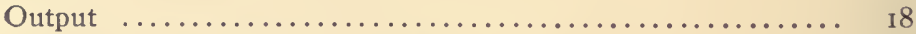

Output, How Dependent on Speed ................... ${ }_{3} 8$

Overload, Dependence on Air-Gap .................. ${ }_{32}$ 


\section{INDEX.}

P olar Diagrams of General Alternating-Current Transformer, Chapter VIII. ............................. 23

Pole-Pitch, Its Influence on Leakage Factor ............. 34

Power Factor; Its Relation to Leakage Coefficient .......... 9

Power Factor; How Affected by Open or Closed Slots....... 2I

Primary Resistance; Its Influence on Diagram ............ 8

Primary Resistance; How Taken Into Account .......... 8 $\mathbf{1}$

Relation Between Leakage Factor and Power Factor........ 26

S emi-Circle Diagram .......................... 5

Seni-Circle Diagram for Single-Plase Motors ............ 60

Short-Circuit Current .......................... 19

Single-Phase Motor, Chapters VI. and VII. ............ 54

Slip and Resistance .............................. 18

Slip and Torque Curves ......................... 52

Slip and Single-Plase Motor ..................... 58

Slots, Number per Pole ........................ 22

Slots; Their Number as Influencing Leakage ............. 23

Slots, Comparison Between Open and Closed ............. 20

Speeds, Winding a Motor for Different ................ 36

Squirrel Cage Armature ......................... 49

Starting Arrangement for Single-Plase Motors ..........71, 72

Steinmetz, C. P. .............................. 242

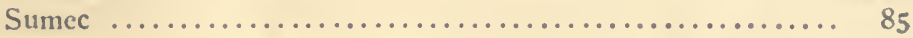

Thompson, Silvanus P. ........................ 17

Three-Phase Motor, Experimental Data of ............. 25

Torque ....................................... 17

Torque Curves of Single-Phase Motor ................ 57

Vectors, Reciprocal ............................79, 80 





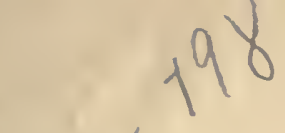

s)

\section{PLEASE DO NOT REMOVE \\ CARDS OR SLIPS FROM THIS POCKET}

\section{UNIVERSITY OF TORONTO LIBRARY}

S\&M

A

198 
